\title{
Conservation of grammatical knowledge: on the acquisition of possessive noun phrases by Turkish and Moroccan learners of Dutch*
}

INEKE van de CRAATS, NORBERT CORVER, and ROELAND van HOUT

\section{Abstract}

This article deals with the acquisition of possessive DP structures by Turkish and Moroccan adults and children learning Dutch without substantial classroom instruction. Our main claim is that $L_{2}$ learners systematically and consistently rely on their grammatical knowledge, which surfaces in the initial stages of the $L_{2}$ acquisition process but also has a strong impact on later developmental stages. Such a strong conservation encompasses parameter settings as well as morphological and vocabulary knowledge.

Before analyzing the various learner variants, we first consider the possessive structures in Turkish, Moroccan Arabic, and Dutch. A thorough analysis of the source languages Turkish and Moroccan Arabic is necessary to reveal the $L_{1}$ properties conserved in the expression of $L_{2}$ utterances. The analysis of the $L_{2}$ possessive variants provides ample evidence that Moroccan learners differ from Turkish learners in their developmental path as well as in the end state attained. We will argue that these differences are due to the different initial states of Turkish and Moroccan learners. The data also provide evidence that adult learners are able to change parametric values that relate to word-order phenomena. They seem less able, however, to acquire new morphological knowledge and languagespecific lexical knowledge, which is crucial in appropriating $L_{2}$ function words.

\section{Introduction}

Possessive relationships are prominent in human culture and interaction. Their linguistic expression has been an important research topic in linguistics. A distinction can be made between research that focuses on the expression of the possessive relationship on the clausal level (e.g. Benveniste 1966; Freeze 1992; Kayne 1993; Heine 1997) and research 
that considers the expression of this relationship within the confines of the noun phrase (e.g. Szabolcsi 1987; Abney 1987; Ritter 1988). In the domain of language acquisition, however, there has not been much interest in the possessive relationship. Exceptions are Clahsen et al. (1994) and Penner and Weissenborn (1996), who discuss the possessive relationship in the context of first-language acquisition. ${ }^{1}$ This study will address the question as to how the noun-phrase-internal possessive relationship is acquired by second-language (henceforth $\mathrm{L}_{2}$ ) learners. More specifcally, we will address the question of how Moroccan and Turkish $\mathrm{L}_{2}$ learners of Dutch acquire the possessive constructions of the target language. To answer this question, longitudinal (spontaneous) production data of Turkish and Moroccan adults and children were studied. The adults' data were drawn from the ESF corpus (cf. Perdue 1993), the children's data from the Vermeer corpus (Vermeer 1986).

The central claim of this paper is that the $\mathrm{L}_{2}$ learner takes a conservative approach toward the construction of his $\mathrm{L}_{2}$ grammar ( $L_{1}$ conservation). The learner is guided by his $\mathrm{L}_{1}$ grammatical knowledge in his production of $\mathrm{L}_{2}$ expressions. We further take the position that universal grammar (UG) plays an essential role as a grammatical knowledge source guiding the $\mathrm{L}_{2}$ learner in the construction of his $\mathrm{L}_{2}$ grammar. Its role lies in the restructuring of the learner's grammatical knowledge, particularly at the level of parameter setting.

This paper is structured as follows. Section 2 discusses the concept of conservation and addresses such questions as (i) what linguistic knowledge guides the learner in the construction of his $\mathrm{L}_{2}$ grammar? and (ii) what is the nature of the various linguistic knowledge states (the initial state, the interlanguage states, and the target state) ${ }^{2}$ during $\mathrm{L}_{2}$ development? Section 3 discusses the basic syntactic properties of the noun phrase in Dutch (the target language), Moroccan Arabic, and Turkish (the source languages of the $\mathrm{L}_{2}$ learners). In section 4 we present an analysis of the various types of possessive constructions found in the three languages and determine the parameterized lexical properties to which the cross-linguistic variation can be related. Section 5 provides information on the two data collections used for this study and gives a basic, descriptive overview of the possessive structures as they occur in the development of the possessive relationship. In section 6 we present our analysis of the possessive structures produced by Turkish adults and children and try to explain the developmental path taken by the learners. In section 7 we do the same for the Moroccan learners. In section 8 we draw some general conclusions regarding conservation, restructuring, and the availability of UG. 


\section{Conservation of grammatical knowledge}

What knowledge of language is potentially available to the $\mathrm{L}_{2}$ learner at the initial state of $L_{2}$ acquisition and guides him in the construction of his $L_{2}$ grammar? One obvious potential knowledge source is the grammar of his mother tongue, which is considered to be an instantiation of universal grammar (UG). A second logically possible source is UG itself. This latter option depends on one's conception of the relationship between UG and the language-specific (mother-tongue) core grammar. If one considers $\mathrm{L}_{1}$ acquisition to be a process in which the UG knowledge system changes into a language-specific knowledge system (i.e. core grammar) through parameter setting, UG knowledge is only indirectly available, namely through its $\mathrm{L}_{1}$ instantiation. Under such a view, parameter values other than the ones chosen by $\mathrm{L}_{1}$ are no longer available to the $\mathrm{L}_{2}$ learner by UG (Clahsen and Muysken 1986; Bley-Vroman 1989). If one takes the alternative view that $\mathrm{L}_{1}$ acquisition is a process in which a language-specific grammar develops as a construct that is separate from though related to $\mathrm{UG}$ - that is, $\mathrm{UG}$ remains constant throughout the $\mathrm{L}_{1}$ acquisition process - then UG knowledge, including the set of options provided by the parameters, is directly available at the $\mathrm{L}_{2}$ initial state (cf. White 1983, 1985, 1986; Flynn 1984, 1987; Flynn and Espinal 1985).

In this paper we will take the position that, in essence, UG is fully accessible to the $\mathrm{L}_{2}$ learner (cf. Epstein et al. 1996), which amounts to the full access hypothesis and to the full transfer/full access hypothesis (cf. Schwartz and Sprouse 1994, 1996). Thus, at the initial state, the $\mathrm{L}_{2}$ learner has two grammatical knowledge sources at his disposal, the $\mathrm{L}_{1}$ steady state and UG. We hypothesize that, initially, the $\mathrm{L}_{2}$ learner's construction of the $\mathrm{L}_{2}$ grammar is guided by his $\mathrm{L}_{1}$ grammar (the conservation hypothesis) and that, in a later stage, $\mathrm{UG}$ guides the learner in

i. identifying mismatches between his derivational output expressions (e.g. his possessive constructions) and the primary linguistic input he gets (e.g. possessive constructions produced by native speakers of Dutch), and

ii. restructuring his initial grammar in such a way that, for him, there is a match between output expressions and the primary linguistic input.

Restructuring here implies assignment of different values, as defined by UG, to parameterized grammatical properties. Strictly speaking there is full continuity of $\mathrm{L}_{1}$ grammar and $\mathrm{UG}$, but $\mathrm{UG}$ is only accessed at a later stage of acquisition. This implies that in the initial stages one and the same system is at the basis of the $\mathrm{L}_{1}$ and $\mathrm{L}_{2}$ derivational output. From this perspective, we prefer the term conservation to transfer, since the latter suggests that $\mathrm{L}_{1}$ knowledge properties are carried over from the $\mathrm{L}_{1}$ grammar to a separate grammar. ${ }^{3}$ 
If the $\mathrm{L}_{2}$ learner takes a conservative approach and models his $\mathrm{L}_{2}$ grammar upon his $\mathrm{L}_{1}$ grammar, what parts of this $\mathrm{L}_{1}$ grammar are conserved? Before considering this question, let us briefly consider the nature of the $\mathrm{L}_{1}$ grammar. ${ }^{4}$ The $\mathrm{L}_{1}$ grammar is taken to be a generative procedure that derives sound-meaning pairs, that is, linguistic expressions consisting (at least) of a PF and an LF representation. The generative procedure consists of two central components: (a) the lexicon, and (b) the computational system of human language $\left(\mathrm{C}_{\mathrm{HL}}\right)$. Within the lexical component a distinction should be made between two types of lexical knowledge: (a) knowledge of lexical properties as defined by UG, and (b) language-specific knowledge of lexical items (LI) and their lexical entries. The computational system of human language consists of such operations as merge (the tree-building property of $\mathrm{C}_{\mathrm{HL}}$ ) and move (i.e. attract; the displacement property of $\mathrm{C}_{\mathrm{HL}}$ ). On the basis of a set of lexical items chosen from the lexicon (the so-called numeration), these operations construct syntactic objects (i.e. phrase markers), which in essence constitute rearrangements of properties of the selected lexical items.

Let us now return to the question of what parts of the learner's $L_{1}$ generative procedure are conserved in the initial $\mathrm{L}_{2}$ grammar. An obvious candidate appears to be the language-invariant part of the generative procedure. Under current assumptions (cf. Chomsky 1994), this means that the computational component $\left(\mathrm{C}_{\mathrm{HL}}\right)$ is conserved at the initial $\mathrm{L}_{2}$ state. It is hard to decide whether knowledge of the computational system at the $\mathrm{L}_{2}$ initial state is modelled upon $\mathrm{UG}$ or the $\mathrm{L}_{1}$ grammar. There are two basic options. The first option assumes two grammars, each grammar consisting of a lexicon and a computational system. This option is represented in (1).

(1) Representation of a bilingual's linguistic knowledge, separate $C_{H L}$ UG

\begin{tabular}{c} 
Grammar $1(\mathrm{GR} 1)$ \\
Lexicon $+\mathrm{C}_{\mathrm{HL}}$ \\
\hline
\end{tabular}

$$
\begin{gathered}
\text { Grammar } 2 \text { (GR2) } \\
\text { Lexicon }+\mathrm{C}_{\mathrm{HL}}
\end{gathered}
$$

This option does not seem entirely adequate. Given the assumption that the computational system is invariant (that is $\mathrm{C}_{\mathrm{HL} 1}=\mathrm{C}_{\mathrm{HL} 2}$ ) and that UG-defined variation resides in the lexicon, a model of the $\mathrm{L}_{2}$ learner's linguistic state as in (2) seems more plausible, with a shared $\mathrm{C}_{\mathrm{HL}}$. Under such a view, bilingual knowledge involves a language-specific grammar consisting of one shared computational system and two separate lexicons whose parameterized properties have been set. 
(2) Representation of a bilingual's linguistic knowledge, shared $\mathrm{C}_{\mathrm{HL}}$

UG

\begin{tabular}{|l|l|}
\hline \multicolumn{2}{|c|}{$\mathrm{C}_{\mathrm{HL}}$} \\
\hline Lexicon 1 & Lexicon 2 \\
\hline
\end{tabular}

What knowledge of the other component of the generative procedure, the lexical component, is conserved in the $\mathrm{L}_{2}$ grammar? As hinted at above, we should distinguish lexical knowledge, as defined by UG, and language-specific knowledge of lexical items and their lexical entries. To avoid confusion, we will refer to the latter type of lexical knowledge as the vocabulary. Within the former type of lexical knowledge, a further distinction can be made between invariant lexical knowledge (e.g. the UG-defined lexical knowledge that the categories $\mathrm{V}$ and $\mathrm{N}$ are members of the categorial inventory of human language) and parameterized lexical knowledge. That is, natural languages differ from each other in the setting of lexical options (parameters) within the lexical system. Those parameters involve, for example,

i. a choice of categories from the UG-defined inventory of lexical and functional categories;

ii. an ordering relation between a categorial head $\mathrm{X}^{0}$ and its complement (the head parameter);

iii. a strength feature determining the overtness or covertness of displacement.

Knowledge of the invariant UG-defined lexical knowledge is naturally conserved in the $\mathrm{L}_{2}$ grammar (through either the $\mathrm{L}_{1}$ grammar or UG). As regards the parameterized lexical knowledge, we hypothesize that at the initial state the $L_{2}$ learner conserves the $L_{1}$ parameter settings in the grammar in which he expresses $\mathrm{L}_{2}$ items.

We should raise the question here as to what extent conservation of knowledge applies. In order to give a precise answer, we should first briefly consider what kind of lexical knowledge is involved when a learner knows some lexical item. First of all, vocabulary knowledge comprises knowledge of the arbitrary sound-meaning pairing. This knowledge is encoded by a phonological matrix and some meaning representation. With Chomsky (1994), we will further assume that besides this itemspecific knowledge, each coding of a lexical item contains a set of formal features $(\mathrm{FF})$. A distinction can be made between intrinsic $\mathrm{FFs}\left(\mathrm{FF}_{\mathrm{i}}\right)$ and optional $\mathrm{FFs}\left(\mathrm{FF}_{\mathrm{o}}\right)$. The former are unpredictable, idiosyncratic grammatical properties of lexical items (e.g. the categorial feature $[+\mathrm{N},-\mathrm{V}]$, the person feature [3 person], the gender feature [-human]); 
the latter include grammatical features that are predictable from other properties of the lexical entry (e.g. the features number and [abstract] case, which might be derived from the categorial feature definition $[+\mathrm{N},-\mathrm{V}]) .{ }^{5}$ The Turkish word araba 'car', for example, can now be represented as in (3).

(3) The Turkish lexical item araba

phonological matrix: /araba/
semantic features: [artifact], ...
$\mathrm{FF}_{\mathrm{i}}:$ [+N,--V]
$\mathrm{FF}_{\mathrm{i}}:-$ human
$\mathrm{FF}_{\mathrm{i}}: 3$ person
$\mathrm{FF}_{\mathrm{O}}$ : singular
$\mathrm{FF}_{\mathrm{O}}$ : accusative

In what way might we now conceive of conservation of vocabulary knowledge? Obviously, conservation does not apply at the level of the phonological matrix. However, one might conceive of early lexical acquisition as a process in which the $\mathrm{L}_{2}$ learner tries to match a meaning representation associated with some lexical item of his $\mathrm{L}_{1}$ vocabulary with a phonological matrix of the target language. Under this view, $\mathrm{L}_{2}$ acquisition of some lexical item involves the identification of the phonological matrix that matches the meaning representation, which is already familiar from the $\mathrm{L}_{1}$ vocabulary.

If we adopt this view of the vocabulary-learning task of the $\mathrm{L}_{2}$ learner, we get the following developmental model of vocabulary learning. The initial state of $\mathrm{L}_{2}$ acquisition is as in (2): the $\mathrm{L}_{2}$ learner has knowledge of UG and a generative procedure. This generative procedure consists of the invariant computational system on the one hand and the lexicon on the other. At the initial $\mathrm{L}_{2}$ state, that is, the state at which the adult $\mathrm{L}_{2}$ learner is still a monolingual speaker, the $\mathrm{L}_{2}$ learner's language-particular knowledge consists of

i. a complete set of $\mathrm{L}_{1}$-instantiated parameterized properties and

ii. an "adult" $L_{1}$ vocabulary. ${ }^{6}$

At the interdevelopmental stages, the $\mathrm{L}_{2}$ learner's language-particular knowledge consists of

i. an $\mathrm{L}_{1}$ lexicon comprising a complete set of $\mathrm{L}_{1}$-instantiated parameterized properties and an "adult" $\mathrm{L}_{1}$ vocabulary, on the one hand, and

ii. an $\mathrm{L}_{2}$ lexicon comprising an incomplete set of $\mathrm{L}_{2}$-instantiated parameterized properties and an incomplete $L_{2}$ vocabulary.

If an $\mathrm{L}_{2}$ learner becomes a competent bilingual speaker, his $\mathrm{L}_{2}$ language-particular knowledge will consist of a complete set of 
$\mathrm{L}_{2}$-instantiated parameterized properties and a complete "adult" $\mathrm{L}_{2}$ vocabulary. These three developmental stages are modeled in Table $1 .^{7}$

What are the consequences of this model of the $\mathrm{L}_{2}$ acquisition process at the derivational output level? At the real initial state, there appears to be no derivational output for the very simple reason that the $L_{2}$ learner has no knowledge yet of the $L_{2}$ vocabulary. Maybe we should formulate it somewhat more carefully and say that there is no AUDIBLE derivational output; strictly speaking, nothing excludes an output representation (i.e. a phrase marker) containing lexical items that lack a phonological matrix. That is, if the $\mathrm{L}_{2}$ learner conserves his lexical knowledge of some lexical item except for its phonological matrix, then one might conceive a derivational expression (i.e. an output structure) that results from the application of the computational system to a numeration consisting of lexical items whose feature constellations are conserved from $\mathrm{L}_{1}$ except for their phonological matrices. That is, the phonological representations are simply absent. So, in an interlanguage, apparently empty constituents are filled by $\mathrm{L}_{1}$ feature constellations lacking a phonological matrix.

The generated representations of the early interdevelopmental grammars are characterized by an $\mathrm{L}_{1}$ syntax and an $\mathrm{L}_{2}$ lexicalization. That is, the structures that are generated display the properties of (conserved) $\mathrm{L}_{1}$ parameter settings (e.g. a rigid head-final phrase structure as in Turkish) and contain lexical items of the target language (e.g. Dutch words). ${ }^{8}$ As

Table 1. Model of the three developmental states; gray area indicates knowledge involved in the generation of $L_{2}$ expressions; $m<n$

\begin{tabular}{|c|c|c|}
\hline Initial state & Interlanguage state & Bilingual target state \\
\hline $\begin{array}{l}\text { UG } \\
\mathrm{C}_{\mathrm{HL}}\end{array}$ & $\begin{array}{l}\text { UG } \\
\mathrm{C}_{\mathrm{HL}}\end{array}$ & $\begin{array}{l}\text { UG } \\
\mathrm{C}_{\mathrm{HI}}\end{array}$ \\
\hline \multirow[t]{2}{*}{ 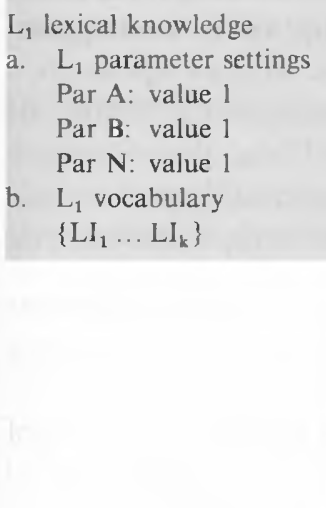 } &  & 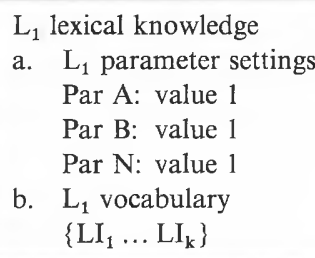 \\
\hline & 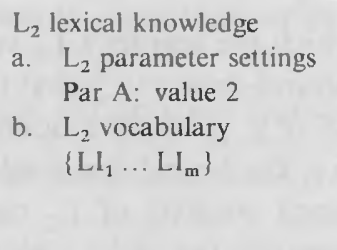 & 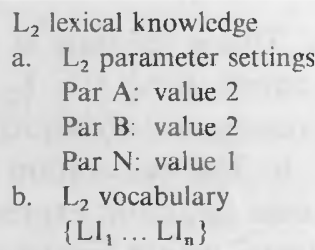 \\
\hline
\end{tabular}


the $\mathrm{L}_{2}$ learner identifies and acquires the (possibly different) values of the $\mathrm{L}_{2}$ language, his output representations get more of an $\mathrm{L}_{2}$ syntax. Notice at this point that one expects output representations that have partly an $\mathrm{L}_{1}$ syntax (i.e. $\mathrm{L}_{1}$ settings) and partly an $\mathrm{L}_{2}$ syntax (i.e. $\mathrm{L}_{2}$ settings). In such cases, the $\mathrm{L}_{2}$ learner has the possibility of making a choice, as it were, at the level of parameter settings during the derivation of the linguistic expression. At the bilingual state, the lexicon has fully developed, both at the level of $\mathrm{L}_{2}$ parameter settings and at the level of $\mathrm{L}_{2}$ vocabulary.

As is clear from above, the burden of (second-)language acquisition lies in lexical knowledge, more specifically in the identification of the $\mathrm{L}_{2}$ values for the parameterized properties and in learning the $\mathrm{L}_{2}$ vocabulary. The question arises of how both forms of lexical knowledge acquisition proceed. Let us consider acquisition of the $\mathrm{L}_{2}$ vocabulary first.

The vocabulary-learning task is plausibly influenced by two important factors, (i) "visibility" of lexical items and (ii) semantic-pragmatic relevance of lexical items. It seems likely that in general those lexical items that have a high degree of perceptual saliency and communicative relevance are acquired earlier than those lexical items that do not, or do so to a lesser extent. ${ }^{9}$ Taking this perspective, one might hypothesize that, generally speaking, content words (e.g. Dutch auto 'car') are more accessible than free-function morphemes (e.g. Dutch veel 'many'), which in turn are more accessible than bound-function morphemes (e.g. inflectional morphemes; clitic-like elements, e.g. the element $-s$ attached to the prenominal possessor in languages like English and Dutch). Given such an accessibility hierarchy, the filling-in task of the $\mathrm{L}_{2}$ vocabulary is initially most successful for content words, less so for free-function words, and least so for the inflectional morphological domain. In view of this, we may - somewhat ideally perhaps - distinguish the following three states or levels of vocabulary knowledge during the acquisition of some grammatical construct (e.g. a possessive noun phrase):

\section{The content-word state (CWS)}

a. This is the state at which the learner's $\mathrm{L}_{2}$ vocabulary mainly contains content words (i.e. $\mathrm{L}_{2}$ sound-meaning pairs) for the generation of some grammatical construct $\mathrm{X}$ (e.g. possessive noun phrase).

b. The numeration (i.e. the lexical items selected for the derivation of some linguistic expression) consists of $\mathrm{L}_{2}$ content words and "lexical items" whose feature constellation lacks a phonological matrix. 
c. In the case of a possessive structure generated by the $\mathrm{L}_{2}$ learner, the CWS is instantiated, for example, when the structure only overtly lexicalizes the possessor and the possessee. This is exemplified in (4a).

The free-functional-morpheme state (FMS)

a. This is the state at which the learner's $L_{2}$ vocabulary contains words and free-functional morphemes for the generation of some grammatical construct.

b. The numeration consists of $\mathrm{L}_{2}$ content words, free-functional morphemes, and "lexical items" whose feature constellation lacks a phonological matrix.

c. In the case of a possessive structure generated by the $\mathrm{L}_{2}$ learner, the FMS is instantiated, for example when, besides the possessor noun and the possessed noun, functional material (e.g. the demonstrative determiner die) is overtly lexicalized. An example of such a possessive variant is given in (4b).

\section{The bound-functional-morpheme state (BMS)}

a. This is the state at which the learner's $\mathrm{L}_{2}$ vocabulary contains content words, free-function morphemes, and bound-function morphemes for the generation of some grammatical construct.

b. The numeration consists of $\mathrm{L}_{2}$ content words, bound-functional morphemes, and, possibly, free-functional morphemes; it may further contain "lexical items" whose feature constellation lacks a phonological matrix.

c. In the case of a possessive structure generated by the $\mathrm{L}_{2}$ learner, the BMS is instantiated, for example when, besides lexicalizations of content words (and free-functional morphemes), there is overt lexicalization of bound-functional material. An example of such a derived possessive variant is given in (4c), where - as will become clear in the course of this paper - van behaves as a genitival suffix. ${ }^{10}$

The three relevant possessive variants are illustrated in (4).

(4) a. vriend huis

friend house

'my friend's house' 


\section{b. garage die chef garage that boss 'the boss of the garage' \\ c. examen-van tolk examen-of interpreter 'the interpreter at the exam'}

From a strong conservation perspective, development of the second language involves among other things "filling in" of the $L_{2}$ vocabulary. At the derivational output level, this results in linguistic expressions that show an increase of phonetic contents in the course of $\mathrm{L}_{2}$ development. Given the accessibility hierarchy discussed above, phonological realization will first be manifested for content words and somewhat later for function words. Within the class of functional elements, free-function morphemes are more accessible (hence added earlier to the $L_{2}$ lexical list) than bound morphemes.

It is important to point out that the learner's having an $\mathrm{L}_{2}$ lexical item in his $\mathrm{L}_{2}$ vocabulary does not mean that he has complete knowledge of the lexical properties of this item. He may have identified a phonological string as being a lexical unit (morpheme, word) without yet having fully identified the (target) formal properties belonging to the formal feature complex of the item or its morphological properties. As a matter of fact, if conservation of knowledge applies at the level of UG-defined lexical knowledge (i.e. at the level of parameter settings), one might also expect it to apply at the level of lexical items belonging to the vocabulary. Under such a view, the learner initially models the lexical entries of his $L_{2}$ lexical items on the equivalent $L_{1}$ lexical items. This modeling upon the information provided by the $\mathrm{L}_{1}$ lexical item obviously does not extend to the phonological matrix of the $L_{1}$ item, but it might extend to the formal features of the $L_{2}$ item. Imagine, for example, a situation in which a learner, knowing a language in which pronouns are categorized as $\mathrm{N}$ (i.e. pronominals), learns a target language in which pronouns are of the categorial type D (i.e. prodeterminers). Taking a conservative approach toward his $\mathrm{L}_{2}$ vocabulary, his first hypothesis will be that $\mathrm{L}_{2}$ pronouns are lexical items carrying the categorial information $\mathrm{N}$. As we will see in the course of this paper, this situation seems to hold of Turkish learners of Dutch (see section 6). The $\mathrm{L}_{2}$ learner will have target knowledge of some lexical item $\mathrm{X}$ when the feature constellation (i.e. phonological matrix, meaning representations, and the formal feature complex) of the learner's lexical item corresponds to that of a native speaker of Dutch. In a way, the $L_{2}$ learner has RESTRUCTURED his 
knowledge at the level of lexical entries. Schematically and somewhat ideally, $\mathrm{L}_{2}$ acquisition of some lexical item (e.g. a pronoun) may be represented in Table $2{ }^{11}$

Restructuring also applies at the level of acquisition of $\mathrm{L}_{2}$ parameter settings. We assume that restructuring in that case involves a transition from a knowledge state in which parameter $\mathrm{X}$ and its setting are only represented in the $\mathrm{L}_{1}$ lexicon to a knowledge state in which they are presented in both the $\mathrm{L}_{1}$ lexicon and the $\mathrm{L}_{2}$ lexicon (possibly with different settings). Recall that we assume that the parameter together with its possible values remains available through UG. On the basis of the primary linguistic input, the $L_{2}$ learner will depart from his conserved $L_{1}$ parameter setting and reset the parameter.

For example, on the basis of positive evidence (or what is considered positive evidence by the learner) in the $\mathrm{L}_{2}$, Dutch, a Moroccan learner concludes that functional heads have weak features (see section 7). Resetting on the basis of indirect negative evidence, that is, the systematic absence of a grammatical construct in the primary linguistic input (cf. Chomsky 1981), is extremely hard and does not occur in early learning stages. Thus far, we have discussed the concepts of conservation of grammatical knowledge and restructuring of grammatical knowledge at two levels:

i. the level of UG-defined parameterized lexical knowledge, and

ii. the level of "vocabulary" lexical knowledge.

Without entering into details, we would like to close off this section by mentioning that we will assume that conservation of knowledge and restructuring of that knowledge extend to morphology. Within the confines of this study, morphological conservation and restructuring will feature in the expression of genitival case and in the formation of possessive pronominals by means of suppletion.

Table 2. Development of lexical item (LI) learning

\begin{tabular}{lcc}
\hline Initial state of $\mathrm{LI}$ & Interlanguage state & Target state \\
\hline $\mathrm{LI}$ in $\mathrm{L}_{1}$ lexicon: & $\mathrm{LI}$ in $\mathrm{L}_{1}$ lexicon: & $\mathrm{LI}$ in $\mathrm{L}_{1}$ lexicon: \\
/abcd/ & /abcd/ & /abcd/ \\
"meaning representation" & "meaning representation" & "meaning representation" \\
$\mathrm{FF}_{1}:+\mathrm{N},-\mathrm{V}$ & $\mathrm{FF}_{1}:+\mathrm{N},-\mathrm{V}$ & $\mathrm{FF}_{1}:+\mathrm{N},-\mathrm{V}$ \\
$\mathrm{LI}$ in $\mathrm{L}_{2}$ lexicon: & $\mathrm{LI}$ in $\mathrm{L}_{2}$ lexicon: & $\mathrm{LI}$ in $\mathrm{L}_{2}$ lexicon: \\
$/ \emptyset /$ & $/$ efgh/ & $/$ efgh/ \\
"meaning representation" & "meaning representation" & "meaning representation" \\
$\mathrm{FF}_{1}:+\mathrm{N},-\mathrm{V}$ & $\mathrm{FF}_{1}:+\mathrm{N},-\mathrm{V}$ & $\mathrm{FF}_{2}: \mathrm{D}$ \\
\hline
\end{tabular}




\section{The structure of the noun phrase}

Before considering how possessive relationships are expressed in the nominal system, it is necessary to examine first the basic properties of the structure of noun phrases in Dutch, Moroccan Arabic, and Turkish. ${ }^{12}$ In line with the program of assimilating the structure of clauses and that of nominals (Szabolcsi 1987, 1992) and adopting the so-called functionalhead hypothesis (cf. Abney 1987; Grimshaw 1991), we will take the nominal structure in (5) as our point of departure (head-complement order irrelevant):

(5) $\left[_{\mathrm{DP}} \operatorname{Spec}\left[_{\mathrm{D}^{\prime}} \mathrm{D}\left[_{\mathrm{AgrP}} \operatorname{Spec}\left[_{\mathrm{Agr}^{\prime}} \mathrm{Agr}\left[_{\mathrm{DetP}} \operatorname{Spec}\left[_{\mathrm{Det}^{\prime}} \operatorname{Det}\left[_{\mathrm{QP}} \mathrm{Spec}\right.\right.\right.\right.\right.\right.\right.$

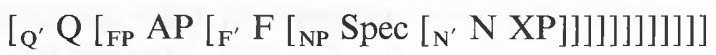

Following Szabolcsi (1987, 1992), we take D to fulfill the function of "subordinator." The determiner D enables the noun phrase to serve as a (theta-bearing) argument of a predicate. We will further assume that DP is the locus where certain "nominal type"-indicating properties are defined. Suppose that, analogously to C, D may carry a type-indicating feature (e.g. $<+$ interrogative $\rangle,\langle+$ deictic $\rangle,\langle+$ d-linked $\rangle$ ) and that (the strength property of) this feature must be checked by some Det(erminer)-like expression that originates in Spec,DetP. In a language like Dutch, the nominal type indicating determiner moves overtly to Spec,DP (see [6]). A language like Hungarian displays the in situ pattern (see [7]); checking of the feature associated with $\mathrm{D}$ will take place at LF after the relevant checking feature (e.g. $<+$ demonstrative $>$ ) has raised to $\mathrm{D}$.

(6) a. [DP Welke $e_{i}\left[D^{\prime} D_{<+w h}>\left[\operatorname{DetP} t_{i}\left[\right.\right.\right.$ Det' $^{\prime}$ Det [jongens $\left.\left.\left.\left.]\right]\right]\right]\right]$ 'which boys'

b. [DP deze $\left[\mathrm{D}^{\prime} \mathrm{D}_{<+\mathrm{dem}}>\left[{ }_{\operatorname{DetP}} \mathrm{t}_{\mathrm{i}}[\right.\right.$ Det $\operatorname{Det}[$ jongens $\left.\left.\left.]]\right]\right]\right]$ 'these boys'

(7) (Hungarian)

a. [DP a [AgrP te [DetP melyik [állítás-od]]]] the you-NOM which statement-2sg 'which statement of yours'

b. [DP a [AgrP te [DetP ezen [állítás-od]]]] the you-NOM this statement-2sg 'this statement of yours'

As indicated in the above structures, we will assume, following Szabolcsi (1987, 1992), that Spec,AgrP is the locus where (prenominal) possessors are located. See section 4 for further discussion. 
QP is the locus of quantification (over individuals/entities) and the place where number properties of the nominal head are checked. We assume that [Spec, QP] is typically occupied by so-called weak determiners (i.e. items like three, many). The specifier position of FP, the lowest functional projection in (8), is the locus of attributive adjectival modification (Cinque 1993).

The lexical projection NP is the domain of thematic discharge. We take the position that the possessor DP in a possessive noun phrase receives its thematic role in the complement position to the noun. ${ }^{13}$ As will be discussed more elaborately in section 4, certain possessor DPs leave NP and are raised to Spec,AgrP for reasons of case checking; others can satisfy case-checking requirements NP-internally and remain within the lexical projection (cf. [8]), yielding a so-called analytic construction featuring a preposition-like element (e.g. van in Dutch).

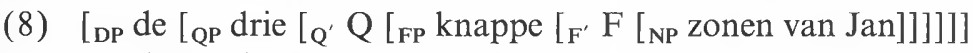
the three handsome sons of Jan

After this brief characterization in the various layers within the extended nominal projection, we take a brief look at the phrase-structural properties of the three languages at issue in this paper. The major properties are summarized in Table $3 .^{14}$

As indicated in the second row of Table 3, we adopt the standard headfinal analysis of Turkish. Thus, the nominal head (carrying inflectional morphology) is always final. Dutch and Moroccan Arabic are headinitial: definite articles (D), for example, precede their complements, and nominal heads $(\mathrm{N})$ take their complement to the right. This is illustrated in (8) above for Dutch and in (9) for Moroccan Arabic.

Table 3. Properties of the noun phrase in Dutch, Moroccan Arabic, and Turkish

\begin{tabular}{|c|c|c|c|}
\hline Property & Dutch & Moroccan Arabic & Turkish \\
\hline Functional projections & $\begin{array}{l}\text { DP,AgrP,DetP, } \\
\text { QP,FP }\end{array}$ & $\begin{array}{l}\text { DP,AgrP,DetP, } \\
\text { QP,FP }\end{array}$ & $\begin{array}{l}\text { DP,AgrP,DetP, } \\
\text { QP,FP }\end{array}$ \\
\hline Headedness & head-initial & head-initial & head-final \\
\hline $\begin{array}{l}\text { Overt } \mathrm{N} \text {-to-X raising } \\
\text { (i.e. } \mathrm{X} \text { has a }<\text { strong }> \\
\text { feature) }\end{array}$ & no & yes & no \\
\hline $\begin{array}{l}\text { Overt raising of XP from } \\
\text { Spec,DetP to Spec,DP } \\
\text { (i.e. D }<\text { strong }>\text { ) }\end{array}$ & yes & yes & no \\
\hline
\end{tabular}


(9) [DP 1- [NP weld dyal t-tažer]]

the- son of the-merchant

'the merchant's son'

As indicated in the first row, we will assume that the three languages share the inventory of functional categories (and projections) that may be present within the extended nominal projection. Let us have a brief top-down view of the various functional layers, starting with DP. The Turkish noun phrase differs from the Dutch and Moroccan Arabic noun phrases in that it never displays any overt definite article. In view of the subordinating function of the functional category $\mathrm{D}$, we will assume that Turkish has a DP projection that closes off the extended nominal projection. We further tentatively propose that the bound morpheme expressing the case of the extended nominal projection relates to the $\mathrm{D}$ position, the locus of referentiality (cf. Chomsky 1995). The correlation between the morphological property of accusative case and the interpretive property of specificity (cf. Enç 1991) is indicative of this relationship.

The specifier position of Agr can be occupied by a possessor DP. All three languages have possessive construction types featuring a possessor in [Spec,AgrP]. Since these patterns will be discussed more elaborately in the next section, we are only exemplifying them here in (10).

$$
\begin{aligned}
& \text { a. [DP [ } \left.\left.\left.\left.\mathrm{D}^{\prime} \mathrm{D} \text { [AgrP }_{\text {Jans }}\left[\mathrm{JPP}_{\mathrm{QP}} \text { drie [zonen } \mathrm{t}_{\mathrm{j}}\right]\right]\right]\right]\right] \\
& \text { Jan's three sons }
\end{aligned}
$$

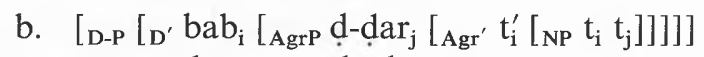

$$
\begin{aligned}
& \text { door the-house } \\
& \text { 'the door of the house' } \\
& \text { c. [DP [AgrP Ayşe-n-in } \text { [FP }_{\text {kirmızı [ }} \mathrm{t}_{\mathrm{i}} \text { araba-si] F] Agr] D] } \\
& \text { Ayşe-GEN red car-3sg } \\
& \text { 'Ayşe's red car' }
\end{aligned}
$$

On the surface, Moroccan Arabic differs from Dutch and Turkish as regards the (postnominal) placement of the possessor. As will become clear later, this superficial order is the result of overt N-raising to D in Moroccan Arabic (cf. the third row in Table 3).

We have analyzed DetP as the locus of nominal-type-indicating elements. We argued that in Dutch, these elements can be moved overtly to Spec,DP (see [6a]). Moroccan Arabic also has such overt movements, witness the examples in (11), drawn from Harrell (1970: 191).

$$
\begin{aligned}
& \left.\left[{ }_{D P} \operatorname{had}_{i}\left[D^{\prime} 1-\left[{ }_{\text {DetP }} t_{i}\left[{ }_{\text {Det' }} \text { Det [NP weld }\right]\right]\right]\right]\right] \\
& \text { this/that the-- } \\
& \text { 'this/that boy' }
\end{aligned}
$$


Turkish displays the in situ pattern in (12a) and (12b): nominal-typeindicating elements remain in their base position in overt syntax.
a. [DP [AgrP Ayşe-n-in [DetP hangi [araba-sı]]]] Ayşe-GEN which car-3sg 'which car of Ayşe's'
b. [DP $\left[{ }_{\text {AgrP }} \operatorname{senin}\left[\right.\right.$ DetP $_{\text {bu }}$ [iki el-in-de]]]] you-GEN these two hand-2sg-LOC 'in these two hands of yours'

This contrast between Dutch/Moroccan Arabic, on the one hand, and Turkish, on the other, is indicated by the fourth row of Table 3.

Nominal structures having a QP-layer containing a weak determiner in Spec, QP are given in (13): ${ }^{15,16}$
a. $\quad\left[{ }_{D P}\left[\mathrm{D}^{\prime}\right.\right.$ de $\left[{ }_{Q P}\right.$ drie $[$ zonen $\left.\left.\left.]\right]\right]\right]$ the three sons
b. [DP D [QP Si [NP ražel $]]]$
a/some man
'a man, some sort of man, some man or other'
c. [DP $\left[{ }_{\mathrm{AgrP}}[\mathrm{QP}\right.$ iki [NP $\mathrm{el-in-de]} \mathrm{Q]} \mathrm{Agr]} \mathrm{D]}$
two hand-2sg-LOC
'in your two hands'

Let us turn finally to the functional projection FP, whose (left-branch) specifier contains an attributive adjectival modifier. The exemplifying patterns for the three languages under discussion are given in (14)-(16):

(14) [DP deze [DetP $_{\mathrm{i}} \mathrm{t}_{\mathrm{i}}$ [QP drie [FP knappe [NP zonen van Jan]]]]] 'these three handsome sons of Jan'

(15) Moroccan Arabic (Harrell 1970)

[DP $\operatorname{duk}_{\mathrm{i}}\left[\mathrm{D}^{\prime} \mathrm{S}-\left[{ }_{\text {DetP }} \mathrm{t}_{\mathrm{i}}\left[\right.\right.\right.$ Det' $^{\prime}$ skayriya $_{\mathrm{k}}\left[\mathrm{FP}\right.$ le-mxezzzin $\left.\left.\left.\left.\left.\left[\mathrm{NP}_{\mathrm{k}} \mathrm{t}_{\mathrm{k}}\right]\right]\right]\right]\right]\right]$ those the- drunkards the-incorrigible 'those incorrigible drunkards'

(16) [DP [DetP bu [FP güzel [NP kitap]]]] this beautiful book

In Dutch and Turkish, the attributive AP precedes the nominal head. In Moroccan Arabic, however, the noun precedes the AP. As indicated in (15), this is the result of $\mathrm{N}$-raising to a higher functional head; see the third row of Table 3. 


\section{Possessive structures and case checking}

\subsection{Mechanisms of case checking}

This section addresses the question as to how the possessive relation is structurally expressed in Dutch, Turkish, and Moroccan Arabic. As the theory of case plays an important role in the formal expression of the possessive relationship, some brief remarks about case theory in the nominal domain are in order.

Along the lines of Chomsky (1986), we will assume that the possessor noun phrase (i.e. DP) carries an abstract genitive case feature and that genitive case is an inherent case, which implies that it will only be assigned by $\mathrm{N}$ to a noun phrase that receives a thematic role from it. ${ }^{17}$ In line with Chomsky's (1995: 285) "minimalist" reinterpretation of inherent case, we will interpret inherent (hence, genitive) case as a +interpretable formal feature. Being + interpretable, the genitive feature of DP need not, but could be, checked in a Spec-head configuration. ${ }^{18}$ For English, this has the consequence that the genitive-case-bearing DP can remain within its base position throughout the derivation (i.e. in both overt and covert syntax), since its genitive case feature need not be checked. This yields possessive constructions such as shown in (17a), in which of is considered to be the morphological realization of the (abstract) genitive case feature on the possessor DP in the complement position to $\mathrm{N}$ (cf. Chomsky 1981, 1986). Alternatively, the possessor DP can raise to the specifier position of some functional head (in this case Agr), where its case feature can be checked off in a Spec-head configuration, the canonical checking environment. Thus in (17b), the possessor DP carrying the genitive case feature is moved to Spec,AgrP. The genitive case is now checked by the (possessed) noun (more precisely, by the genitive-caseassignment feature that is part of the formal feature complex of the possessed noun child). Checking of the genitive case feature takes place in LF, after the (formal feature complex of the) possessed noun has raised to Agr. ${ }^{19}$

(17) a. the child of the mother/Mary

b. the mother/Mary's child

The two modes of genitive case licensing are schematically represented below: ${ }^{20}$

(18) no checking: of insertion (= spell-out of genitive case)

a. [DP the [NP child $\left.\left.\left[{ }_{D P} \text { the mother }\right]_{<\text {gen }}>\right]\right]$

b. the child of + the mother 
(19) checking in Spec-head configuration

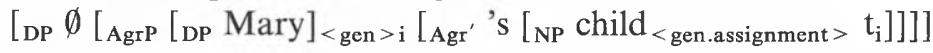

The question arises of which Spec-related formal feature of Agr attracts overt raising of the possessor DP. We will assume that Agr is specified for a categorial $\mathrm{D}$ feature (i.e. $[+\mathrm{N},-\mathrm{V},+\mathrm{D}]$ ). If this feature is defined as $<$ strong $>$, the categorial feature of the possessor (i.e. $[+\mathrm{N},-\mathrm{V},+\mathrm{D}]$ is attracted, dragging along other features of the possessor. One of the features that gets carried along is the genitive case feature. The genitive case feature gets a free ride, so to speak, and ends in a structural position where it can enter into a checking relation with an adequate genitive case checker. We assume that in English, $\mathrm{N}$ is the appropriate case checker, more specifically its genitive-case-assignment feature.

As will become clear in the course of our discussion, languages vary in their modes of genitive case licensing. Table 4 provides information about which modes of genitive licensing are used in the various construction types attested in the three languages at issue. We will discuss the various manifestations of the possessive relationship, starting with Moroccan Arabic.

\subsection{Moroccan Arabic possessive noun phrases}

Moroccan Arabic distinguishes two major types of possessive construction: (i) the analytic or absolute construction (AC) and (ii) the so-called construct-state construction (CS). The two constructions are exemplified in Table 4. At the surface, the CS and the AC have one thing in common: the possessed nominal (weld) precedes the possessor noun phrase $(t$-tažer). Closer examination, however, reveals many differences between the two constructions. First of all, in the AC the (genitive) possessor is introduced by the prepositional element $d y a l$. In the CS the possessor is a bare noun phrase. Second, in the AC the possessor noun phrase can be separated from the head noun by attributive APs modifying the head noun (see [20a]). In the CS, the bare possessor must immediately follow the head noun. Attributive APs modifying the head noun must follow the possessor (see [20b] and [20c].

(20) a. 1-bab 1-qehwi dyal d-dar the-door the-brown of the-house 'the brown door of the house'

b. *bab 1-qehwi d-dar door the-brown the-house 'the brown door of the house' 







\section{c. bab d-dar l-qehwi \\ door the-house the-brown \\ 'the brown door of the house'}

Third, definite AC noun phrases must be introduced by a definite determiner, such as the definite article $l$ (cf. [20a]). CS noun phrases do not allow a definite determiner $(l)$ in initial position; $\left({ }^{*} l\right)$-weld $t$-tažer. Thus, the possessed noun is initial. The definiteness of the entire possessive construction is determined by the definiteness feature of the possessor.

How is genitive case distributed in the two types of possessive construction? In the AC, the possessor remains in its base position. As its genitive case is inherent, it need not be checked in a Spec-head configuration. Even though the possessor remains in situ, the possessed noun ( $b a b)$ raises to a higher functional head (say Q), yielding a sequence like (21), in which the possessed noun precedes the attributive AP occupying Spec,FP. Schematically,

(21) [DP $1-\left[\right.$ [QP bab $_{\mathrm{i}}\left[\mathrm{FP}\right.$ l-qehwi $\left[\mathrm{NP}_{\mathrm{i}} \mathrm{t}_{\mathrm{i}}\right.$ d-dar $\left.\left.\left.\mathrm{d}_{<\mathrm{gen}}>1\right]\right]\right]$ the- door the-brown the-house

The structure in (21) gets spelled out morphologically. Spell-out of the abstract genitive case feature on the possessor DP is realized in the form of the adpositional marker dyal.

The second major manifestation of the possessive relation, the construct state, has a derived structure as in (22): ${ }^{21}$

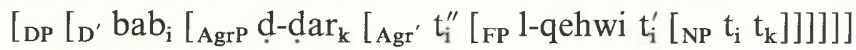

$$
\begin{aligned}
& \text { door the-house the-brown }
\end{aligned}
$$

In this structure, genitive case is checked off in a Spec-head configuration. The genitive case feature on the possessor DP is checked off by the caseassigning feature associated with the possessed noun. The required Spec-head configuration is created in overt syntax: Agr has a $<$ strong $>$ Spec-related categorial $\mathrm{D}$ feature (i.e. $[+\mathrm{N},-\mathrm{V},+\mathrm{D}]$, which attracts the possessor (including its genitive case property) to Spec,AgrP. It further has a $<$ strong $>$ head-related $\mathrm{N}$-feature that attracts the possessed noun. After N (including its formal feature complex) has raised to Agr, the genitive-case-assigning property of $\mathrm{N}$ checks off the genitive case feature associated with the possessor DP $d$-dar. Schematically (leaving out FP),

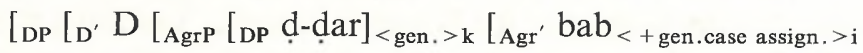

$$
\begin{aligned}
& \left.\left.\left.\left.\left[N P t_{i} t_{k}\right]\right]\right]\right]\right]
\end{aligned}
$$

After genitive case has been checked off, the possessed noun moves on to $\mathrm{D}$, yielding a surface order in which the possessed noun immediately 
precedes the possessor. We tentatively assume that $\mathrm{D}$ is specified for a head-related categorial feature $[+\mathrm{N},-\mathrm{V}]$, which has the strength property $<$ strong $>.^{22}$

Consider next a CS like (24), in which the pronoun is realized as a clitic on the possessed noun. ${ }^{23}$

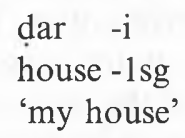

Essentially following a proposal made by Sportiche (1995) for clitic constructions at the clausal level, we will assume that the possessive clitic pronoun in (24) (e.g. $-i$ ' $\mathrm{me} / \mathrm{my}$ ') is generated as the head of a functional projection AgrP within the extended nominal projection. In Sportiche (1995), it is proposed for the clausal domain that such base-generated clitic heads stand in a syntactic relationship to an argument DP occupying the complement position to the theta-role-assigning head (i.e. V). In nonclitic-doubling languages (see [25a]), the argument is an empty pronominal pro; in clitic-doubling languages (see [25b]), the argument can be lexical (i.e. overt).
a. (French)
je le vois pro
I him saw $3 \mathrm{sg}$
'I saw him'
b. (Moroccan Arabic)
ana šeft-ha dak l-bent f-el-madrassa
I saw-her that the-girl in-the-school
'I saw the girl in the school'

In order to sanction agreement with the clitic pronoun, the (overt or covert) DP argument must move to the specifier position of the clitic head: the agreement features of the moved phrase are checked off against those of the clitic head in a Spec-head configuration, which is the canonical configuration for checking of agreement features.

When we extend Sportiche's analysis to noun-phrase-internal possessive clitics, we end up with an underlying structure for (24) as shown in (26). After application of overt N-to-Agr raising, we get the structure in (26b); subsequent movement of the $\mathrm{N}+$ clitic complex yields the structure in (26c). As far as the morphological spell-out of genitive case is concerned, we will assume that genitive case is not morphologically expressed by dyal because of the absence of a lexical (i.e. phonetically realized) host; that is, pro does not permit attachment of dyal. 
(26) a. [DP $\left[\mathrm{AgrP}\left[\mathrm{Agr}^{\prime} \mathrm{i}[\mathrm{NP}\right.\right.$ ḍar pro] $\left.\left.]\right]\right]$

b. [DP $\left[\operatorname{AgrP}\left[{ }_{A g r}{ }_{\text {Agr }}\right.\right.$ dar $\left._{i}+\mathrm{i}\right]\left[{ }_{N P} t_{i}\right.$ pro $\left.\left.\left.]\right]\right]\right]$

c. $\left[D P\left[\operatorname{dar}_{i}+\mathrm{i}\right]_{j}\left[\mathrm{AgrP}_{\mathrm{j}} \mathrm{t}_{\mathrm{NP}} \mathrm{t}_{\mathrm{i}}\right.\right.$ pro]]]

We will assume that an Agr head occupied by a clitic differs from an Agr head present in a (nonclitic) construct state in the strength of the Spec-related D feature. Whereas we assume the latter to have a strong Spec-related feature definition and, consequently, to trigger overt movement of the possessor argument, we take the former to be specified as $<$ weak >, to the effect that the D feature on Agr is checked off in LF. In LF, then, we have a representation as in (26c), where pro occupies the complement position to $\mathrm{N}$.

The reason for assuming a $<$ weak $>$ Spec-related feature on the clitic head comes from the existence of possessive doubling constructions like (27), which instantiate the phenomenon of clitic doubling within the nominal domain. ${ }^{24}$

(27) $\mathrm{mm}^{-h a_{\mathrm{i}}}$ dyal dik l-bent $\mathrm{i}_{\mathrm{i}}$ mother-her of that the-girl

'the mother of that girl'

Such a construction is hybrid in the sense that it displays properties of both construct states and analytic constructions: it lacks a definite article at the beginning of the noun phrase (a CS property), but it allows a dyal phrase (an analytic property).

In line with Sportiche's analysis of clitic doubling, we propose an underlying structure like (28) for the doubling pattern:

[DP [AgrP ha [NP mm [DP $\operatorname{dik}\left[{ }_{D} 1\right]\left[_{N P}\right.$ bent $\left.\left.\left.\left.]\right]\right]\right]\right]$

Overt head-raising of $\mathrm{N}(\mathrm{mm})$ to Agr (see [29a]) and subsequent raising of the complex $m m+h a$ to D yields the structure in (29b):

a. [DP $\left[{ }_{A g r P} m_{i}+h a\left[{ }_{N P} t_{i}\left[{ }_{D P} \operatorname{dik}\left[{ }_{D} 1\right]\left[{ }_{N P}\right.\right.\right.\right.$ bent $\left.\left.\left.\left.]\right]\right]\right]\right]$

b. $\quad\left[D P\left[D m_{i}+h a\right]_{j}\left[{ }_{A g r P} t_{j}\left[{ }_{N P} t_{i}\left[D P<\operatorname{gen}>\operatorname{dik}\left[{ }_{D} 1\right]\left[{ }_{N P}\right.\right.\right.\right.\right.$ bent $\left.\left.\left.\left.]\right]\right]\right]\right]$

The placement of the full argument in (27) suggests that the Spec-related feature of the possessive clitic head is weak. Feature checking of the categorial $\mathrm{D}$ feature takes place in LF. This also holds for the agreement properties associated with the doubled phrase; those are checked off in $\mathrm{LF}$ against the agreement features of the possessive clitic.

Recall that checking is not required for inherent case. In the complement position, genitive case is morphologically expressed by the insertion of the dummy preposition dyal. Insertion is permitted as there is a lexical host for the preposition to attach to.

Table 5 summarizes the major outcomes of the above discussion. 


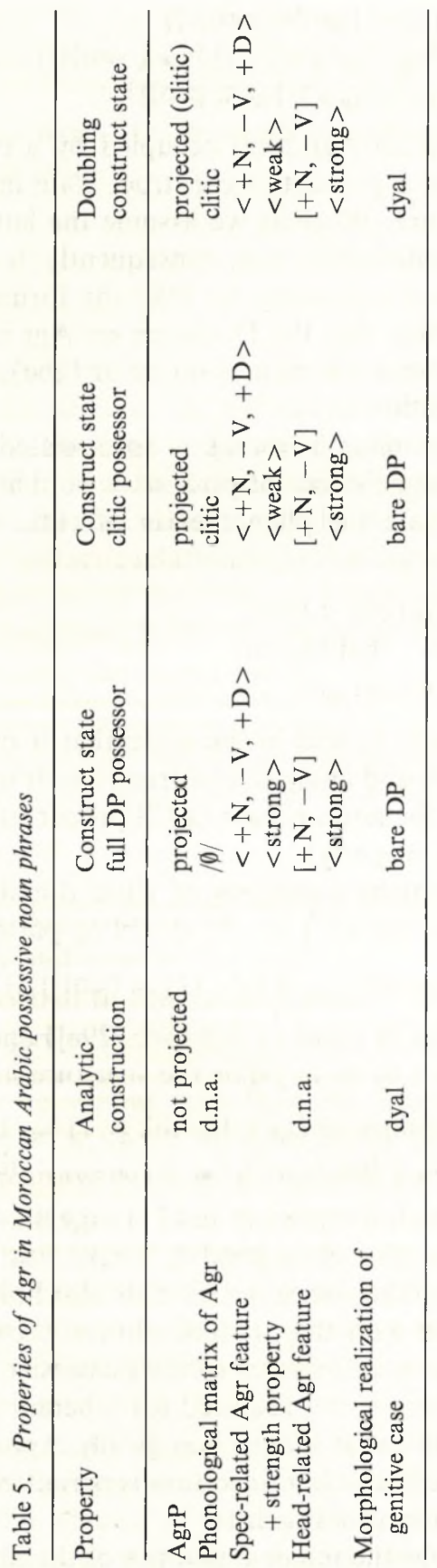




\subsection{Turkish possessive noun phrases}

The Turkish possessive construction has agreement in person and number between the possessed noun and the possessor. This agreement is manifested by the agreement suffix $s \imath$ in Table 4 . The genitive case feature on the possessor is formally expressed by the case morpheme in. We assume that these inflectional morphemes are part of the lexical items in the numeration. In this respect, they behave differently from an adpositional marker like Moroccan Arabic dyal, which is inserted late in the derivation, namely in the morphological component after spell-out.

As shown by (30), the possessor DP occurs in Spec,AgrP in overt syntax, which suggests that there is some $<$ strong $>$ Spec-related feature of the Agr node that attracts the possessor DP. We assume that Agr in Turkish has a $<$ strong $>\mathrm{D}$ feature, triggering overt raising of the possessor DP carrying the genitive feature.

$$
\begin{aligned}
& {\left[{ } _ { D P } \left[{ }_{A g r P}\right.\right. \text { sen-in }} \\
& \text { you-GEN } \left.\left.\left.\left[{ }_{D e t P} \text { bu [QP iki }\left[_{N P} t_{i} \text { el-in-de }\right]\right]\right]\right]\right] \\
& \text { 'in these two hands of yours' }
\end{aligned}
$$

The features associated with the complex possessed noun are checked off in covert syntax (i.e. feature-raising applies covertly). This implies that there is no overt N-raising to Agr in Turkish. Consequently, the required configuration for genitive case checking between the possessor DP and the genitive-case-assigning nominal head $\mathrm{N}$ is absent in overt syntax. At LF, the formal feature complex associated with the morphologically complex possessed noun (e.g. el-in-de in [30]) raises to the dominating functional heads and checks off the formal features associated with these functional heads. At the point where the formal feature complex of the possessed noun gets adjoined to Agr, the genitive-case-assigning feature of this complex is able to check the genitive case feature of the possessor DP, which heads the DP occupying Spec,AgrP.

Pronominal possession as in (31) also involves a Spec-head configuration. Here, the personal pronoun (e.g. ben 'I') carries a genitive case suffix and the possessed noun agrees with the possessor (e.g. -im) in person and number. Checking of the genitive feature on the possessor goes along the same lines as genitive checking with nonpronominals (see above).

$$
\begin{aligned}
& {\left[\text { AgrP ben-im }{ }_{i}\left[{ }_{N P} t_{i} \text { ev-im] }\right]\right.} \\
& \text { I-GEN house-1sg } \\
& \text { 'MY house' }
\end{aligned}
$$

As indicated by the interpretation in (31), presence of a lexical possessor pronoun yields a reading in which the possessor is emphasized (e.g. MY 
house as opposed to yours). In neutral (i.e. nonfocused) readings, the pronoun is not lexically expressed. With Kornfilt (1990), we assume that in those cases Spec,AgrP is occupied by an empty pronominal pro.

A final remark should be made about the role that the possessor plays in defining the definiteness of the entire possessive construction. As opposed to the possessor in the Moroccan Arabic construct state (cf. section 4), the possessor in Turkish does not determine the (in)definiteness of the entire possessive construction. An indefiniteness interpretation can be forced by the lexical item bir, as in (32).

(32) Ayşe-n-in bir kitab-1

Ayşe-GEN a book-3sg

'a book of Ayşe's'

Table 6 summarizes the properties of Agr within the Turkish noun phrase.

\subsection{Dutch possessive noun phrases}

As shown in Table 7, the possessive relationship in Dutch manifests itself in various construction types. Each of them has its own characteristic way of formally expressing the possessive relation. The analytic construc-

Table 6. Properties of Agr in the Turkish possessive noun phrase

\begin{tabular}{ll}
\hline Property & Agreement pattern \\
\hline AgrP & (always) present \\
Phonological matrix of Agr & $/ \emptyset /$ \\
Spec-related Agr feature + strength property & {$[+\mathrm{N},-\mathrm{V},+\mathrm{D}],<$ strong $>$} \\
Head-related Agr feature + strength property & {$[+\mathrm{N},-\mathrm{V}],<$ weak $>$} \\
Morphological realization of $<$ genitive $>$ & inflectional case morpheme \\
\hline
\end{tabular}

Table 7. Noun phrase typology and distribution in possessive constructions

\begin{tabular}{|c|c|c|}
\hline $\begin{array}{l}\text { Proper name } \\
\text { Jan 'Jan' }\end{array}$ & $\begin{array}{l}\text { Animate (human) common noun } \\
\text { jongen 'boy' }\end{array}$ & $\begin{array}{l}\text { Inanimate common noun } \\
\text { boot 'boat' }\end{array}$ \\
\hline $\begin{array}{l}\text { de broer van Jan } \\
\text { the brother of Jan }\end{array}$ & $\begin{array}{l}\text { de broer van de jongen } \\
\text { the brother of the boy }\end{array}$ & $\begin{array}{l}\text { de romp van de boot } \\
\text { the hull of the boat }\end{array}$ \\
\hline $\begin{array}{l}\text { Jan z'n broer } \\
\text { Jan his brother }\end{array}$ & $\begin{array}{l}\text { de jongen z'n broer } \\
\text { the boy his brother }\end{array}$ & $\begin{array}{l}\text { *?de boot z'n romp } \\
\text { the boat his/its hull }\end{array}$ \\
\hline $\begin{array}{l}\text { Jans broer } \\
\text { Jan-s brother }\end{array}$ & $\begin{array}{l}*_{\text {de jongens broer }} \\
\text { the boy-s brother }\end{array}$ & $\begin{array}{l}\text { *de boots romp } \\
\text { the boat-s hull }\end{array}$ \\
\hline
\end{tabular}


tion features the adposition van; the Saxon genitive displays the grammatical elements $-s$ on the possessor. The doubling possessive pattern, finally, is characterized by the presence of a "doubling" possessive clitic $(z$ ' $n)$, which agrees in person, gender, and number with the "doubled" possessor. The variety in expressing the possessive relationship is subject to certain lexical restrictions. Although all construction types are found with possessor proper names (cf. first column, Table 7), common nouns do not permit realization in the form of the Saxon genitive (cf. second column). The doubling possessive construction has the additional lexical restriction that it only permits human (or animate) possessors. ${ }^{25}$

The analytic construction (die broer van Jan/haar) has a structure like (33). ${ }^{26}$ The genitive case feature on the DP Jan need not be checked, since it is an inherent case property. After spell-out, the abstract genitive case feature gets realized as van, yielding the sequence de broer van Jan/haar.

$$
\text { [DP de [NP broer [DP }<\text { gen }>\text { Jan/haar] ] }
$$

Let us next turn to the Saxon genitive construction, which has the possessor in prenominal position. Following insights from Longobardi (1996), we take the position that these are in essence hidden construct noun phrases. This is based on the fact that the Saxon genitive and the doubling construction share certain properties with the construct state as found in Moroccan Arabic. Quite similar to the contrast between the Moroccan Arabic construct state and its analytic counterpart as regards the distribution of the definite article, the Saxon genitive, (34a), and the possessive doubling construction, (34b), in Dutch block presence of a definite article, whereas the analytic construction, (34c), does not.

$$
\begin{aligned}
& \text { a. (*) Jans broers } \\
& \text { (*the) Jans brothers } \\
& \text { b. (*de) Jan z'n broers } \\
& \text { (*the) Jan his brothers } \\
& \text { c. (de) broers van Jan } \\
& \text { (the) brothers of Jan }
\end{aligned}
$$

More strikingly perhaps, the Saxon genitive construction and the doubling construction display the (construct state) property of (in)definiteness inheritance: the definiteness value of the head noun depends on the $+/-$ definite status of the possessor. Evidence for this comes from the examples in (35), representing existential constructions.

(35) Er stond [iemands fiets] voor de deur there stood someone's bicycle at the door

*Er stond [Jans motor] voor de deur there stood Jan's motorcycle at the door 
The contrast between (35) and (36) suggests that it is the (in)definiteness property of the possessor (iemand versus Jan) that determines the (in)definiteness of the entire possessive noun phrase. ${ }^{27,28}$

A notable property of the Saxon genitive is the presence of what could be called the possessive morpheme $-s$. We will analyze $-s$ as an instantiation of Agr. ${ }^{29}$ Thus, it occupies an independent syntactic slot (cf. Corver 1990). Schematically,

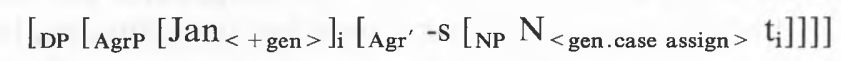

We will assume that the $<$ strong $>$ Spec-related categorial D feature of Agr attracts the possessor DP. The genitive case feature that is part of the feature complex of the possessor-D gets checked off in LF, after the (formal feature complex of the) possessed noun (including the genitivecase-assigning feature) has moved to Agr.

As for the formal expression of the Saxon genitive, we can say that, similarly to the Moroccan Arabic construct state, the genitive case on the possessor is not morphologically realized in the form of an adposition or some case morpheme. The possessor in Spec,AgrP is a bare noun phrase. In Dutch, this "bare form" of the possessor noun phrase is somewhat hidden due to phonological cliticization of the functional head $-s$ onto the possessor.

The next possessive to consider is the possessive clitic doubling construction. Its major characteristic is a possessive clitic that doubles the possessor noun phrase. As illustrated in (38), the clitic agrees in phi features (person, number, and gender) with the doubled possessor (thus not with the possessed noun).
a. Jan z'n broer Jan his brother
b. Marie d'r broer Marie her brother
c. deze meisjes d'r/hun kleren these girls her/their clothes

As we did for the possessive clitics in the Moroccan Arabic noun phrase, we will analyze the possessive clitic $\left(z^{\prime} n, d^{\prime} r\right)$ as heading the functional phrase AgrP within the extended nominal projection. We will further assume that the doubled possessor originates within the lexical projection $\mathrm{NP}$ and raises overtly to the specifier position of Agr. Schematically,

$$
\left[{ }_{D P}\left[{ }_{A g r P} \text { de jongen }{ }_{j}\left[\text { Agr' } Z^{\prime} n\left[{ }_{N P} \text { broer } t_{j}\right]\right]\right]\right]
$$

Overt raising of the possessor DP is triggered by the property $<$ strong $>$ that is associated with one of the formal features of $z^{\prime} n$ in (39). This 
feature is the Spec-related D feature of $z^{\prime} n$; this clitic possessive pronoun requires a DP in its Spec position. Thus, Dutch crucially differs from Moroccan Arabic in the strength of the D feature associated with the clitic.

As with the other instantiations of Agr in Dutch, we will assume that the clitic possessive pronoun is specified for a weak head-related $\mathrm{N}$ (i.e. $[+\mathrm{N}-\mathrm{V}]$ ) feature. Thus, at LF, this categorial feature of the possessed noun, together with the "pied-piped" formal feature complex of the possessed noun, will attach to the Agr head. The genitive-case-assigning feature, which is part of this LF-raised feature complex, will now be able to check off the genitive case feature on the possessor D.

Our discussion of the doubling construction paves the way to those possessive constructions that involve weak/clitic possessive pronouns that precede the possessed noun. Some examples are given in (40):

(40) $\mathrm{m} n / \mathrm{je} / \mathrm{z}^{\prime} \mathrm{n} / \mathrm{d}$ 'r broer

$\mathrm{my} /$ your/his/her brother

We will assume that analogously to the pronominal CS constructions in Moroccan Arabic, the possessive clitic heads the AgrP projection and stands in an agreement relationship to an empty pronominal argument pro, which underlyingly occupies the complement position to the possessed noun, (41a). This agreement relationship is sanctioned when pro enters into a Spec-head relationship with the possessive clitic: this required configuration is created after pro has been raised to the specifier position of the possessive clitic, Spec,AgrP. As we have argued for possessive doubling constructions in Dutch, possessive clitics have a $<$ strong $>$ categorial D feature. This strong D feature on Agr (overtly) attracts the $\mathrm{D}$ feature of the possessor DP. The raised categorial D feature drags along the rest of the possessor DP, yielding a structure like (41b).
a. [DP $\left[{ }_{\mathrm{AgrP}}\left[{ }_{\mathrm{Agr}} \mathrm{Z}^{\prime \prime n}\left[{ }_{\mathrm{NP}}\right.\right.\right.$ broer $\left.\left.\left.\left.\mathrm{pro}_{\mathrm{j}}\right]\right]\right]\right]$
b. [DP $\left[{ }_{A g r P} \operatorname{pro}_{j}\left[{ }_{A g r} Z^{\prime} n\left[{ }_{N P}\right.\right.\right.$ broer $\left.\left.\left.\left.t_{j}\right]\right]\right]\right]$

At LF, the feature complex of $\mathrm{N}$ (containing the genitive-case-assignment feature) raises to the Agr head; the case-assigning feature can now check off the genitive case property associated with the possessor in Spec,AgrP.

Let us turn finally to those constructions having a strong (i.e. nonreduced) pronominal possessor. The relevant paradigm is given in the left column of Table 8; the right column contains strong object forms of personal pronouns. ${ }^{30}$

Table 8 shows a strong similarity between the object pronominal forms and the full possessive pronominal forms. On the basis of this, we propose that the possessive pronominal forms are derived from the object forms. 
Table 8. Pronominal forms for Dutch possessives and object forms

\begin{tabular}{ll} 
Strong possessive pronouns & $\begin{array}{l}\text { Strong object pro- } \\
\text { nouns }\end{array}$ \\
\hline mijn 'my' & mij 'me' \\
jouw 'your' & jou 'you' \\
zijn 'his' & hem 'him' \\
haar 'her' & haar 'haar' \\
ons 'our' & ons 'us' \\
jullie 'your' & jullie 'you' \\
hun 'their' & hen/hun 'them' \\
\hline
\end{tabular}

More precisely, we claim that the possessive construction like haar huis 'her house' derives from a structure like (42) through overt movement of haar to Spec,AgrP.

(42) [DP [AgrP [NP huis [DP haar] $]]]$

As for the forms zijn 'his' and mijn 'my', we will assume that these forms are suppletive forms that are realized in the morphological (i.e. languagespecific) component of the Dutch grammar. One might hypothesize that there is a rule that realizes the object forms mij and hem in Spec,AgrP as the suppletive forms mijn, zijn, respectively, when they occur in the specifier position of (phonetically empty) AgrP.

The major findings on Dutch possessive noun phrases are summarized in Table 9.

Table 9. Properties of Agr in the possessive noun phrase of Dutch

\begin{tabular}{|c|c|c|c|}
\hline Property & Analytic construction & Saxon genitive & Doubling possessive \\
\hline AgrP & not projected & projected & projected \\
\hline Phonological matrix & d.n.a. & $\mid-\mathrm{s} /$ & $\begin{array}{l}\text { /CLITIC/ } \\
\text { (e.g./z'n/) }\end{array}$ \\
\hline $\begin{array}{l}\text { Spec-related Agr feature } \\
\text { + strength property }\end{array}$ & d.n.a. & $\begin{array}{l}{[+\mathrm{N},-\mathrm{V},+\mathrm{D}]} \\
<\text { strong }>\end{array}$ & $\begin{array}{l}{[+\mathrm{N},-\mathrm{V},+\mathrm{D}]} \\
<\text { strong }>\end{array}$ \\
\hline $\begin{array}{l}\text { Head-related Agr feature } \\
\quad+\text { strength property } \\
\text { Morphological realization }\end{array}$ & d.n.a. & $\begin{array}{l}{[+\mathrm{N},-\mathrm{V}]} \\
<\text { weak }>\end{array}$ & $\begin{array}{l}{[+\mathrm{N},-\mathrm{V}]} \\
<\text { weak }>\end{array}$ \\
\hline of genitive case & van & bare DP & bare DP \\
\hline
\end{tabular}




\subsection{What has to be learned?}

We have discussed a variety of possessive constructions found in the three languages that are central in this paper, Moroccan Arabic, Turkish, and Dutch. Table 10 summarizes the relevant grammatical details in which the task of a Moroccan Arabic-speaking learner of Dutch differs from the task of a Turkish-speaking learner of Dutch. Table 10 should be read in a row-wise fashion. The first row concerns the manner of case licensing and the necessity of projecting an Agr category. The second row concerns the lexicalization of Agr by clitic-like elements. The third and fourth rows compare the overtness vs. covertness of movement operations, which is related to the lexically defined strength property. Rows five and six provide information about the morphological realization of genitive. It is important to point out that these properties related to the instantiation of the possessive relationship can be characterized as either lexical or morphological. They are defined in either the lexicon or the morphological component, that is, the components of the grammar where language variation is found.

The starting point for the structural analyses of the $\mathrm{L}_{2}$ data is the conservation hypothesis. It is claimed that, initially, the Turkish learner of Dutch will generate possessive constructions on the basis of the linguistic knowledge used for producing those structures in Turkish. The nature of this knowledge consists of (i) parameterized, (ii) lexical, and (iii) morphological knowledge. In order to attain the target linguistic knowledge necessary for the formation of Dutch possessive structures, the Turkish $\mathrm{L}_{2}$ learner has to make changes in at least these three respects. For the Turkish learner this means a restructuring and acquisition of the items listed in Table 11.

Table 12 makes clear what a Moroccan learner of Dutch has to acquire. With respect to the analytic construction, the two languages differ only at the level of vocabulary: Moroccan Arabic spells out genitive case by means of dyal, whereas Dutch uses van. Comparison of the (nominal) construct state and the Saxon genitive (a hidden construct state; see Longobardi 1996) shows that the two languages differ in the aspects mentioned in Table 12.

\section{Data and subjects}

The core data in this study come from the ESF corpus. These data were collected within the framework of the European Science Foundation 


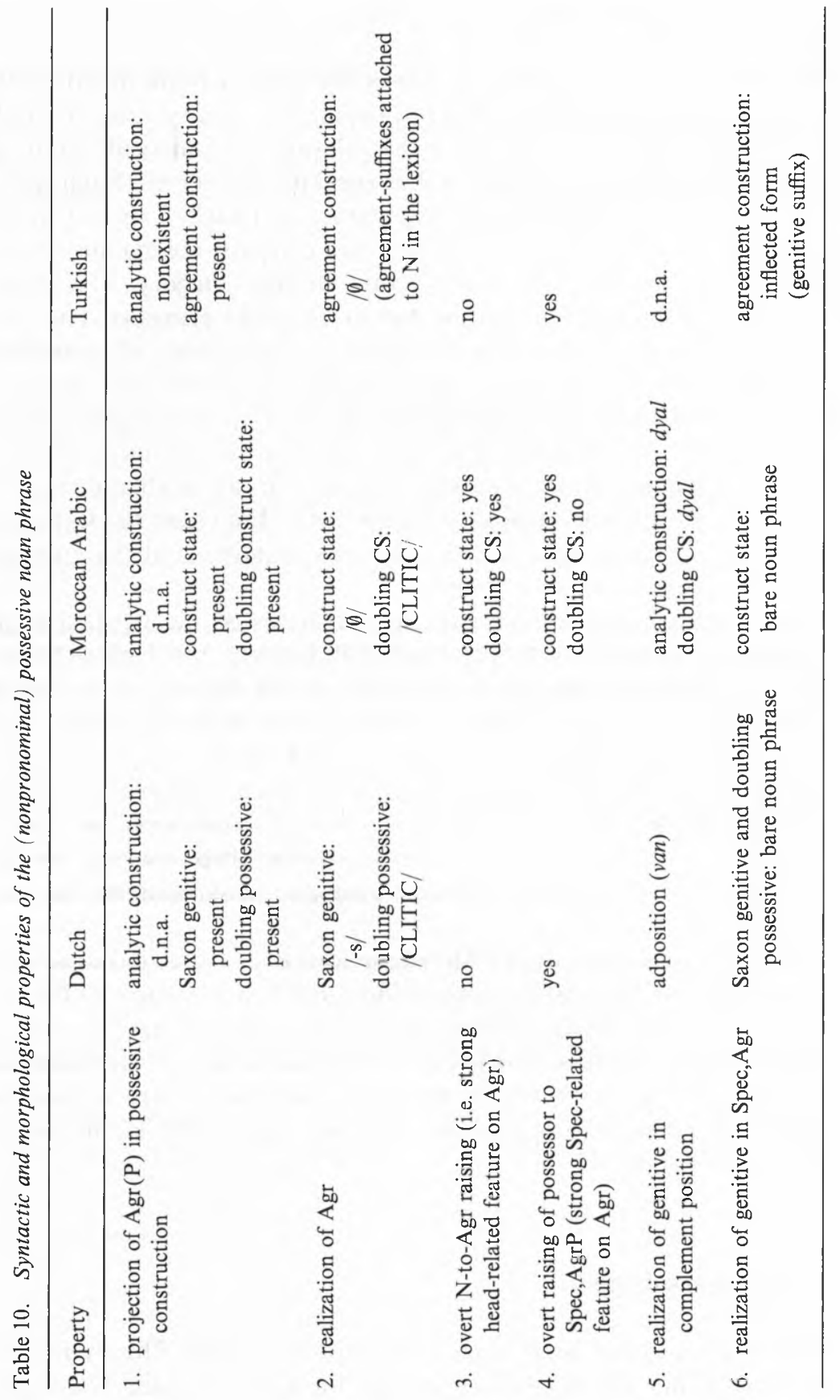


Table 11. Knowledge to be acquired by a Turkish learner

\begin{tabular}{|c|c|}
\hline Resetting & Acquisition \\
\hline $\begin{array}{l}\text { resetting of head parameter from head- } \\
\text { final to head-initial } \\
\text { resetting of the Spec-related strength } \\
\text { feature on D from < weak }>\text { to } \\
\text { <strong }>\end{array}$ & $\begin{array}{l}\text { acquisition of lexical items (and their } \\
\text { properties) that can head } \\
\text { - Agr: 's, clitic possessive pronouns, } \\
\text { zero forms }(/ \emptyset /) \\
\text { - D definite articles } \\
\text { acquisition of } \\
\text { - the morphological knowledge that the } \\
\text { genitive case is not spelled out as a } \\
\text { suffix } \\
\text { - the morphological rule that } \\
\text { morphologically spells out abstract } \\
\text { genitive case as the adpositional } \\
\text { marker van } \\
\text { - the suppletion rule for strong } \\
\text { possessive pronominal forms }\end{array}$ \\
\hline
\end{tabular}

Table 12. Knowledge to be acquired by a Moroccan learner

\begin{tabular}{ll}
\hline Resetting & Acquisition \\
\hline resetting of the head-related strength & acquisition of lexical items (and their \\
feature on functional heads (no & properties) that can head \\
$\mathrm{N}$-raising) & - Agr: 's \\
resetting of the $<$ weak $>$ value of the & $-\mathrm{D}$ indefinite article \\
$\begin{array}{ll}\text { Spec-related D feature if Agr is filled by } \\
\text { a clitic }\end{array}$ & - the suppletion rule for strong \\
& possessive pronominal forms \\
\hline
\end{tabular}

(ESF) Program on Second Language Acquisition by Adult Immigrants (for design, elicitation techniques, and topics, see Perdue 1993). The ESF project was set up as a longitudinal and cross-linguistic multiple case study. The focus here is on the acquisition of Dutch by two Moroccan immigrants: Mohamed (MOH) and Fatima (FAT), and two Turkish immigrants, Ergün (ERG) and Mahmut (MAH), learning Dutch in an untutored learning situation. The four informants were followed during almost two and a half years. The period of investigation was divided into three cycles of nine sessions, one session a month. At the first session the informants had been living in the Netherlands for seven to 12 months. They had a very low proficiency in Dutch, were monolingual, and had a limited level of education. Several elicitation tasks were repeated in each cycle, such as interviews, role-playing, and film-retelling tasks. Especially the sessions where inter- 
viewer and informant were looking at photographs of the informant's relatives provided many instances of possessive constructions.

The research was extended to child learners of Dutch, because the adult learners largely remain within stages of strong conservation and therefore do not provide insights into processes of restructuring. As will become clear from the data, the child data show restructuring effects. The child data come from the Vermeer corpus (Vermeer 1986), which contains production data from 16 Moroccan and 16 Turkish children. They were followed over 2.5 years from the time they entered primary school. Some of them were born in the Netherlands, others had been in the Netherlands for only two years, but the primary socialization had been in their mother tongue. They were all children of parents with a low education (skilled and unskilled workers). At the first recording the children's age ranged from $6 ; 4$ to 7;9 years. Every fifth month, an audiorecording was made. The spontaneous production data consisted of a conversation with different visual elicitation material such as a series of pictures and a book without text. In the "spontaneous" conversation, the topics were friends, free time, and television.

Both corpora were exhaustively scanned for nominal possessive constructions. Possessive expressions at the clausal domain (e.g. have constructions) as well as at word level (compounds) were excluded from this study. ${ }^{31}$ As the adults' data form the largest and most comprehensive corpus, an overview of the various possessive construction patterns and their frequencies is given for the adults' data in Table 13. The classification in Table 13 is based on straightforward criteria: (1) the order of possessor and possessee, (2) the nominal or pronominal status of the possessor. Examples are given in (43), where $\mathrm{Y}$ is the possessor and $\mathrm{X}$ is the possessee.
a. $Y_{n} X$ 'John's car'
b. $\mathrm{Y}_{\mathrm{p}} \mathrm{X}$, (possessor-initial and pronominal) 'his car'
c. $\mathrm{XY}_{\mathrm{n} / \mathrm{p}}$ (possessor-final and nominal) 'the car of John'
(possessor-final and pronominal) 'the car of him'
(possessor-initial and nominal)
d. $\mathrm{Y}_{\mathrm{p}} \mathrm{X} \mathrm{Y}_{\mathrm{p} / \mathrm{n}}$ (pronoun possessor-initial and possessor-final) 'his car of John/him'

No distinction is made between the nominal and pronominal status in (43c) because it turned out that there is no syntactic difference between the two patterns, as will be made clear in sections 6 and 7. The analyses in these sections are structured along the four-way distinction made in (43). 


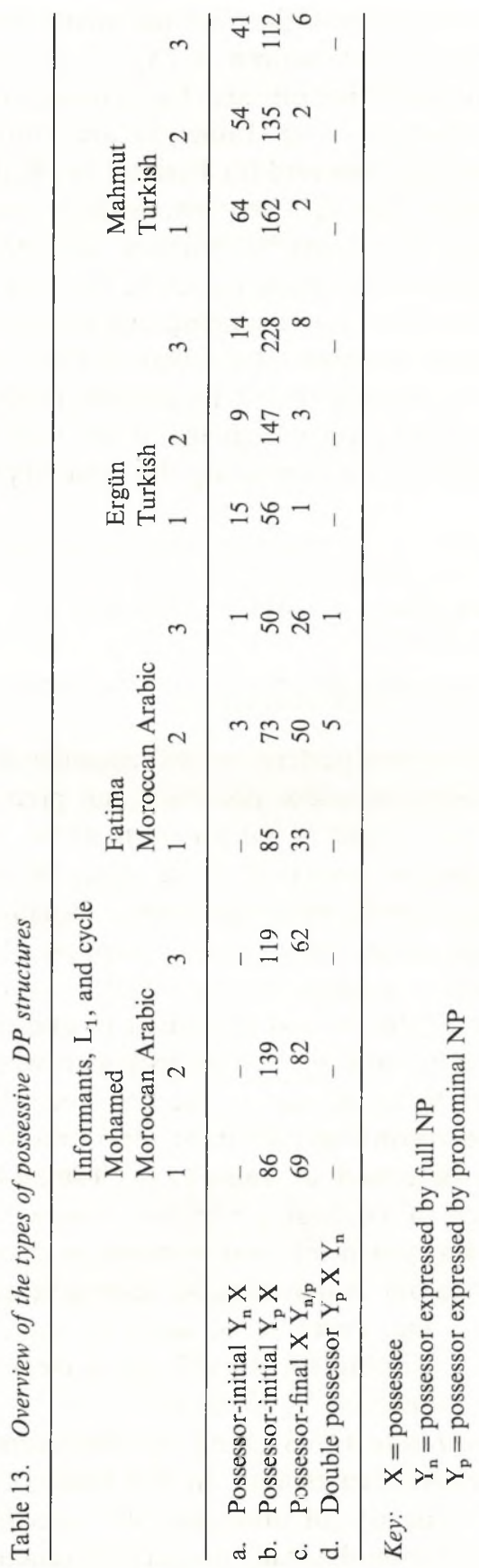


As Table 13 shows us, each of the four informants uses a great number of possessive pronouns (see pattern $b\left[Y_{p} X\right]$ in Table 13) from the beginning of the data collection onward. Occurrences of the nonpronominal variant $Y_{n} X$ (pattern a in Table 13) are completely absent in Mohamed's data and are very rare for Fatima. In all, it is an uncommon pattern for Moroccans. The $Y_{n} X$ pattern regularly occurs in the data of the Turkish learners. The opposite situation emerges for the analytic pattern. The nominal pattern (pattern $\mathrm{c}\left[\mathrm{X} \mathrm{Y}_{n}\right]$ in Table 13) can be found in the Moroccan data from the beginning and is rare in the data of the Turks, but its number increases at the end of the data collection. The results given in Table 13 suggest that $\mathrm{L}_{2}$ learners prefer the pattern they already know from their native language, if the target language allows more than one possibility for expressing the same linguistic element. ${ }^{32}$

\section{Possessive constructions of Turkish $L_{2}$ learners}

\subsection{The $Y_{n} X$ pattern: nominal possessor-initial constructions}

The first type of possessive pattern we will consider is the one in which the possessor is a nonpronominal possessor and precedes the possessee. Table 14 provides two types of information about the Turkish adult learners. First, it gives an overview of the types of possessive variants found. Second, it indicates which possessive variants appear at what developmental stage according to our conception of $\mathrm{L}_{2}$ development. Each type of possessive variant is exemplified by a token. It represents the first occurrence of the possessive variant in question in our corpus. The rightmost column indicates the recording in which the token was found. ERG-X and MAH-X refer to the ESF recordings (adults), T-X refers to the Vermeer recordings (children). (Information about frequency of occurrence can be found in Table 15. $)^{33}$ Table 14 is descriptive in providing the range of possessive variants attested in the data; it is interpretive in the assignment of these variants to developmental stages. In order to motivate our assignment of possessive variants to specific development stages, the structure of each of these variants will be analyzed in detail. By doing so, we will get a clear picture of the $\mathrm{L}_{2}$ development of the possessive $Y_{n} X$ pattern.

At the content-word state (CWS), the $\mathrm{L}_{2}$ learner's computational system generates $L_{2}$ possessive expressions on the basis of the lexical input (numeration) $^{34}$ that consists of phonologically specified content words (typically nouns) and phonologically unspecified functional categories. A 
Table 14. Possessive variation of the $Y_{n} X$ type attested in the developmental stages of Turkish learners

\begin{tabular}{|c|c|c|}
\hline Stage & Example & $\begin{array}{l}\text { Subject } \\
\text { code }\end{array}$ \\
\hline
\end{tabular}

1. Conservation stage
a. Content-word state (CWS)
b. Free-functional-morpheme state (FFS)
- vriend huis
MAH-3
friend house
'my friend's house'
- garage die naam
ERG-3
garage that name
'the name of the garage'
- [die grote broer] die kleine dochter
MAH-5
that big brother that little daughter
'the little daughter of my eldest
brother'
c. Bound-functional-morpheme state (BFS)
- examen van tolk
ERG-25
exam of interpreter
'the interpreter of/at the exam'
- de auto van de lichten
T41-6
the car of the lights
'the lights of the car'

2. Restructuring stage

stage a
- vocabulary: $z$ ' $n$ and 's as instantiations of Agr
- prepossessor van as morphological expression of genitive case

- die van z'n ding

$\mathrm{T} 25-4$

that of his thing

'his thing'

- van Omers huis

of Omer's house

'Omer's house'

- van Hendry z'n foto

of Hendry his photograph

'Hendry's photo'

- van Zorro van Turks film

of Zorro of Turkish film

'the Turkish film Zorro'

- prepossessor $z$ 'n as agreement marker

- $z^{\prime} n$ jongen $z$ ' $n$ tekening

stage $b$

his boy his drawing

'the boy's drawing'

- absence of prepossessor van - de pan z'n deksel

the pan his cover

'the cover of the pan' 
Table 14. Continued

\begin{tabular}{|c|c|c|}
\hline Stage & Example & $\begin{array}{l}\text { Subject } \\
\text { code }\end{array}$ \\
\hline $\begin{array}{l}\text { - absence of agreement } \\
\text { between possessor and } \\
\text { possessive pronominal: } \\
\text { underspecified } z \text { 'n }\end{array}$ & $\begin{array}{l}\text { - juffrouw Lia z'n feest } \\
\text { miss Lia his party } \\
\text { 'miss Lia's party' } \\
\text { - Mark en Mieke z'n moeder } \\
\text { M. and M. his mother } \\
\text { 'M. and M.'s mother:' }\end{array}$ & T27-1 \\
\hline 3. Target state & $\begin{array}{l}\text { - mijn ooms zoon } \\
\text { my uncle's son } \\
\text { - Kees z'n vader } \\
\text { Kees his father } \\
\text { 'Kees's father' } \\
\text { - Ayhan d'r broer } \\
\text { Ayhan her brother } \\
\text { 'Ayhan's brother' }\end{array}$ & $\begin{array}{l}\text { ERG-26 } \\
\text { T39-4 }\end{array}$ \\
\hline
\end{tabular}

possessive variant like vriend huis, for example, has a structural representation like (44).



The structure in (44) has the parameter settings characteristic of Turkish: the structure is head-final and the <strong $>$ Spec-related D feature on Agr induces movement of the possessor D (with concomitant pied-piping of the whole DP) to Spec,AgrP. In LF, the formal feature complex associated with the possessed noun huis raises to Agr; the genitive-caseassigning feature, which is part of this feature complex, is then able to check off the genitive case feature of the possessor D. ${ }^{35}$ Thus, the $\mathrm{L}_{2}$ derivational output is the result of a "conservative grammar" and an impoverished numeration, in the sense that it is only the lexical categories (i.e. content words) that have a phonological matrix. The functional categories are feature complexes lacking a phonological matrix. 
In the free-functional-morpheme state (FFS), the numeration is "enriched" by free function words carrying a phonological matrix: demonstrative determiners and other determiner-like elements show up, as is illustrated in (45).
a. ERG-3
garage die naam
garage that name
'the name of the garage'
b. MAH-12
Thijs die vader
Thijs that father
'Thijs's father'

In (45a) and (45b), a demonstrative element shows up between the possessor (garage/Thijs) and the possessed noun (naam/vader). Such a linear ordering of lexical elements is not permitted in Dutch but is precisely the one found in Turkish. This is consistent with the conservation hypothesis. Although the numeration consists of lexical items from Dutch, the parameter settings are still those of Turkish. More specifically, in the grammar of the Turkish $\mathrm{L}_{2}$ learner, the Spec-related feature of the functional category D initially has the value weak, which implies that a nominal-type-indicating feature like $<+$ demonstrative $>$ will raise at LF because of checking. Demonstrative determiners carrying this feature do not raise in overt syntax in Turkish. In Dutch, however, the nominal type feature of D is strong and requires overt movement of a determiner-like element to Spec,DP. It implies that garage die naam has the structure of (46).




Possessive learner structures like (46) can become more complex. In the string die grote broer die kleine dochter (that big brother that little daughter/'the little daughter of my eldest brother'), for example, the possessor DP die grote broer contains an attributive AP and a demonstrative determiner. The structure associated is the one in (47).

\section{(47) [DP [DetP $\operatorname{die}\left[\right.$ Det' $^{\prime}\left[\mathrm{FP} \operatorname{grote}\left[\mathrm{F}^{\prime}[\mathrm{NP}\right.\right.$ broer $\left.\left.\left.\left.\left.] \mathrm{F}\right]\right] \mathrm{Det}\right]\right] \mathrm{D}\right]$}

The next variant in Table 14, examen van tolk (exam of interpreter 'the interpreter of/at the exam'), is characterized by the presence of the item van. In possessive structures of native speakers of Dutch this element is an adpositional (i.e. prepositional) marker that is the morphological spell-out of the abstract genitive feature associated with the possessor DP. This morphological spell-out only applies to the possessor when it follows the possessed noun (i.e. in a possessor-final construction). A Dutch-based analysis of examen van tolk as in (48) is highly unlikely, however; under such an analysis, in which tolk is the complement to the noun examen, the entire noun phrase need to be interpreted as 'the exam taken by the interpreter'. This is not the reading it has, which is 'the interpreter at/of the exam'; examen acts as the "possessor."

\section{ERG-25}

[NP examen [DP van tolk]]

The occurrence of the next possessive variants in Table 14, de auto van de lichten (the car of the lights/'the lights of the car'), such as (50), in which the possessor (auto van) is separated from the possessed noun by an intervening determiner (de), suggests that auto is not in the complement position to lichten. ${ }^{36}$

What other interpretations are feasible? Two hypotheses come to mind. One hypothesis is that the Turkish $\mathrm{L}_{2}$ learner treats van as a lexical item of the categorial type Agr. In view of the word order, this would imply that the learner has found out the head-initial nature of the Dutch nominal structure. This gives the structure in (49) (in which the resetting on the head-initial value is taken to apply to the complete nominal structure).

$$
\begin{aligned}
& \text { ERG-25 } \\
& {\left[{ }_{\text {DP }}\left[{ }_{\text {AgrP }} \text { examen }_{i}\left[{ }_{\text {Agr' }}\left[{ }_{\text {Agr }} \text { van }\right]\left[{ }_{N P} \text { tolk } t_{i}\right]\right]\right]\right]}
\end{aligned}
$$

The second hypothesis takes van to be an inflectional suffix attached to the possessed noun, drawing a parallel between van and the inflectional element -nin in Turkish expressions like Ayse-nin araba-si (Ayse-Gen 
car-3sg/'Ayse's car'). Under this hypothesis, the word order is still compatible with a head-final setting of the nominal structure; see (50).

$$
\text { [DP }\left[\text { AgrP }[\text { examen-van }]_{i}\left[_{\text {Agr' }}\left[{ }_{N P} t_{i} \text { tolk] Agr }\right]\right] D\right]
$$

Under the second hypothesis, the Agr head is still "available" to become lexically instantiated. Under the former analysis, van would be in competition (i.e. complementary distribution) with other lexical items instantiating Agr. The occurrence of possessive variants like (54) support an analysis in which van is analyzed as an inflectional suffix. ${ }^{37}$



This nominal expression differs from a possessive construction like die van auto (that of car /'his car'/'that one's car') in having the lexical item $z$ 'n as part of its nominal structure. This weak pronoun heads the Agr projection.

The acquisition of the weak possessive pronominal system seems to mark an important point. The acquisition by Turkish learners of the lexical knowledge that these items are instantiations of Agr (i.e. are of the categorial type Agr) leads to a restructuring at the level of the lexicon. The learner's $\mathrm{L}_{2}$ lexicon no longer contains just the zero token of Agr. Rather, the $\mathrm{L}_{2}$ lexicon is enriched with lexical items of the categorial type Agr whose phonological matrix is nonempty. This lexical restructuring has the concomitant effect of restructuring parameter settings: lexical instantiations of Agr precede the possessed noun, which shows that the parameterized property of headedness is reset from a head-final value to a head-initial value. It is conceivable that possessive structures lacking any overt realization of the Agr node are still of the head-initial type.

Another important part of the restructuring stage is the status of van, when the $\mathrm{L}_{2}$ learner discovers that it is not an inflectional suffix. The changed status can be seen in initial structures as in (52), in which the possessor is preceded by van. As a matter of fact, sometimes this prepossessor van cooccurs with the postpossessor van, as in (52b). Evidently, the Turkish $\mathrm{L}_{2}$ learner still tries to overtly mark the realization of the genitive case on the possessor in Spec,AgrP, presumably because this morphological procede is a defining property of possessors in Turkish.

$$
\begin{aligned}
& \text { a. T29-6 } \\
& \text { van Hendry z'n foto } \\
& \text { of Hendry his photo } \\
& \text { 'Hendry's photo' }
\end{aligned}
$$


b. T25-1

van Zorro van Turks film

of Zorro of Turkish film

'the Turkish film Zorro'

How to interpret this van? One could interpret this element in the learner's derivational output as a genitival prefix. Under that view, the Turkish $\mathrm{L}_{2}$ learner would have restructured his $\mathrm{L}_{2}$ grammar in such a way that instead of a morphological rule of expressing genitive case by means of suffixation, he now uses a rule of prefixation. Such an analysis seems unlikely for at least two reasons. First of all, it would mean that in a sequence like (52b), genitival case would be expressed morphologically twice on one and the same nominal stem, viz. by means of a prefix van and the suffix van (i.e. $\left[_{N} v a n+N+v a n\right]$ ). Second, the occurrence of a pattern like (53), attested in the Turkish children's $L_{2}$ data, suggests the interpretation of prepossessor van as an element that combines with a phrasal constituent.

$$
\begin{aligned}
& \text { T41-2 } \\
& \text { [DP }\left[\text { AgrP van de } \operatorname{rand}_{i}\left[{ }_{\text {DetP }} \text { de }\left[{ }_{N P} t_{i} \text { zee }\right] \text { Det }\right] \text { Agr }\right] \text { D] } \\
& \text { of the border the sea } \\
& \text { 'the border of the sea' }
\end{aligned}
$$

The possessive variants observed in this stage can be accounted for by analyzing van as an adpositional marker, which attaches to the possessor. Under this interpretation, the $\mathrm{L}_{2}$ learner has identified the nature of van: it is a semantically vacuous preposition that morphologically spells out abstract genitive case on the case-assigned nominal complement. Developmental evidence for this interpretation comes from the fact that the prepossessor van in possessor-initial variants (i.e. van $+\mathrm{Y}_{\mathrm{n}} \mathrm{X}$ ) cooccurs $^{38}$ with the prepossessor van in possessor-final (i.e. analytic: $\mathrm{X}$ van $+\mathrm{Y}_{\mathrm{n}}$ ) constructions. The $\mathrm{L}_{2}$ learner overgeneralizes the morphological rule of genitive spell-out; he does not restrict the rule to possessor noun phrases in the complement position of the possessed noun but extends it to possessors in Spec,AgrP. Or, to put it more formally, genitival spell-out by means of an adpositional marker is overgeneralized to multimembered (i.e. $\left\{\mathrm{DP}_{\mathrm{i}}, \mathrm{t}_{\mathrm{i}}\right\}$ ) chains.

When the learner has identified $z$ ' $n$ as an instantiation of Agr whose Spec can be filled by a possessor DP, we can still observe conserved properties of the Turkish possessive construction. An interesting example is $(54)$.
(54) T39-6
$z$ ' $n$ jongen $z$ ' $n$ tekening
his boy his drawing
'the boy's drawing' 
In (54), the agreement relation between the possessor and the possessed noun, which in Turkish is manifested by inflectional morphology on the possessor and the possessee, is expressed by means of the possessive clitic $z^{\prime} n$, which shows up on both the possessor and the possessed noun. At about the same time as the Agr identification of $z^{\prime} n$, the learner starts to identify the bound morpheme $-s$ as an instantiation of Agr. This yields possessive variants as in (55).

$$
\begin{gathered}
{\left[\mathrm{DP}\left[\mathrm{AgrP} \text { van } \operatorname{Omer}_{i}\left[\mathrm{Agr}^{\prime}-\mathrm{S}\left[\mathrm{NP} \text { huis } \mathrm{t}_{\mathrm{i}}\right]\right]\right]\right]} \\
\text { of Omer }
\end{gathered}
$$

\section{'Omer's house'}

Presumably at the time the Turkish $\mathrm{L}_{2}$ learner has figured out the domain restriction on the realization of van, he starts producing "bare" possessorinitial structures, that is, structures in which the possessor is not accompanied by an element reflecting a Turkish property on a possessor in Dutch, such as de pan z'n deksel (the pan its cover/'the pan's cover'). Full mastery of the Dutch possessor-initial construction, however, requires knowledge of the lexical and - in the case of the possessive doubling construction agreement constraints on the possessor. As for the former, the $\mathrm{L}_{2}$ learner has to learn that inanimate nominals do not appear as possessors in Spec,AgrP. Thus, although the string de pan z'n deksel is assigned the correct structural analysis by the $\mathrm{L}_{2}$ learner, he has not yet learned the animacy requirement on the possessor. As regards the agreement constraint, we can observe the production of possessive variants as in (56), where the possessor $z^{\prime} n$ cooccurs with a noun of feminine gender, (56a), or plural number, (56b):
a. T27-5
juffrouw Lia z'n feest
miss Lia his party
'miss Lia's party'
b. T43-6
Mark en Mieke z'n moeder
Mark and Mieke his mother
'Mark and Mieke's mother'

This (apparent) disagreement pattern is typically found with $z^{\prime} n$. A possible interpretation of this state of affairs is that the $L_{2}$ learner considers $z^{\prime} n$ to be an underspecified possessive pronominal form; although it is specified for third person it lacks number and gender features.

In the final stage of the acquisition of the $Y_{n} X$ pattern, the $L_{2}$ learner acquires lexical, language-specific restrictions on the formation of posses- 
sor-initial constructions. He will form patterns as given under the label target state in Table 14.

Having provided an analysis of the possessive variants attested in our corpora and having motivated their assignment to particular developmental stages, we need to consider the following questions:

- What types of possessive variants are attested in the adults' and children's production data?

- How many occurrences of each possessive variant are attested in the learner's production data?

- Do the learners attain target knowledge of the $Y_{n} X$ pattern?

Answers to these questions can be inferred from Table 15. The possessive variants in Table 15 are distinguished according to developmental stages. It should be kept in mind in interpreting the data in Table 15 that the ESF data collection was more extensive ( 27 recordings in three cycles over 2.5 years), whereas, at the same time, adults were slower in their progress than children. This yields a more detailed view for the two adults on the three vocabulary-knowledge states (CWS, FFS, and BFS). As regards the children's production data, there were only six recordings in 2.5 years. The number of occurring possessive variants was too small to split the learner's variants over different recordings for each child separately. We divided the children into two groups of eight children each. The first group consists of the children using possessive variants that belong to the conservation stage or to the first step of the restructuring stage. They exhibit a real $\mathrm{L}_{2}$ acquisition process. The second group

Table 15. Distribution of possessive ( $Y_{n} X$ pattern) produced by Turkish learners over developmental stages

\begin{tabular}{lccccccc}
\hline & \multicolumn{3}{c}{ 1. Conservation } & \multicolumn{2}{c}{ 2. Restructuring } & \multirow{2}{*}{ 3. Target state } \\
& & CWS & FFS & BFS & stage a & stage b & \\
\hline \multirow{2}{*}{ ERG } & cycle 1 & 13 & 2 & - & - & - & - \\
& cycle 2 & 4 & 5 & - & - & - & - \\
\multirow{2}{*}{ MAH } & cycle 3 & 4 & 7 & 2 & - & - & 1 \\
& cycle 1 & 52 & 9 & - & - & - & - \\
& cycle 2 & 45 & 11 & - & - & - & - \\
\multirow{2}{*}{ Group I (8 children) } & $7 / 3^{\mathrm{a}}$ & - & $3 / 2^{\mathrm{a}}$ & $24 / 7^{\mathrm{a}}$ & $19 / 6^{\mathrm{a}}$ & $27 / 7^{\mathrm{a}}$ \\
Group II (8 children) & - & - & - & $1 / 1^{\mathrm{a}}$ & $18 / 6^{\mathrm{a}}$ & $30 / 8^{\mathrm{a}}$ \\
\hline
\end{tabular}

a. The first number is the number of occurrences, the second is the number of subjects producing these constructions. 
show only errors related to gender agreement or animacy restrictions and in this respect do not differ from Dutch children of the same age.

What becomes immediately clear from Table 15 is that the two adult learners are sill in the conservation stage at the end of the data collection. Most instantiations of the $Y_{n} X$ pattern consist of free lexical and free functional morphemes (e.g. die). Instantiations of bound morphology surfacing in the target possessive constructions, the Saxon genitive and the doubling possessive construction, are not attested in the adult $\mathrm{L}_{2}$ data: the possessive clitic $-s$ appearing in the Saxon genitive is absent, ${ }^{39}$ and so are instantiations of the weak (i.e. clitic) possessive pronoun (e.g. $z^{\prime} n$ ) showing up in doubling possessive structures. Adult learners apparently have not yet identified these elements as instantiations of the Agr node. The $\mathrm{L}_{2}$ lexicon of the two adult learners is still in a stage of conservation in the lexical instantiation of the category Agr; just as in the Turkish $L_{1}$ lexicon, the $L_{2}$ lexicon only contains instantiations of Agr with an empty phonological matrix.

As is clear from the BFS column in Table 15, the adult learners, especially ERG, start producing utterances containing van, which suggests that they have identified this Dutch morpheme as an element playing a role in the formal expression of genitive case. As we discussed, the $\mathrm{L}_{2}$ learner seems to use this element as a genitival case suffix attached to the stem of the possessed noun; in other words, he tries to realize the Turkish morphological procedure of expressing genitive case by means of van. It means that at the level of morphological realization of genitive case, the Turkish $\mathrm{L}_{2}$ learner has also conserved his $\mathrm{L}_{1}$ knowledge in the production of $\mathrm{L}_{2}$ data.

In short, the adult Turkish learners generate strings featuring the linear order "possessor + possessee." The structural representations associated with these strings are similar to those associated with Turkish outputs. The $\mathrm{L}_{2}$ output and the $\mathrm{L}_{1}$ output of possessive structures only diverge on the lexical (or, better, phonological) instantiation of the syntactic tree. All this implies that the adult Turkish learner has not yet started to restructure his $\mathrm{L}_{1}$ grammatical knowledge.

As is made clear by Table 15, Turkish children do reach the stage of restructuring and get close to or reach the stage of full mastery of the target grammatical knowledge required for the production of Dutch possessor-initial constructions. As can be deduced from the columns falling under the restructuring stage in Table 15 (in combination with the possessive variants falling under the restructuring stage in Table 14), seven children analyze van as an adpositional marker (e.g. van Ipek fiets, of Ipek bike/'Ipek's bike') in the course of the data collection; at that stage they have not acquired yet the target knowledge that this spell-out 
is restricted to noun phrases in complement position. After the children have acquired this "domain restriction" on the morphological spell-out of genitive case, they produce van-less possessor-initial structures (e.g. Angelique z'n broer, Angelique his brother/'Angelique's brother'). The majority of children acquire the lexical knowledge that clitic possessive pronouns instantiate the Agr node and, consequently, produce possessive patterns of the target doubling possessive type (cf. van Hendry z'n foto in Table 14). To a somewhat lesser extent, children are producing possessor-initial structures of the Saxon genitive type (cf. van Omers huis in Table 14). Those children have acquired the lexical knowledge that the clitic element $-s$ lexically instantiates Agr. The fact that more Agr instantiations with $z$ 'n are found than with $-s$ plausibly relates to (i) the more widespread distribution and use of the possessive doubling constructions in the primary linguistic input, and (ii) the fact that $z^{\prime} n$ is easier to identify as a separate lexical item than $-s$.

Recall that acquisition of the lexical knowledge that $z$ ' $n$ and $-s$ instantiate Agr has a concomitant restructuring effect at the level of parameterized UG-defined lexical knowledge. That is, on the basis of the linear positioning of $z^{\prime} n /-s$ with respect to the possessed noun, it is clear that, at least for the categorial head Agr, the learner has reset the lexical options provided by the headedness parameter: Agr takes the head-initial value rather than the (Turkish) head-final value. In view of the uniformity of headedness within the Turkish extended nominal projection, it does not seem implausible that the Turkish child, after having identified the head-initialness of the Dutch Agr projection, extends this head-initial setting to all levels of projection within the nominal domain. At the final stage of acquisition, the children still tend to make errors with regard to the animacy of the possessor; see (57).

\section{(57) T42-5}

deze pan z'n dopje

this pan his cover

'the cover of the pan'

As indicated by the last column (the target state) in Table 15, all 16 children reach a stage in which they produce target possessive constructions, instantiating either the clitic $-s$ of the Saxon genitive or a possessive pronominal clitic. This suggests that all children have reached a stage at which the $L_{2}$ syntactic tree has been (partially or completely) syntactically restructured from head-final to head-initial. Restructuring will be partial if the child $\mathrm{L}_{2}$ learner takes the minimal option that resetting of headedness only applies to the projection whose head overtly evidences a different linear ordering with respect to its complement. It leads to a 
syntactic tree that is head-final except for the Agr projection. As pointed out above, given the uniformity of headedness within the Turkish nominal projection, the alternative hypothesis seems somewhat more plausible: evidence for head-initiality of the AgrP projection leads to a uniform, complete resetting of the headedness parameter within the nominal domain.

\subsection{The $Y_{p} X$ pattern: pronominal possessor-initial constructions}

The acquisition order of the pronominal possessor-initial pattern proceeds roughly along the same lines as that of the nominal possessor-initial pattern. Certain characteristics make a separate discussion of the pronominal variants necessary, though. Table 16 provides an overview of the types of $\mathrm{L}_{2}$ possessive patterns that instantiate this construction type. It further indicates which patterns appear at what stage, according to our conception of the $\mathrm{L}_{2}$ acquisition process.

Table 16 shows that in the initial stages target forms (mijn buurman, zijn vrouw $)^{40}$ occur, that is, possessive constructions that, superficially, are identical to possessive structures uttered by native speakers of Dutch. As immediately suggested by subsequent stages of acquisition, the $\mathrm{L}_{2}$ learner does not really know the underlying "Dutch rules." What rather seems to be the case is that the Turkish learner has stored the pronominal forms as unanalyzed words in his lexicon. Although he has knowledge of certain lexical properties associated with those lexical items (e.g. the fact that mijn has the lexical properties "first number" and "singular"),${ }^{41}$ he has no knowledge of the morphological basis of such forms. When the $\mathrm{L}_{2}$ learner starts to decompose the possessive pronominal form, he comes up with such expressions like hij papa (he papa/'his father'), where we have a subject form of the third person masculine singular personal pronoun. Interestingly, in certain possessive pronominal variants a demonstrative element (die) shows up. As is exemplified in (58), these demonstratives occur with various surface forms of the possessive pronominal.

(58) MAH-5

a. die mijn dochter that my daughter 'my daughter'

b. die ik papa that I papa 'my daddy' 
Table 16. Possessive variants of the $Y_{n} X$ pattern attested in the developmental stages of Turkish learners

\begin{tabular}{|c|c|c|c|}
\hline \multicolumn{2}{|l|}{ Stage } & Example & $\begin{array}{l}\text { Subject } \\
\text { code }\end{array}$ \\
\hline \multicolumn{4}{|c|}{ 1. Conservation stage } \\
\hline \multirow[t]{3}{*}{ a. } & $\begin{array}{l}\text { Content-word state (CWS) } \\
\text { - unanalyzed pronoun }\end{array}$ & $\begin{array}{l}\text { - mijn buurman } \\
\text { 'my neighbor' }\end{array}$ & MAH-2 \\
\hline & & $\begin{array}{l}\text { - zijn vrouw } \\
\text { 'his wife' }\end{array}$ & ERG-6 \\
\hline & - subject/object form & $\begin{array}{c}\text { - hij/mij papa } \\
\text { he/me papa } \\
\text { 'his father' }\end{array}$ & ERG-12 \\
\hline \multirow[t]{2}{*}{ b. } & $\begin{array}{l}\text { Free-functional-morpheme } \\
\text { state (FFS) } \\
- \text { die + possessive pronoun }\end{array}$ & $\begin{array}{l}\text { - die mijn dochter } \\
\text { that my daughter } \\
\text { 'my daughter' }\end{array}$ & MAH-5 \\
\hline & & $\begin{array}{l}\text { - die ik papa } \\
\text { that I papa } \\
\text { 'my daddy' }\end{array}$ & МАН-5 \\
\hline \multirow[t]{6}{*}{ c. } & $\begin{array}{l}\text { Bound-functional-morpheme } \\
\text { state (BFS) } \\
- \text { van }+ \text { possessive pronoun }\end{array}$ & $\begin{array}{l}\text { - die van mijn broer } \\
\text { that of my brother } \\
\text { 'my brother' }\end{array}$ & ERG-3 \\
\hline & & $\begin{array}{l}\text { - van hem moeder } \\
\text { of him mother } \\
\text { 'his mother' }\end{array}$ & ERG-18 \\
\hline & - possessive pronoun $+v a n$ & $\begin{array}{l}\text { - die van auto } \\
\text { that of car } \\
\text { 'his car' }\end{array}$ & \\
\hline & & $\begin{array}{l}\text { - onze van broer } \\
\text { our of brother } \\
\text { 'our brother' }\end{array}$ & $\mathrm{T} 25-2$ \\
\hline & $\begin{array}{l}- \text { van }+ \text { poss. pronoun } \\
\quad+\text { die/een }\end{array}$ & $\begin{array}{l}\text { - van ons die fabriek } \\
\text { of our that factory } \\
\text { 'our factory' }\end{array}$ & ERG-22 \\
\hline & & $\begin{array}{l}\text { - van hem die meisje } \\
\text { of him that girl } \\
\text { 'his girlfriend' }\end{array}$ & ERG-27 \\
\hline \multicolumn{4}{|c|}{ 2. Restructuring stage } \\
\hline & $\begin{array}{l}\text { Syntactic restructuring level } \\
\text { - die/een relates to the } \\
\text { entire NP }\end{array}$ & $\begin{array}{l}\text { - een [van mijn vader [vriend]] } \\
\text { a [of my father] friend } \\
\text { 'a friend of my father' }\end{array}$ & ERG-22 \\
\hline & & $\begin{array}{l}\text { - die [van haar vader [vriend]] } \\
\text { that of her father friend }\end{array}$ & ERG-27 \\
\hline \multirow[t]{2}{*}{ b. } & $\begin{array}{l}\text { Morphological realization } \\
\text { - no suppletion }\end{array}$ & $\begin{array}{l}- \text { de ['m [voet]] } \\
\text { the him foot } \\
\text { 'his foot' }\end{array}$ & T23-1 \\
\hline & & $\begin{array}{l}\text { - hem foto } \\
\text { him photo } \\
\text { 'his photo' }\end{array}$ & T42-6 \\
\hline
\end{tabular}


Table 16. Continued

\begin{tabular}{|c|c|c|}
\hline Stage & Example & $\begin{array}{l}\text { Subject } \\
\text { code }\end{array}$ \\
\hline \multicolumn{3}{|l|}{ 3. Target state } \\
\hline - no addition of die or van & $\begin{array}{l}\text { - mijn vriend } / m \text { ' } n \text { vriend } \\
\text { 'my friend' }\end{array}$ & T27-1 \\
\hline $\begin{array}{l}\text { - suppletion: } h e m+\text { genitive }=z i j n \\
\text { - weak pronoun }\left(z^{\prime} n\right) \text { in Agr }\end{array}$ & $\begin{array}{l}\text { - zijn vriend/z' } n \text { vriend } \\
\text { 'his friend' }\end{array}$ & T29-4 \\
\hline
\end{tabular}

Two possible analyses of these sequences come to mind. According to the first analysis, depicted in (59), die belongs to the possessed noun (papa, dochter) and the possessor is a separate constituent occupying Spec,AgrP. According to the second analysis, depicted in (65b), die forms a constituent with the possessor and the constituent die + possessor occupies Spec,AgrP. ${ }^{42}$

$$
\begin{array}{ll}
\text { a. } & {[[\text { die }[[\mathrm{ik}] \text { papa }]]]} \\
\text { b. } & {[[\text { die }} \\
\text { ik }] \text { papa }]
\end{array}
$$

Although (59a) is intuitively maybe the most appealing analysis, it seems that (59b) is the correct structural interpretation of the $L_{2}$ possessive construction at hand. A first problem posed by the analysis in (59a) is the fact that the demonstrative precedes the possessor. As we have seen in the previous subsection, such a pattern is quite uncommon with full nominal possessors. That is, although we have encountered such expressions as garage die naam (garage that name/'the name of the garage'), where the possessor precedes the demonstrative, we have not come across, at the earliest stages, such expressions as die vleesfabriek chef (that meat factory boss/'that boss of (the) meat factory'), where the demonstrative is interpreted as belonging to the possessed noun rather than to the possessor noun. The absence of such structures ${ }^{43}$ is due to the fact that the Turkish $\mathrm{L}_{2}$ learner has conserved the $\mathrm{L}_{1}$ parameter setting for the Spec-related strength feature of the functional head $\mathrm{D} ;{ }^{44}$ since this strength feature is set as being <weak $>$, nominal type indicators like demonstratives are not expected to occur in a prepossessor position.

The (59b) analysis also receives support from the categorial status of pronouns in Turkish. Turkish pronouns seem to be pronominals (rather than proDETERMINERs) in the true sense of this word, that is, they seem to be of the lexical categorial type $\mathrm{N}$ rather than of the functional categorial type D (see Kornfilt 1997: 300). Support for this comes, for example, from their behavior with respect to various morphological rules; just like common nouns, pronominals in Turkish function as stems to 
which case and plural morphology can be attached. Consequently, given the conservation hypothesis, a Turkish $\mathrm{L}_{2}$ learner assumes that Dutch pronominals are of the categorial type $\mathrm{N}$ as well. Being $\mathrm{N}$, their projection may contain a slot for demonstrative determiners (viz. Spec,DetP). Thus, the structure in ( $58 \mathrm{~b})$ would be more precisely stated as $(60)$ :

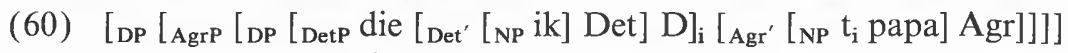
'my daddy/father' that I papa

The correctness of this analysis is corroborated by the occurrence of such forms as die ik and die haar in emphatic contexts like those in (61). ${ }^{45}$

a. MAH-4

[die ik] hier werken

that I here work

'I work here'

b. ERG-8

hij wil niet [die haar] is dood he wants not that her is dead 'he does not want her dead'

As can be seen in Table 16, the $\mathrm{L}_{2}$ learner tries, at an early stage, to realize the morphological expression of the genitive case characteristic of Turkish on the pronominal possessor. This is done by means of the item van. Analogously to the nominal possessors, we observe two patterns: (i) a pattern in which van follows the pronominal possessor (cf. [62]), and (ii) one in which it precedes it (cf. [63]) ${ }^{46}$ The syntactic representation that we assume to be at the basis of these strings is given in the prime examples (moved items are in italics).

(62) T25-2

onze van broer

$\left[{ }_{\mathrm{DP}}\left[{ }_{\mathrm{AgrP}} \text { onze }+ \text { van }\left[{ }_{\mathrm{Agr}}{ }_{\mathrm{NP}} \mathrm{t}_{\mathrm{i}} \text { broer }\right] \mathrm{Agr}\right] \mathrm{D}\right]^{47}$

a. ERG-18

van hem moeder

[DP $\left[{ }_{\text {AgrP }}\right.$ van hem ${ }_{\mathrm{i}}\left[{ }_{\text {Agr' }}\left[{ }_{\mathrm{NP}} \mathrm{t}_{\mathrm{i}}\right.\right.$ broer $\left.\left.] \mathrm{Agr}\right] \mathrm{D}\right]$

b. ERG-27

van hem die meisje

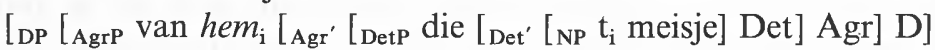

On a par with nominal possessors, we interpret postpossessor van as a suffix attached to the pronominal stem: [ [ $N$ onze-van] broer]. The most obvious analysis of prepossessor van is the one in which it is treated on a par with prepossessor van occurring on nominal possessors (cf. van 
Ipek fiets, of Ipek bike/'Ipek's bike'): that is, as an adpositional marker spelling out abstract genitive case on a noun phrase.

We argued that those learners who produce strings like van Ipek fiets have acquired the morphological knowledge that Dutch realizes genitive case in the form of an adpositional marker, but not the knowledge that this spell-out only applies in the complement position to the possessed noun (i.e. the domain restriction). There are a number of reasons, however, which make this analysis less plausible for early possessive variants in which van is attached to a PRONOMINAL possessor. First of all, possessive forms of the type van + pronominal are attested in the adult data at an early developmental stage at which no analytic constructions were yet produced. ${ }^{48}$ Second, if van is analyzed as an adpositional marker attached to a pronominal occupying Spec,AgrP, the question arises of why this spell-out only occurs on pronominal forms. That is, our adult learners produce strings of the type $[v a n+$ pronominal $]+$ possessee, whereas they do not produce any instance of the pattern [van + full DP] + possessee (e.g. van Ipek fiets, of Ipek bike/'Ipek's bike'). Importantly, the child learners do produce such forms. It seems that early occurrences of van + pronominal should be treated differently from late occurrences of $v a n+$ (pro)nominal (where late occurrences are those that appear at the time analytic constructions are attested in the data). A third reason for rejecting an analysis in which van is analyzed as an adpositional marker spelling out genitive case on the possessor DP comes from such forms as (64).

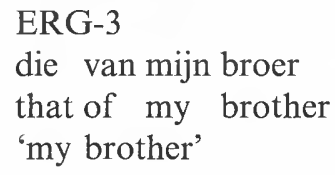

In such possessive variants, a demonstrative appears besides the possessive pronoun. As we have argued before on the basis of strings like die mijn/ik dochter (that my/I daughter/'my daughter'), it is implausible to analyze this string as [die [mijn [dochter]]]. Rather, the demonstrative and the pronominal seem to form a unit: [[die mijn] dochter]. As sequences like die van mijn broer show up in the acquisition data around the same time at which the pattern [die + pronominal]+ possessee appears, it seems plausible that the former is a variant of this latter pattern. That is, die van mijn broer should be analyzed as (65).

$$
\begin{aligned}
& \text { [DP [AgrP [DP [DetP die [Det' }[\text { van mijn] Det]]D }]_{i} \\
& \text { [Agr' }\left[\mathrm{t}_{\mathbf{i}} \text { broer] Agr] } \mathrm{D}\right]
\end{aligned}
$$

Under an analysis in which van is treated as an adpositional marker 
realizing genitive case, one is forced to state that genitive case is spelled out on the NP projection rather than on the DP projection. The latter would yield the unattested string [van die mij(n)] broer. Why the adpositional marker attaches to the NP projection rather than to the highest projection (say, DP), would remain unclear under this analysis.

In view of the above considerations, we come to the conclusion that van in such early possessive variants as (64) forms a lexical, unanalyzed word unit with the pronoun; see (66).

$$
\left[\mathrm{DP} \cdots\left[\left[_{\mathrm{DetP}} \operatorname{die}\left[\left[_{\mathrm{NP}}\left[\mathrm{N}_{\mathrm{N}} \operatorname{van}+\operatorname{mij}(\mathrm{n})\right]\right]\right] \operatorname{Det}\right] \mathrm{D}\right]\right.
$$

The frequent occurrence of the sequence van + pronominal in copular constructions (e.g. dat boek is van mij, that book is of me/"that book is mine') of the primary linguistic input - which presumably relates to their deictic nature - might be one of the reasons why these forms are memorized at an early stage and occur as fixed lexical units in early possessive variants.

It is only at a later developmental stage, that the Turkish learner treats van as an adpositional marker and assigns it an analysis that is similar to possessive constructions having van on a nominal possessor preceding the possessed noun (e.g. van Ipek fiets). Such forms as in (67), produced by the adult informants around the time at which they also start to produce analytic constructions with the van phrase in postnominal position, might plausibly be analyzed as possessive constructions in which van is analyzed as an adpositional marker on the possessor DP, which has been raised to Spec,AgrP.

a. ERG-22

van ons die fabriek

of us/our that factory

'our factory'

b. ERG-27

[DP $\left[\right.$ AgrP $v a n+o n s_{\mathrm{i}}\left[{ }_{\mathrm{Agr}}\right.$ [DetP $\operatorname{die}\left[\right.$ Det' $_{\mathrm{NP}} \mathrm{t}_{\mathrm{i}}$ fabriek $\left.\left.\left.] \mathrm{Det}\right] \mathrm{Agr}\right] \mathrm{D}\right]$

van hem die meisje

of him that girl

'his girl'

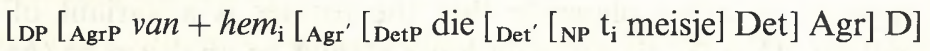

As is clear from the examples in (67), there is no movement of the demonstrative (a nominal type indicator) to Spec,DP. There is no movement because the Spec-related feature of D is specified as $\langle$ weak $\rangle$, an $\mathrm{L}_{1}$ property that is conserved in this structure. 
For a final argument in support of the appearance of unanalyzed wordlike units of the type van + pronominal, we want to focus on the possessive variant in (68), uttered by one of the Turkish children.

(68) T33-2

van die van ons de echte kerk

of that of us the real church 'our real church'

What is striking in (68) is that the possessor van die van ons contains two elements van. The leftmost van can be analyzed as the adpositional marker spelling out the genitive case feature on DP. Under the natural assumption that genitive case is not spelled out twice (by an adpositional marker) within the possessor DP, it seems evident that the second van forms a lexical unit (i.e. a word) with the pronominal. We end up with the structural analysis in (69). ${ }^{49}$



The pronominal possessive constructions considered thus far are in essence derivational outputs of a "conservative grammar" applied to a lexical input of Dutch lexical items. More specifically, the computational system is sensitive to parameter settings that are also characteristic of Turkish; that is, the $<$ strong $>$ Spec-related feature of Agr 
triggers movement of the possessor to Spec,AgrP and the <weak $>$ Spec-related feature of D accounts for the absence of nominal type indicators (e.g. demonstrative determiners) in Spec,DP. Also at the level of morphological realization, the $\mathrm{L}_{2}$ derivational outputs considered thus far are conservative. The Turkish $\mathrm{L}_{2}$ learner searches for a way of expressing morphologically the genitive case feature in a way identical to the realization of genitive case in Turkish. The $\mathrm{L}_{2}$ learner uses the element van for this.

At a certain stage in the acquisition process, however, the $\mathrm{L}_{2}$ learner discovers certain ways in which the environmental linguistic input differs from his $\mathrm{L}_{2}$ derivational output. This may lead him to a restructuring of the grammatical knowledge. As we have seen in our discussion of nominal possessive constructions, restructuring may apply at the lexical level (e.g. the acquisition of new lexical items forming instantiations of functional heads); this may have the concomitant effect of restructuring at the level of parameter settings. We assumed earlier that lexical acquisition of the elements $z^{\prime} n /-s$ led to a resetting of the headedness parameter from a head-final setting to a head-initial one. The examples in (70) are suggestive of another restructuring of parameter settings:
a. ERG-22
een van mijn vader vriend
one of my father friend
'a friend of my father' 50
b. ERG-27
die van haar vader vriend that of her father friend 'her father's friend'

The relevant question here is whether the string should be assigned a structure like (71) or one like (72).

(71) a. [[een van mijn] vader] vriend

b. [[die van haar] vader] vriend

(72) a. [een [[van mijn] vader] vriend

b. [die [[van haar] vader] vriend]

The structural analysis in (71) is reminiscent of the analysis we gave for such strings as die van mijn broer (that of my brother/'my brother') in (64)-(66) above, where die was interpreted as an element specifying the pronominal possessor and van as an adpositional marker realized on the lexical projection NP. Importantly, such strings in which the demonstrative functions as a specifier of the possessive pronominal occur at a rather 
early stage of the acquisition of the $\mathrm{Y}_{\mathrm{p}} \mathrm{X}$ pattern. ${ }^{51}$ The strings in (70) are produced at a later stage of acquisition (viz. ERG-22; ERG-27). So, it might very well be that, although superficially quite similar to the string in (64), the strings in (70) have a different syntactic structure. In Table 16, we can observe that at the same moment of recording (viz. ERG-22 and ERG-27) the subject ERG forms such strings as in (67). The latter we have analyzed as structures having a $<$ weak $>$ Spec-related feature on D, to the effect that there is no overt raising of the demonstrative to Spec,DP. The only way in which the strings in (67) seem to differ from those in (70) is the placement of the demonstrative; in (70), the demonstrative precedes the possessor. Especially for (70a), it is quite clear that the specifying element een enters into a dependency relation with the possessed noun, rather than with the possessor. The interpretation is ' $a$ friend of my father's' rather than 'a father's friend'. Consequently, the proper way to interpret the strings in (70) seems to be the one in (72). Such an analysis implies that the Turkish $\mathrm{L}_{2}$ learner has discovered the target-language property that determiner-like elements (like demonstratives) are raised overtly from Spec,DetP to Spec,DP. The fact that both the strings in (67) and those in (70) are uttered at the same session and therefore in the same stage of acquisition suggests that the subject ERG has just identified this property of Dutch and has not fully mastered (i.e. automatized) the knowledge that the Spec-related feature of $\mathrm{D}$ is $<$ strong $>$.

Besides restructuring of parameter settings, we also see evidence for restructuring at the level of morphological realization: at a certain stage, the (child) $\mathrm{L}_{2}$ learner no longer attempts to express morphologically the genitive case by means of the attachment of van to possessor nouns preceding the possessed noun. ${ }^{52}$ Furthermore, the learner discovers that the personal pronoun object forms (mij, hem) form the basis of strong possessive pronominals in Dutch. It leads to the appearance of such forms as in (80).
a. $\mathrm{T} 42-6$
hem foto
him photo
'his photo'
b. T27-6
hem z'n kamer
him his bedroom
'his bedroom'

Although superficially similar, the strings in (73) may well have a different syntactic structure. In (73a), we have a string that lacks overt realization 
of the functional category Agr; in (73b), Agr is lexically instantiated by $z$ ' $n$. As we have argued, the latter element is pivotal for the restructuring of the syntactic structure from head-final to head-initial. We end up with a structure like (74) for (73b):

$$
\text { [DP D [AgrP } \left.\left.\text { hem }_{i}\left[\text { Agr' }^{\prime} \text { 'n [NP kamer } t_{i}\right]\right]\right]
$$

This structure plausibly extends to (73a), with Agr being phonologically empty.

At the target state, the learner has discovered that forms like mijn and $z i j n$ are in fact suppletive forms resulting from the merger of the object form (mij and hem) with the Agr head. Thus, although the surface output forms of mijn buurman (MAH-2) and mijn vriend (T27-6) are the same, their structural analyses are completely different.

Having discussed in detail the various pronominal variants instantiating the construction type $Y_{p} X$, we turn to the question of which variants are found in adult and child learners and how successful they are in attaining the target instantiations of this construction type. The distributional figures can be found in Table $17 .{ }^{53}$

When we compare the results of the adults with those of the children in Table 17, it is clear again that the two adult learners do not acquire full competence of the $\mathrm{Y}_{\mathrm{p}} \mathrm{X}$ construction type, whereas children do; all 16 children produce instantiations of this pattern. Throughout the cycles, the adult subjects produce possessive pronominal forms that have the

Table 17. Distribution of pronominal variants ( $Y_{p} X$ pattern) produced by Turkish learners over developmental stages

\begin{tabular}{|c|c|c|c|c|c|c|c|c|}
\hline & & 1. Con & ervation & & 2. Rest & ucturing & 3. Targ & state \\
\hline & & CWS & FFS & BFS & level a & level b & $\begin{array}{l}\text { strong } \\
\text { pronou }\end{array}$ & clitic \\
\hline ERG & cycle 1 & 48 & 2 & 6 & - & - & - & - \\
\hline & cycle 2 & 106 & 21 & 18 & - & - & - & - \\
\hline & cycle 3 & 106 & 5 & 100 & 17 & - & - & - \\
\hline & $\begin{array}{l}\text { (last } \\
\text { recording) }\end{array}$ & (1) & $(-)$ & (39) & (1) & - & - & - \\
\hline MAH & cycle 1 & 135 & 23 & 4 & - & - & - & - \\
\hline & cycle 2 & 128 & 4 & 3 & - & - & - & - \\
\hline & cycle 3 & 93 & 16 & 3 & - & - & - & - \\
\hline Group & ( 8 children) & $1 / 1^{\mathrm{a}}$ & $1 / 1^{a}$ & $26 / 12^{\mathrm{a}}$ & $1 / 1^{\mathrm{a}}$ & $5 / 4^{a}$ & $344 / 8^{a}$ & $284 / 8^{a}$ \\
\hline Group & ( 8 children) & $-1-$ & $-1-$ & $4 / 4$ & $1 / 1^{a}$ & $2 / 2^{a}$ & $299 / 8^{a}$ & $294 / 7^{a}$ \\
\hline
\end{tabular}

a. The first number is the number of occurrences, the second is the number of subjects producing these patterns. 
target form (e.g. zijn) but are in all likelihood stored as morphologically unanalyzed words. As shown by the FFS column of the conservation stage, the adult learners use the subject personal pronoun form and pronominal forms specified by demonstratives throughout the three cycles. On the basis of the ten occurrences (tokens) of the pattern [determiner [possessor] possessee], we might conclude that ERG has started restructuring at the level of parameter setting: the occurrence of the determiner, which specifies the possessed noun, in front of the possessor suggests that ERG has acquired the UG-defined parameterized lexical knowledge that Dutch D has a $<$ strong $>$ Spec-related feature rather than a $<$ weak $>$ one. Assignment of the $<$ strong $>$ value to this parameterized lexical property associated with $\mathrm{D}$ leads to movement of demonstratives to Spec,DP in overt syntax.

Although there is variation among the children in the frequence of use of possessive pronominal forms, it can be concluded that all children are successful in acquiring the target knowledge required for the formation of the pattern $Y_{p} X$. In their final output, all children, however, still have some residual patterns of earlier stages. As indicated by the two columns falling under the label of the target state, the children's data contain both strong and weak (i.e. clitic) pronominal forms. Recall from Table 8 that the former originate as object pronominals in the complement position to the noun and are moved overtly to Spec,AgrP; the latter, on the contrary, are analyzed as instantiations of Agr; see (75a) and (75b).

$$
\begin{aligned}
& \text { a. } \left.\quad{ }_{\text {AgrP }} \text { hem }\left[{ }_{\text {Agr' }} \emptyset[\text { fiets }]\right]\right] \rightarrow \text { zijn fiets } \\
& \text { him }-\mathrm{s} \text { bike } \\
& \text { 'his bike' } \\
& \text { b. [AgrP }\left[\text { Agrr' }^{\prime}\right. \text { 'n [fiets]]] }
\end{aligned}
$$

Finally, there is a striking asymmetry between the frequent occurrence of (die +) van + pronoun in adults' data and the infrequent use of this string by children. The sequence $v a n+N$, on the other hand, is completely absent in the adults' data, whereas it is quite common for the children. This is explicable in terms of the stages in which these strings appear. Adults have not yet sufficiently understood the function of the adpositional marker and therefore do not use this device in $\mathrm{Y}_{\mathrm{n}} \mathrm{X}$ constructions. The use of van in pronominal strings, however, is evidence for a missing adequate morphological analysis.

\subsection{The $X Y_{n / p}$ pattern: possessor-final constructions (analytic)}

In this section we discuss the acquisition of the possessor-final construction type, in abbreviated form $\mathrm{XY}_{\mathrm{n}}$, together with the pronominal 
( $\mathrm{X} \mathrm{Y}_{\mathrm{p}}$ ). In Table 11 we made clear what knowledge the Turkish learner has to acquire. For the analytic constructions the following elements are involved: (1) resetting of the head parameter, (2) no projection of Agr, and (3) the morphological rule that spells out abstract genitive case as the adpositional marker van.

To what extent do the Turkish $\mathrm{L}_{2}$ learners succeed in acquiring this target knowledge? We should stress that none of this linguistic knowledge is part of the $\mathrm{L}_{1}$ grammar of the Turkish $\mathrm{L}_{2}$ learners. Turks are not familiar with possessive constructions in which the possessor follows the possessed noun. Hence, there is no conservation stage at issue for this construction type. Patterns of the possessor-final type are only expected to occur as the result of restructuring of $\mathrm{L}_{1}$ grammatical knowledge by the Turkish $\mathrm{L}_{2}$ learner.

When we look at Table $18,{ }^{54}$ we get quite a clear picture of the order of restructuring. Turkish $\mathrm{L}_{2}$ learners identify and produce quite early possessive patterns in which the possessor follows the possessed noun. Those early instantiations are further characterized by the absence of the element van. This suggests that restructuring of the parameterized lexical knowledge takes place before morphological restructuring: at a quite early stage, the $L_{2}$ learner resets the headedness parameter and assigns a head-initial value to it.

The head-initial $\mathrm{N}$ is the earliest case of a switch of headedness we have noticed in the adults' data. The question arises whether this switch of headedness is indicative for a uniform switch of headedness at all projection levels. As the functional heads in the possessor-initial patterns are all empty heads for the adult informants, we can only speculate about their position. In the adult data, it is clearly the case that acquisition of the analytic pattern precedes all further restructuring of the possessorinitial patterns. The distribution of the variants over the informants is given in Table 19.

It is clear from Table 19 that adults and children produce target constructions of the analytic pattern for the nominal variant. Adults exhibit some instances of restructuring, children do not. As for the pronominal variant, only one adult and five out of 16 children use the target pronominal (analytic) pattern. Each of the five children produced this pattern only once.

\section{4. $Y_{p} X Y_{n}$ pattern: the double possessor construction}

There is one possessive variant that we would like to discuss separately, distinguished as a separate construction in Table 13. Among the adults, 
Table 18. Acquisition order for the analytic pattern by Turkish learners

\begin{tabular}{|c|c|c|}
\hline Stage & Example & $\begin{array}{l}\text { Subject } \\
\text { code }\end{array}$ \\
\hline
\end{tabular}

1. Conservation stage

2. Restructuring

CWS/FFS:

$\mathrm{Y}_{\mathrm{n}}$ (with nominal complement)

$Y_{p}$ (with pronominal complement)

$Y_{p}-$ full pronoun

$Y_{n}$ (the conserved pattern: agreement pattern; see Table 14)

- kinderen die vrouw

ERG-5

children that women

'the children of that women'

- vrouw jongen

MAH-13

woman boy

'the boy's wife'

- baas mijn

boss my

'my boss'

MAH-26

3. Target stage

- garage van die pakistani jongen

ERG-23 garage of that pakistan boy

- die andere mensen van transport the other people of the transport

- de buik van de sneeuwpop the belly of the snowman

- die zieken(fonds) van mij that medical insurance of me

- water van ons

water of us

'our water'
MAH-21

T24-6

ERG-24

T33-4

Key: $\quad \mathrm{Y}_{\mathrm{n}}=$ nominal possessor.

$\mathrm{Y}_{\mathrm{p}}=$ pronominal possessor.

Table 19. Distribution over the acquisition stages of the analytic pattern by Turkish learners

\begin{tabular}{llcccc} 
& \multirow{2}{*}{$\begin{array}{l}\text { 1. Conservation } \\
\text { d.n.a. }\end{array}$} & \multicolumn{2}{c}{ 2. Restructuring } & \multicolumn{2}{c}{ 3. Target stage } \\
& $\mathrm{Y}_{\mathrm{n}}$ & $\mathrm{Y}_{\mathrm{p}}$ & $\mathrm{Y}_{\mathrm{n}}$ & $\mathrm{Y}_{\mathrm{p}}$ \\
\hline ERG & 2 & - & 5 & 5 \\
MAH & 4 & 2 & 2 & - \\
Group 1 (8 children) & & & & \\
Group 2 (8 children) & $-/-$ & $-/-$ & $22 / 7^{\mathrm{a}}$ & $-/-$ \\
& & $-/-$ & $-/-$ & $63 / 8^{\mathrm{a}}$ & $5 / 5^{\mathrm{a}}$ \\
\hline
\end{tabular}

a. The first number is the number of occurrences, the second is the number of subjects producing these constructions. 
only a few occurrences of this type are found for Fatima (Moroccan). This variant can be characterized as a double possessor construction. However, it is not a doubling of the Dutch type (cf. [76a]), but more of the Moroccan Arabic type (cf. [76b]), in the sense that the doubling pronoun cooccurs with a possessor introduced by the adposition van. The instances of this doubling possessive variant are given in (77).

(76) a. Jan z'n broer

Jan his brother

'Jan's brother'

b. xet-ha dyal Touria

sister-her of Touria

'Touria's sister'

(77) a. T24-6

zijn hoed van z'n moeder

his hat of his mother

'the mother's hat'

b. T25-5

z'n naam van die land

his name of that country

'the name of that country'

c. T42-2

m'n kleine zusje van mij

my little sister of me

'my little sister'

These doubling variants are attested in the production data of four Turkish children (T24, T25, T42, and T43). At a descriptive level, these variants are combinations of the $Y_{p} X$ pattern and the $X Y_{n / p}$ pattern. And, in fact, at the time children start producing these doubling variants, instances of the $Y_{p} X$ and the $X Y_{n / p}$ patterns are attested in their speech. ${ }^{55}$

The question arises as to how to interpret analytically these doubling variants, which, interestingly, are attested neither in Turkish nor in Dutch. The most plausible structure for this construction is the one in which the possessive pronoun $z^{\prime} n / m^{\prime} n$ in Agr is not (yet) specified for a strong Specrelated feature. This explains why the possessor van z'n moeder 'of his mother' in (84a) is not moved to Spec,AgrP.

\subsection{Overview and main conclusions}

Taking the results of section 6 together, the development of the nounphrase-internal possessive relationship can be summarized as in Figures 
1-3 and Table 20. The former summarize which possessive patterns are produced at three stages of development, which should be interpreted as falling within the boundaries of the interlanguage state. Table 20 provides information about the grammatical knowledge that is required at each stage for the production of these patterns. Of course, the stages are not rigidly demarcated in time; there is overlap, especially at moments at which restructuring of grammatical knowledge takes place. So, there are months in which typical conserved constructions from Figure 1 and the first column in Table 20 cooccur with analytic constructions from Figure 2 and the second column.

Two major alterations can be distinguished in the development of the possessive construction. The first involves the resetting of the head parameter. The learner acquires the knowledge that possessors can be realized in a right-branch complement position and be associated there with genitive case. Recall that due to the inherent status of genitive case, raising of the possessor to a Spec position of $\mathrm{AgrP}$, where case is licensed, is not necessary. As a matter of fact, guided by the principle of economy of representation, the learner concludes that $\operatorname{Agr}(\mathrm{P})$ is simply absent in analytic constructions.

We would like to emphasize here that the emergence of analytic constructions does not imply the end of the conservation stage. Structures as represented in Figure 2 cooccur with (conserved) structures as given in Figure 1.

The second alteration point is marked by the identification of $z^{\prime} n$ and $-s$ as instantiations of Agr. This leads to a restructuring of the $\mathrm{L}_{2}$ vocabulary and a concomitant restructuring of the $\mathrm{L}_{2}$ knowledge at the level of parameter setting: the category AgrP can be lacking or has a strong Specrelated feature when it is filled by $z^{\prime} n /-s$. After this restructuring of the $\mathrm{L}_{2}$ lexical knowledge, both the possessor-final (i.e. analytic) and the possessor-initial pattern can be generated on the basis of an $\mathrm{L}_{2}$ syntax (Figure 3 and third column in Table 20; prolonged restructuring stage).

From the first alteration, we can conclude that Turkish (both child and adult) learners are able to acquire a new type of possessive construction, one that is not available in the $L_{1}$. The question arises as to why this construction is acquired rather easily. The abundant availability (positive evidence) of possessor-final patterns in the primary input data presumably leads the learner to hypothesize that possessors originate in a complement position following the possessed noun. As a result, the head parameter is set for the $\mathrm{L}_{2}$ lexicon as [-complement]. In view of the uniformity of headedness in the $\mathrm{L}_{1}$ language, we will assume that the head parameter is set as head-initial for the functional projections as well. Furthermore, since the possessor can occur in a postnominal posi- 
tion, the conclusion is drawn that possessive constructions can be generated without an Agr category. As already said above, at this stage possessor-final patterns are still generated by an $L_{2}$ syntax, whereas the possessor-initial patterns are generated on the basis of a conserved $\mathrm{L}_{1}$ syntax.

The second alteration takes place somewhat later, possibly because of the fact that bound functional morphemes (i.e. clitic-like elements) are harder to identify in the primary linguistic input. The learner may be helped in the identification and localization of these elements, on the basis of his knowledge that the target language has a head-initial parameter setting. On the basis of input data of the type Jan z'n fiets and Jan's fiets, the $\mathrm{L}_{2}$ learner decides that $z^{\prime} n$ and $-s$ are left-branch Agr heads. Given the fact that the possessor precedes the clitic-like elements, they hypothesize that these elements have a $<$ strong $>$ Spec-related feature; this knowledge is now incorporated in their $\mathrm{L}_{2}$ lexicon.

The occurrence of such sequences as van Hendry z'n foto shows that after having acquired the morphological spell-out rule for genitive case

(i) Agreement pattern (possessor-initial)


a. vriend $\varnothing \quad$ huis
b. garage die chef
die jongen $\varnothing \quad$ naam
c. moeder-van de kop

\section{pronominal}

$\begin{array}{lll}\text { a. mijn } & \varnothing & \text { buurman } \\ \text { b. zijn } & \varnothing & \text { vrouw } \\ \text { die mijn } \varnothing & \text { dochter } \\ \text { c. die van-mijn } & \varnothing & \text { broer } \\ & \text { van-hem } \varnothing & \text { moeder } \\ \text { onze-van } & \varnothing & \text { broer } \\ \text { die-van } \varnothing & \text { auto }\end{array}$

Figure 1. Conservation stage $(a=C W S ; b=F F S ; c=B F S)$ 
(i) Analytic pattern (possessor-initial)

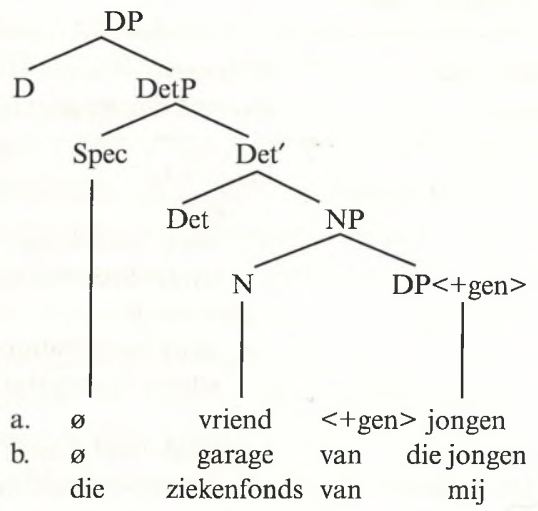

Figure 2. Restructuring stage (essential) $(a=C W S ; b=F F S ; c=B F S$ )

(i) Hidden construct pattern (possessor-initial)

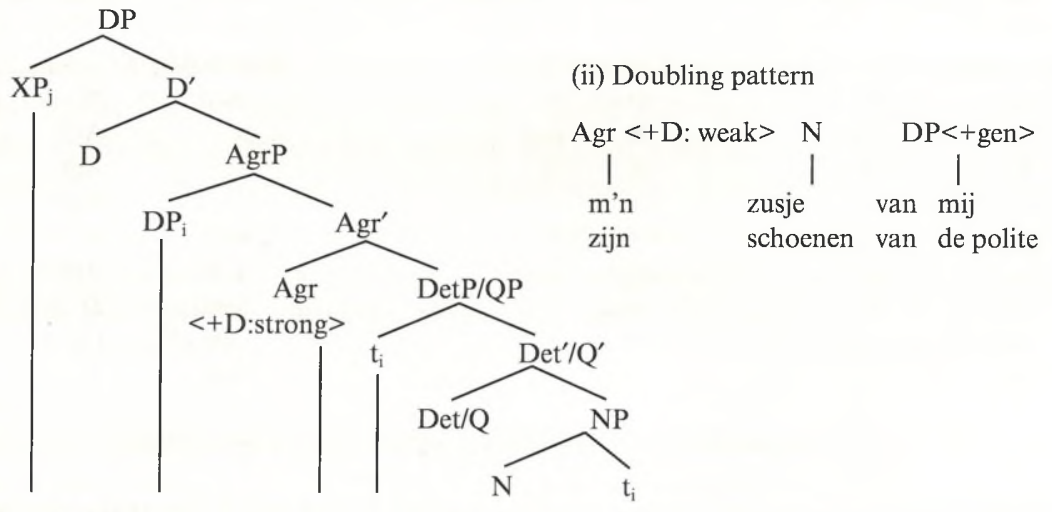

nominal

\begin{tabular}{l|lll} 
c. & van Ergün & $\varnothing$ & auto \\
van Ömer & 's & huis \\
die jongen-van & z'n & vader \\
z'n Smurrf & z'n & huis
\end{tabular}

pronominal

$\begin{array}{llll}\text { I van hem } & \varnothing \text { die } & \text { vader } \\ \text { een } & \text { van mijn vader } & \varnothing & \text { vriend } \\ \text { die } & \text { van haar vader } & \varnothing & \text { vriend } \\ & \text { die-van } & \text { z'n } & \text { ding } \\ & \text { hem } & \text { (z'n) } & \text { kamer }\end{array}$

Figure 3. Prolonged restructuring stage ( $a=C W S ; b=F F S ; c=B F S$ ) 
Table 20. Overview of the developing grammatical knowledge of Turkish $L_{2}$ learners: changes in the conservation stage are in italics; $\emptyset=$ phonetically empty

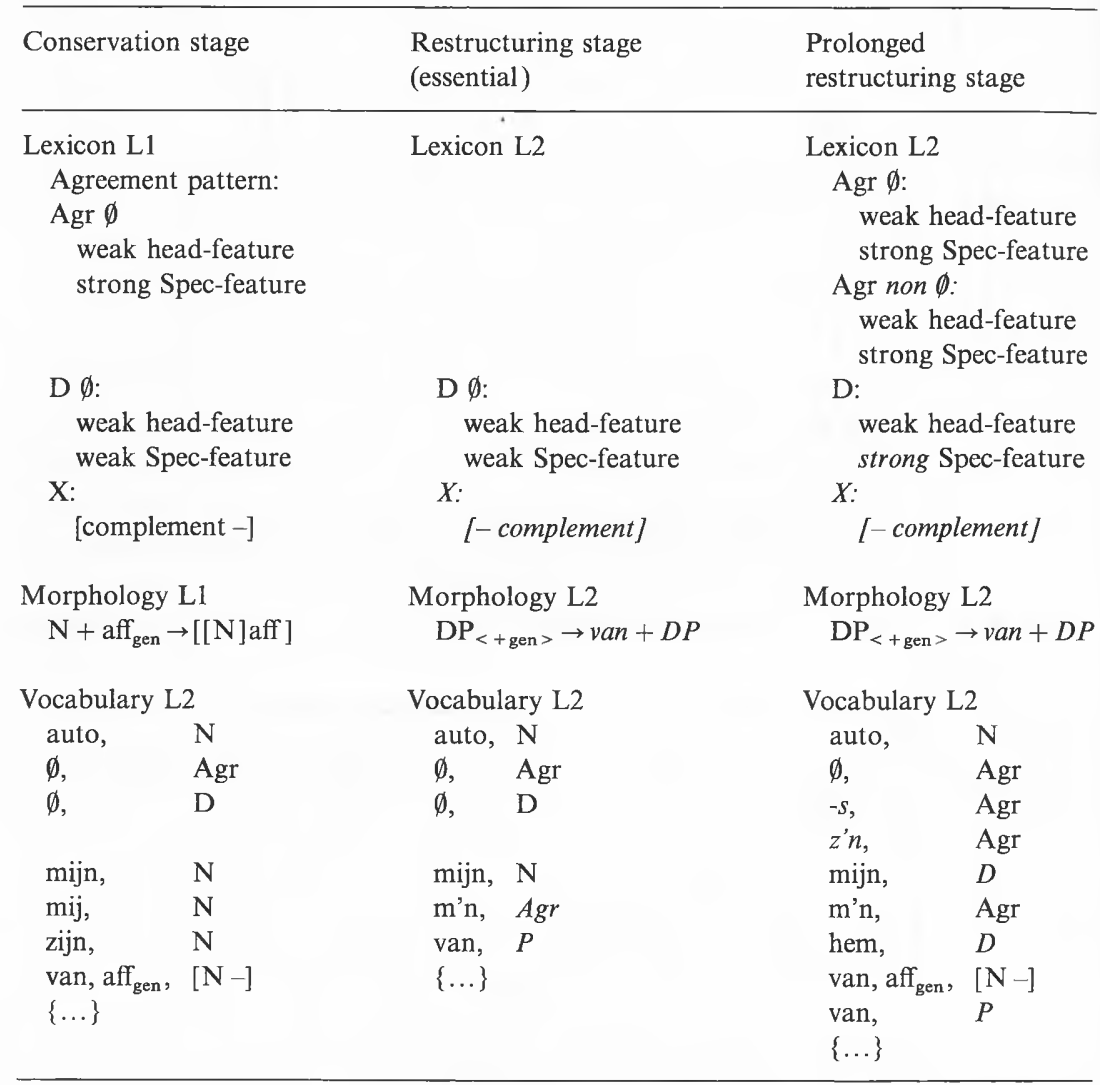

in the analytic construction, certain learners overgeneralize this rule to prenominal possessors.

A third type of alteration in parameter setting concerns the Specrelated feature of D. In Turkish, D has a $<$ weak $>$ Spec-related feature and, therefore, does not trigger overt movement of demonstrative determiners to D. This explains the occurrence of such sequences as garage die chef in the conservation stage, where the possessor is in Spec,AgrP and the demonstrative in Spec,Det. At the prolonged restructuring stage (Figure 3), the learner produces such forms as een/die van mijn vader vriend, where the determiner, which goes together with the possessed noun, precedes the possessor. This placement of the determiner suggests that the Turkish $\mathrm{L}_{2}$ learner has acquired the $\mathrm{L}_{2}$ knowledge that the Specrelated feature of $\mathrm{D}$ is $<$ strong $>$. 
What leads the $\mathrm{L}_{2}$ learner to this resetting? An important factor might be the systematic absence in the environmental input of the possessorinitial patterns featuring die (say, Jans die vriend, Jan's that friend/"that friend of Jan's'), that is, the equivalent of the (well-formed) Turkish possessive construction. In other words, on the basis of indirect negative evidence, the learner hypothesizes that Dutch is a language in which determiners (base-generated in Spec,DetP) must overtly raise to Spec,DP and consequently resets the Spec-related feature of $\mathrm{D}$ as being $<$ strong $>$. Of course, this raises the question of why he produces such possessive variants as een/die van mijn vader vriend, since these are systematically absent as well in the environmental input (*die Jans vriend, that Jan's friend/'that friend of Jan's').

We believe that the production of this pattern relates to a piece of conserved (i.e. Turkish) grammatical knowledge that relates to the property of (in)definiteness. As was pointed out in section 4, the possessor in Spec,AgrP does not seem to determine the definiteness of the entire Turkish possessive construction. Thus, in Ayşe-nin bir kitab-l (Ayşe-Gen a book-3sg), where Ayse is obviously definite, we have an indefinite reading of the entire possessive DP. In the Dutch Saxon genitive pattern, however, the possessor in Spec,AgrP does determine the definiteness of the entire construction (cf. section 4.4). In note 30 , we tentatively suggested that this property of (in)definiteness inheritance blocks the occurrence of a determiner encoding (in)definiteness. The occurrence of such patterns as een/die van mijn vader vriend suggests that the learner has not yet discovered this blocking effect that holds for Dutch.

\section{Possessive constructions used by Moroccan L2 learners}

\subsection{The $Y_{n} X$ pattern: nominal possessor-initial constructions}

In this section we discuss how and to what extent Moroccan $\mathrm{L}_{2}$ learners acquire the grammatical knowledge required for the generation of Saxon genitive and doubling possessive constructions in Dutch. As was pointed in section 4, Dutch and Moroccan Arabic are quite different superficially, to the extent that Dutch displays the order of possessor before possessed noun whereas Moroccan Arabic only displays the order possessed noun before possessor. At the analytical level, however, the Moroccan Arabic construct state and the Dutch Saxon genitive/doubling possessive construction turn out to share important grammatical properties (e.g. inheritance by the containing projection of the [in]definiteness feature realized on the possessor). The major difference is overt N-raising in Moroccan 
Arabic construct states versus the absence of such overt head movement in Dutch in Saxon genitives and doubling possessive structures (whence their characterization as "hidden construct states").

Two important questions arise. Do Moroccan $\mathrm{L}_{2}$ learners produce possessive patterns of the Moroccan Arabic construct-state type? Are they able to restructure their $\mathrm{L}_{1}$ grammar in such a way that overt $\mathrm{N}$ movement does not apply within the $\mathrm{L}_{2}$ noun phrase, and if so, do they attain the Saxon genitive and the Dutch doubling possessive pattern?

The conservation hypothesis predicts that construct states will be found in the early $\mathrm{L}_{2}$ derivational output. And, in fact, this is precisely what we find. Although the number of construct-state variants is limited, we do encounter such forms as given in Table 21 under the label conservation stage at the very early stages of the acquisition process. ${ }^{56,57}$

A possessive variant like nummer telefoon (number telephone 'telephone number') is derived by applying an $\mathrm{L}_{1}$ grammar (i.e. a computational system governed by $\mathrm{L}_{1}$ parameter settings) to a numeration that consists partly of phonologically specified lexical items of $\mathrm{L}_{2}$ and partly of phonologically unspecified ones. The generated structure for a string like nummer telefoon is given in (78).

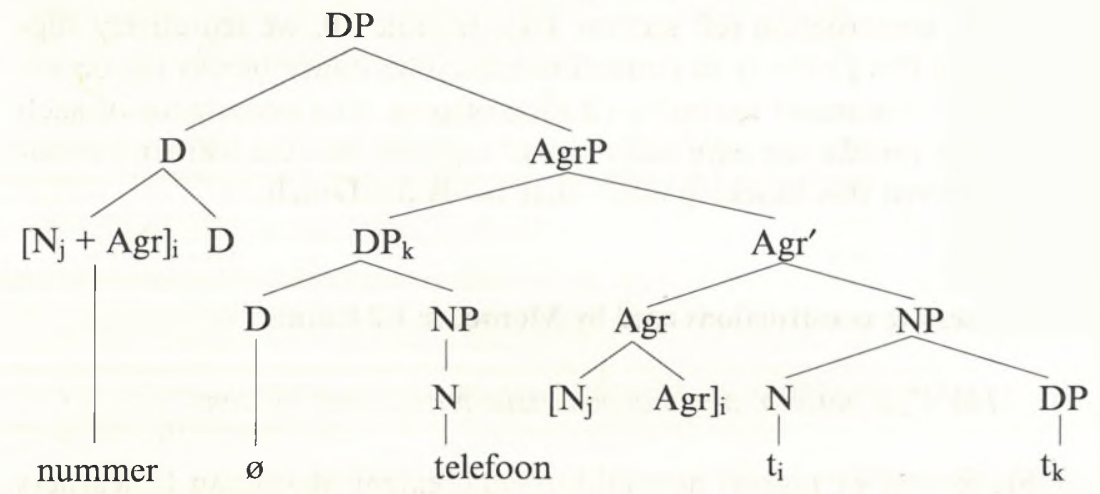

Additional empirical evidence for the existence of overt $\mathrm{N}$-raising in early $\mathrm{L}_{2}$ expressions are the examples in (79) and (80), which have a postnominal attributive adjective. The postnominal placement is the result of $\mathrm{N}$-raising as depicted in the structural descriptions in (79) and (80).

(79) FAT-5

meisje marokkaans

girl Moroccan

'Moroccan girl'

[DP $\left[\mathrm{QP}\right.$ meisje $_{\mathrm{i}}\left[\mathrm{FP}\right.$ marokkaans $\left.\left.\left.\left[\mathrm{NP}_{\mathrm{i}}\right]\right]\right]\right]$ 
Table 21. Possessive variation of the type $Y_{n} X$ attested in the developmental stages of Moroccan learners

\begin{tabular}{ll} 
Stage & Example \\
\hline $\begin{array}{l}\text { 1. Conservation stage } \\
\text { a. Content-word state (CWS) }\end{array}$ & nummer telefoon \\
& number telephone \\
& 'telephone number' \\
& - klas Pascal \\
& class Pascal \\
& 'Pascal's class' \\
& - school de trui \\
b. Free-functional-morpheme & school the sweater \\
state (FFS) & 'the knitting class'
\end{tabular}

Subject

code

2. Restructuring stage

syntactic restructuring: no N-raising

a. Content-word state (CWS)

- Keesje kamer

Keesje room

'Keesje's bedroom'

- [mij vader] vrouw

[my father] wife

'my father's wife'

b. Free-functional morpheme state (FFS)
- [gym van] kleren
[gymnastics of] clothes 'sports outfit'
- van de wielen de dingen
[of the wheels] the things
'the tires'

FAT-2

M5-1

FAT-3

c. Absence of agreement between pos'sor and possessive

pronominal

- number

- vader en moeder zijn bed

M10-6 father and mother his bed

- gender

'father and mother's bed'

- mama z'n zusje

mamma his sister

'mamma's sister'

M14-2

M8-2

- zijn oma's mand

M2-1

'his grandmother's basket'

- hem vaders auto

M2-6

him father's car

'his father's car'

- konijntje $z$ ' $n$ hand

rabbit his hand

'the rabbit's hand'

- mama d'r mond

mamma her mouth

M17-3

'mamma's mouth' 
(80) $\mathrm{MOH}-4$

die film marokkaan

that film Moroccan

'the Moroccan film'

[DP $\operatorname{die}\left[{ }_{Q P}\right.$ film ${ }_{\mathrm{i}}\left[\mathrm{FP}\right.$ marokkaan $\left.\left.\left[\mathrm{NP}_{\mathrm{i}} \mathrm{t}_{\mathrm{i}}\right]\right]\right]$

Nominal expressions are further attested in which partial overt $\mathrm{N}$-raising has taken place; that is, the $\mathrm{N}$ has raised overtly to some intermediate functional head (e.g. Q) and not to the highest functional head to which it should have moved according to the Moroccan Arabic grammatical system. The expression in (81) exemplifies such partial $\mathrm{N}$ movement.

\section{(81) M5-1}

m'n zusje kleine

my sister little

'my little sister'

$\left[{ }_{D P}\left[{ }_{A g r P} \text { m'n }\left[{ }_{Q P} \text { Zusje }_{i}\left[{ }_{F P} \text { kleine }\left[{ }_{N P} t_{i} \text { pro }\right]\right]\right]\right]\right]^{58}$

At a rather early stage of the acquisition process (more specifically, after the recordings of the first five months), the process of overt $\mathrm{N}$-raising within the nominal domain has disappeared from the $\mathrm{L}_{2}$-derivational output. At this point, the $\mathrm{L}_{2}$ learner has restructured his grammar as regards the head-related strength property of the functional heads Agr and $\mathrm{D}$ : the strength value has been reset from a $<$ strong $>$ value to a $<$ weak $>$ one. After having reset this parametric property, the intergrammar will only generate nominal expressions in which the nominal head $\mathrm{N}$ follows attributive adjectives; see (82).
a. FAT-18
die kleren van die marokkaans ouwe mens those clothes of those Moroccan old people 'the clothes of the Moroccan old people'
b. $\mathrm{MOH}-4$
die marokkaans cafe
that Moroccan cafe
'the Moroccan cafe'

With the head related feature of Agr and D being reset from a $<$ strong $>$ value to a $<$ weak $>$ value, one might expect widespread occurrence of possessive variants that look like the Saxon genitive target construction. It turns out, though, that such forms are scarce in the Moroccan learners' production data; we will come back to this later on in this section. Let 
us for the moment concentrate on the question of what structural representation could be assigned to these instantiations of the possessor-initial pattern. Obviously, such a pattern will only be generated if the Specrelated feature of Agr has a $<$ strong $>$ value. Abstracting away from the question whether this < strong $>$ property is a setting conserved from $\mathrm{L}_{1}$ or whether it is a newly assigned (identical) $\mathrm{L}_{2}$ parameter value, we end up with a structural representation like (83b) for a string like (83a):

(83) M15-6

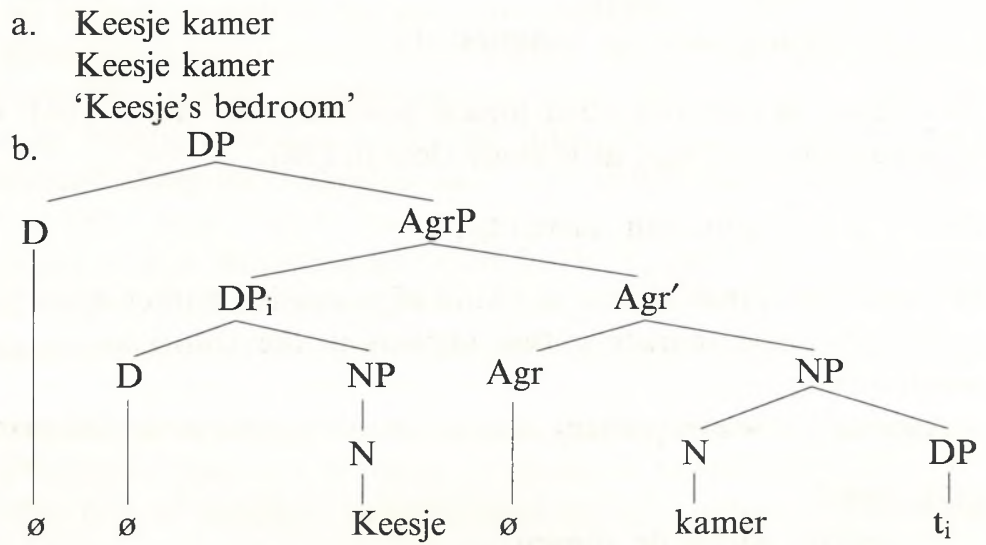

In (83b), the functional Agr-head has an empty phonological matrix and the possessor noun (Keesje) is a bare form. Besides a possessive variant like (83a), a variant like (84) is attested, in which the possessor noun is followed by the element van. Like the variant in (87), this possessive variant is very limited in its occurrence.

(84) M14-2

gym van kleren
gymnastics of clothes
'sports outfit'

The question, of course, arises of how to interpret van. An interpretation of van as an inflectional genitive suffix (cf. our discussion of van in possessive variants produced by Turkish learners) seems unlikely given the fact that the learner is not familiar with such a case morpheme on the basis of his first language. An interpretation of van as the morphological spell-out of genitive case, a procedure the Moroccan Arabic learner is familiar with on the basis of his knowledge of the analytic dyal construction, raises the question of why van follows rather than precedes the possessor; in Moroccan Arabic dyal precedes the possessor. Furthermore, 
if the $\mathrm{L}_{2}$ learner hypothesized that the adpositional marker in Dutch might be realized in postpossessor position, one would expect instances of the "possessor + van" pattern in analytic constructions as well. However, as will become clear in section 7.3, these are not attested in the $L_{2}$-derivational output. That is, along with such sequences as $(85 \mathrm{a})$, we do not find such sequences as (85b).
a. baas [van die] (attested) boss [of that]
b. \#baas [die van] (unattested)

This leaves us with one other logical possibility for van in (84): van as an instantiation of Agr, as is made clear in (86).

$$
\text { [DP } \left.\left.\left[\operatorname{AgrP}_{\mathrm{g}} \operatorname{gym}_{\mathrm{i}} \text { van }\left[\text { kleren } \mathrm{t}_{\mathrm{i}}\right]\right]\right]\right]
$$

In a way, van is treated here as a kind of possessive marker, quite parallel to the possessive marker $-s$ that appears in the Dutch Saxon genitive construction.

Another possessive variant attested in our corpus is the following:

(87) $\mathrm{M} 8-2$

van de wielen de dingen

of the wheels the things

'the tires'

This construction has the peculiarity of having a prepossessor van on a prenominal possessor. The most likely interpretation of this van is that of an adpositional marker attached to the DP; it cannot be interpreted as some genitival affix (i.e. prefix) to the noun, in view of the fact that the determiner de intervenes. ${ }^{59}$ Thus, such forms as (87) are in fact the result of an extension of the structural environment in which the morphological spell-out rule can operate: $\mathrm{L}_{2}$ learners producing such utterances as (87) have broadened the domain of application of the morphological spell-out rule which inserts van.

Besides this peculiarity of van, the construction in (88) features the definite article $d e$ in between the possessor and the possessed noun. Two potential analyses of the placement of de come to mind: (i) de as head of DP, with van de wielen in Spec,DP (cf. [88a]); (ii) de in Agr, with van de wielen in Spec,AgrP (cf. [88b]).

(88) a. [DP van de wielen ${ }_{i}\left[{ }_{D^{\prime}}\right.$ de $\left[{ }_{N P}\right.$ dingen $\left.\left.\left.t_{i}\right]\right]\right]$

b. [DP $\left[{ }_{\mathrm{AgrP}}\right.$ van de wielen ${ }_{\mathrm{i}}\left[\mathrm{Agr}^{\prime}\right.$ de $\left[{ }_{\mathrm{NP}}\right.$ dingen $\left.\left.\left.\left.\mathrm{t}_{\mathrm{i}}\right]\right]\right]\right]$ 
Analysis (88a) interprets de as a definite article. The structure is, first of all, not very likely from a conservation point of view (i.e. if the structure is governed by an $\mathrm{L}_{1}$ grammar): in Moroccan Arabic it is never possible to have a possessor in a Spec,DP position (whether D is filled or not). Second, the primary linguistic input does not provide instances of possessive constructions in which a definite article is immediately preceded by a possessor. The structure in (88b) seems counterintuitive, at first sight. However, recall that in the Moroccan Arabic construct state, $\operatorname{Agr}(\mathrm{P})$ plays an important role in the way (in)definiteness is defined over the entire possessive construction. As was argued in section 4, the containing possessive DP inherits (in)definiteness from the possessor. For the Moroccan Arabic construct state, this inheritance may be technically implemented along the following lines. The definiteness feature of the possessor DP is picked up by the overtly raised noun, which after having been raised to Agr moves on to D. In D, the "picked-up" definiteness feature on $\mathrm{N}$ projects (percolates) to the maximum projection DP. Returning to example ( $88 \mathrm{~b}$ ), we could say that the learner, who does not apply overt $\mathrm{N}$-raising to Agr, tries to express the definiteness inheritance by means of another linguistic means, viz. expression of the definiteness feature inherited from van de wielen by means of the determiner.

Another type of possessive pattern found in the $\mathrm{L}_{2}$ output of Moroccan Arabic (child) speakers is exemplified in (89).

(89) M10-6

a. vader en moeder zijn bed father and mother his bed 'father and mother's bed'

b. mama z'n zusje mamma his sister 'mamma's sister'

This pattern is similar to what we have called the doubling possessive construction in Dutch. The formation of such structures is possible only after the $\mathrm{L}_{2}$ learner has acquired the target knowledge that Dutch possessive clitics have a $<$ strong $>$ Spec-related feature (triggering overt movement of the complement to Spec,AgrP). The structural representation of these possessive variants is the following: ${ }^{60}$
a. [DP $\left[{ }_{\text {AgrP }}\right.$ vader en moeder ${ }_{i}\left[\right.$ Agr' $^{\prime}$ zijn $\left[{ }_{N P}\right.$ bed $\left.\left.\left.\left.t_{i}\right]\right]\right]\right]$
b. [DP $\left[{ }_{\mathrm{AgrP}} \mathrm{mama}_{\mathrm{i}}\left[{ }_{\mathrm{Agr}} \mathrm{Z}^{\prime} \mathrm{n}\left[\mathrm{NP}_{\mathrm{N}}\right.\right.\right.$ Zusje $\left.\left.\left.\left._{\mathrm{i}}\right]\right]\right]\right]$

As is obvious from these examples, the $\mathrm{L}_{2}$ learner has not yet acquired the agreement requirement between possessor and the doubling possessive pronominal. Possibly, $z^{\prime} n / z i j n$ is interpreted as a form that is unspecified 
Table 22. Distribution of possessive variants of the type $Y_{n} X$ produced by Moroccan learners over developmental stages

\begin{tabular}{lllllll}
\hline & \multicolumn{2}{l}{ 1. Conservation } & \multicolumn{2}{c}{ 2. Restructuring } & \multirow{2}{*}{ 3. Target } \\
& CWS & FFS & level a & level b & level c & \\
\hline FAT & 1 & 2 & 3 & 1 & - & - \\
MOH & 2 & - & - & - & - & - \\
Group 1 (4 children) & $-/-$ & $-/-$ & $-/-$ & $-1-$ & $-/-$ & $-1-$ \\
Group 2 (8 children) & $3 / 1^{\mathrm{a}}$ & $-/-$ & $7 / 4^{\mathrm{a}}$ & $4 / 4^{\mathrm{a}}$ & $2 / 2^{\mathrm{a}}$ & $7 / 2^{\mathrm{a}}$ \\
Group 3 (4 children) & $-/-$ & $-/-$ & $-/-$ & $-/-$ & $-/-$ & $10 / 4^{\mathrm{a}}$ \\
\hline
\end{tabular}

a. The first number is the number of occurrences, the second is the number of subjects producing these phrases.

for number and gender features (cf. our discussion of the Turkish learners). In the target stage, the $\mathrm{L}_{2}$ learner has become aware of this agreement rule and starts producing such forms as mama d'r mond (mommy her mouth/'mommy's mouth'; see Table 21).

At the end of the acquisition process, some Moroccan $\mathrm{L}_{2}$ learners identify $-s$ as an instantiation of the functional category Agr and start producing Saxon genitive constructions (cf. Table 21: zijn oma's mand and hem vader's auto). ${ }^{61}$

Having provided an analysis of the possessive variants attested in our corpora and having motivated their assignments to particular developmental stages, we need to consider the following questions:

What types of possessive variants are attested in the adults' and children's production data?

- How many occurrences of each possessive variant are attested in the learner's production data?

- Do the learners attain target knowledge of the $Y_{n} X$ pattern?

Answers to these questions can be inferred from Table 22. A major conclusion we can draw from Table 22 is that the occurrence of the possessor-initial pattern is very limited, for adults and children both. The adult informant $\mathrm{MOH}$ does not produce even a single instantiation of the $\mathrm{Y}_{\mathrm{n}} \mathrm{X}$ pattern. He only produces two instances of the conserved construct state. The other adult informant, FAT, produces three instances of the construct-state variant (involving overt N-to-D raising) and three instances of the possessor-initial pattern (lacking overt N-to-D raising; so, a case of partial conservation). The three construct-state constructions instantiate full conservation, whereas the possessor-initial patterns instantiate partial conservation. As regards the $Y_{n} X$ pattern, we divided the children into three groups. The children in group 1 did not produce 
any instances of this type. The children in group 2 are the real learners: one informant produced construct-state constructions, and two of them even attained the target. The third group of four children did not show any learner variants, only a few target variants. Furthermore, only seven children (out of 16) produce possessor-initial patterns that match those of the target language.

\subsection{The $Y_{p} X$ pattern: pronominal possessor-initial constructions}

As discussed in section 4, clitic pronouns in Moroccan Arabic are basegenerated in Agr. Construct states in which the possessor is a pronominal are derived by overt head movement of the possessed noun to a position adjoined to Agr, yielding the sequence "possessed noun + clitic pronoun," and subsequent raising of this complex head to D. Occurrences of such patterns are extremely rare in the $\mathrm{L}_{2}$-derivational output of Moroccan Arabic speakers. Some instances have been found, though, in our corpus. ${ }^{62}$ One example is the string zus $i k$ (sister I/'my sister'), given in Table 23.

If this string is the result of a (conserved) $\mathrm{L}_{1}$ grammar applied to an $\mathrm{L}_{2}$ lexical input, the derived structure will look like (91):

$$
\text { a. [DP } \left.\left[\mathrm{Zus}_{\mathrm{i}}+\mathrm{ik}\right]_{\mathrm{j}}\left[{ }_{\text {AgrP }} \mathrm{t}_{\mathrm{j}}\left[\mathrm{NNP}_{\mathrm{i}} \mathrm{t}_{\mathrm{i} P \mathrm{P}} \text { pro] }\right]\right]\right]
$$

The fact that the construct state is found more frequently with nominal than with pronominal possessors may be related to the fact that the pronouns are acquired somewhat later than nouns. This, in combination with the early discovery by Moroccan Arabic learners that Dutch does not permit overt N-to-D raising, ${ }^{63}$ may account for the fact that construct-state constructions with pronominal possessors are nearly absent in our corpus.

Having acquired the knowledge that Dutch does not permit overt $\mathrm{N}$-raising, the $\mathrm{L}_{2}$ learner produces possessive variants in which the pronominal possessor precedes the possessed noun. From the point of view of the conservation hypothesis, the $\mathrm{L}_{2}$ learner considers Dutch possessive pronominals to be the same kind of elements occupying the same structural slots as their Moroccan Arabic equivalents; that is, he treats them as functional categories heading the AgrP projection, which enter into an agreement relationship with the empty pronominal argument (pro) of the possessed noun. Thus, at this early stage of acquisition, strong pronouns surfacing in possessive constructions are not morphologically analyzed; the learner does not yet know the rule that strong possessive forms 
Table 23. Possessive variation of the type $Y_{p} X$ attested in the developmental stages of Moroccan learners

\begin{tabular}{lcc}
\hline Stage & Example & $\begin{array}{l}\text { Subject } \\
\text { code }\end{array}$ \\
\hline $\begin{array}{l}\text { 1. Conservation stage } \\
\text { Construct state (CWS) }\end{array}$ & FAT-3 \\
& $\begin{array}{l}\text { zus-ik } \\
\text { sister-I } \\
\text { 'my sister' }\end{array}$ &
\end{tabular}

2. Restructuring stage

Syntactic restructuring: no N-raising and:

a. Possessive pronoun in Agr (CWS)

no morphological analysis

- mijn man

'my husband'

zijn vader

'his father'

b. Free-functional-morpheme state (FFS)

first analysis: subject form

- ik mijn vader

I my father

'my father'

- hij broer

he brother

FAT -1

MOH-3

FAT-3

'his brother'

c. Bound-functional-morpheme state (BFS)

- mij familie

object form, no suppletion

me family

'my family'

- hem vrouw

him wife

'his wife'

d. Genitive realization, no suppletion (BFS)

- hem de bed

him the bed

'his bed'

- van ons mam

of our mamma

'our mamma'

3. Target stage

Suppletive forms, reduced forms

- haar/d'r moeder

haar moeder

'her mother'

- zijn/z'n handen

'his hands'

MOH-11

MOH-1

MOH-11

M5-2

M2-2

FAT-9

M11-6

are the result of a merger of an object pronominal form and an Agr head. This means that at first a string like (91a) has the structure (91b):

(91) FAT-1

b. mijn man

c. ${ }_{\mathrm{DP}}\left[{ }_{\mathrm{AgrP}}\left[{ }_{\mathrm{Agr}} \mathrm{mijn}\right][\mathrm{NP} \operatorname{man}[\mathrm{DP}\right.$ pro $\left.\left.]]\right]\right]$ 
Besides these variants, in which the possessor has the shape of the target possessive pronoun, we encounter possessive variants that feature a pronoun having the shape of a target subject personal pronoun (hij) or that of a target object personal pronoun (hem); see (92). ${ }^{64}$
a. $\mathrm{MOH}-1$
hij broer (subject form)
he brother
'his brother'
b. MOH-11
hem vrouw (object form)
him wife
'his wife'

It is not clear from these data whether the pronoun is still analyzed as being an instance of the Agr head (cf. [93a]) or whether it is reanalyzed as an item standing in Spec,AgrP (cf. [93b]).
a. [DP $\left[{ }_{A g r P}\left[{ }_{A g r}\right.\right.$ hij/hem $]\left[{ }_{N P}\right.$ broer [DP pro $\left.\left.\left.]\right]\right]\right]$
b. [DP $\left[\mathrm{AgrP} \mathrm{hij} / \mathrm{hem}_{\mathrm{i}}\left[{ }_{\mathrm{Agr}} \emptyset\left[\mathrm{NP}\right.\right.\right.$ broer $\left.\left.\left.\left.\mathrm{t}_{\mathrm{i}}\right]\right]\right]\right]$

As indicated by the structure in (93b), the latter analysis presupposes a restructuring of the grammar: the strong possessive pronouns are no longer considered to be of the categorial type Agr, but rather are analyzed as functional heads (plausibly D) heading a maximal projection that originates in the complement position to the possessed noun and is moved to Spec,AgrP (AgrP now being headed by a phonologically empty element). Furthermore, it presupposes the knowledge that Agr has a $<$ strong > Spec-related feature that triggers overt movement of the strong pronominal to Spec,AgrP. Evidence for the existence of a structure like (93b), in which the "subject form" occupies Spec,AgrP, might come from a possessive structure like (94), which is essentially a doubling construction:

\section{(94) FAT-3}
a. ik mijn vader
I my father
'my father'
b. [DP $\left[{ }_{A g r P} \mathrm{ik}_{\mathrm{i}}\left[\mathrm{Agr}^{\prime}\left[\mathrm{Agr}_{\mathrm{Ag}}\right.\right.\right.$ mijn $\left.\left.\left.]\left[\mathrm{NP}_{\text {vader }} \mathrm{t}_{\mathrm{i}}\right]\right]\right]\right]$

We also encounter possessive patterns similar to those found with nominal possessors (cf. our discussion of [86] and [88]); see (95). Hence, an analysis along the lines sketched for nominal possessors seems likely. 

a. $\mathrm{M} 2-2$
van ons mam
of our mommy
'our mommy'
b. M5-2
hem de bed
him the bed
'his bed'

For (95b), this would lead to the structural analysis in (103), where de is interpreted as a lexicalization of the definiteness feature associated with the Agr node. Notice also that in this structure the strong pronoun hem appears in Spec,AgrP; the Agr head is occupied by the de; see (96).

$$
\text { [DP } \left.\left.\left[{ }_{\text {AgrP }} \text { hemi }_{i}\left[{ }_{\text {Agr' }} \text { de [NP bed } t_{i}\right]\right]\right]\right]
$$

The element van in (95a) would be interpreted as a morphological spellout of abstract genitive case by means of an adpositional marker. The $\mathrm{L}_{2}$ learner seems to extend the rule for morphological spell-out of abstract genitive case by means of an adpositional marker to the specifier position. In other words, he has, so to speak, broadened the domain of application of the morphological spell-out rule that inserts van; see (97).

$$
\text { [DP } \left.\left.\left[{ }_{\text {AgrP }} \text { van ons }{ }_{i}\left[{ }_{\text {Agr' }} \text { Agr [NP } \text { mam t }_{i}\right]\right]\right]\right]
$$

Let us now consider how many occurrences of each possessive variant are attested in the learners' production data and whether they attain target knowledge of the $Y_{p} X$ possessive pattern. The relevant data are given in Table $24 .{ }^{65}$

The cooccurrence of the possessive pronominal forms (mijn/zijn) and the object forms (mij/hem) throughout the three cycles suggest that the adult learners have not yet acquired the target grammatical rules that underlie the formation of strong possessive pronouns in Dutch. The increasing number of object forms and the decreasing number of unanalyzed forms in MOH's data suggest that this informant has discovered that (strong) possessive pronouns are formed on the basis of object forms. It is not clear from the data, though, whether he also assigns them a different structural position, namely Spec,AgrP rather than Agr. Table 24 further indicates that only in the first cycle are subject forms attested. A final observation we should make is that only the adult data contain strong possessive pronominal forms (mijn/zijn).

At first sight, it seems quite hard to decide on the basis of the children's data whether they have acquired the target knowledge for the formation of pronominal possessive variants. If we divide them into three groups 


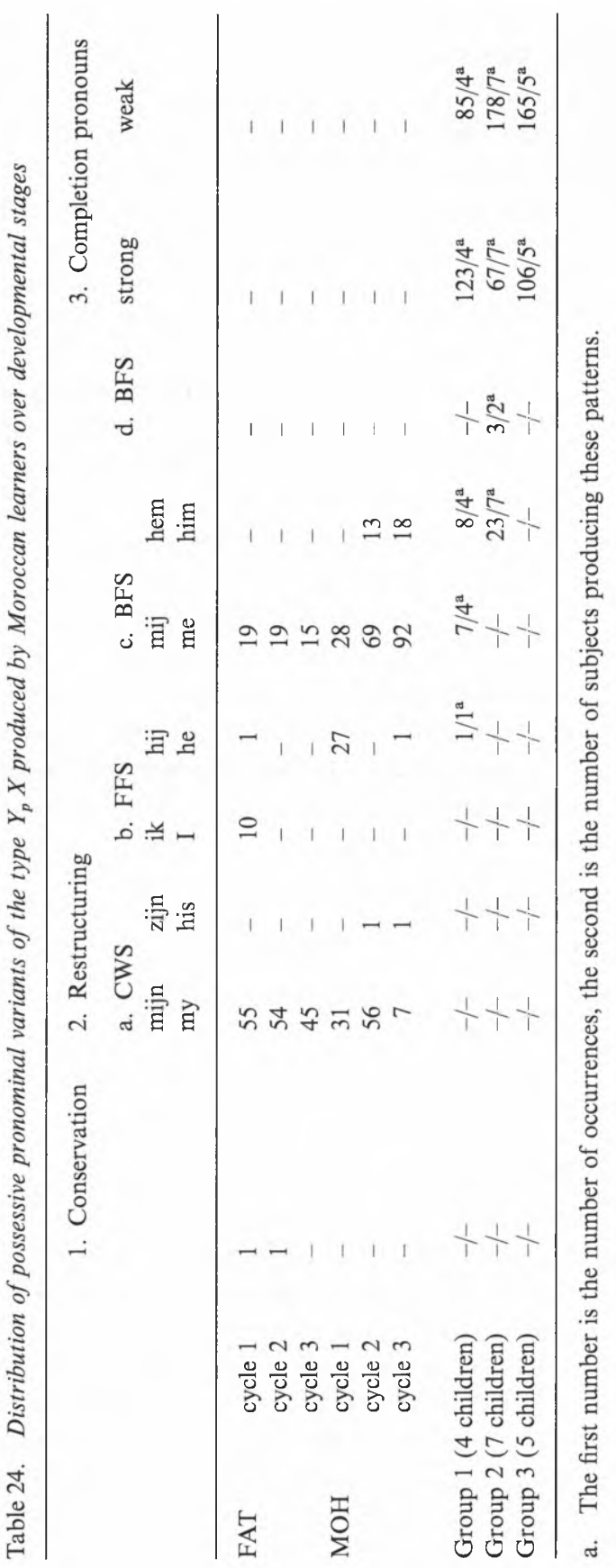


again, a clearer picture emerges. Group 1 are those who produce object forms for the first and third person role. The members of group 2 are acquiring bound morphemes and their related features. They sometimes realize features where the target language does not allow this, as in hem de bed and van ons mam (column d in Table 24). The third group does not produce any learner errors. How can we be sure that this group are not the beginners who produce only unanalyzed forms? The number of weak pronouns is decisive: group 3 produces considerably more weak pronouns than group 1 and fewer strong pronouns. For groups 1 and 2, both possessive pronominal forms and object forms are attested in their production data. Only one possessive variant (cf. restructuring column, stage d) has been found in which there is suggestive evidence for the placement of an object form in Spec,AgrP, namely hem de bed, where de was analyzed as a lexicalization of the definiteness feature. The children's data differ from those of the adults in displaying both strong possessive pronominal forms (zijn) and weak ones $\left(z^{\prime} n\right)$. The fact that they have identified this distinction suggests that they are/become aware of the different grammatical properties of the two forms. Presumably, this distinction is not manifested structurally at first; that is, it may be the case that both (phonological) forms are (conservatively) analyzed as instantiations of Agr. As a matter of fact, the occurrence of both the strong form and the weak form in doubling constructions (cf. Table 23) suggests that initially both forms can instantiate Agr; see (98).

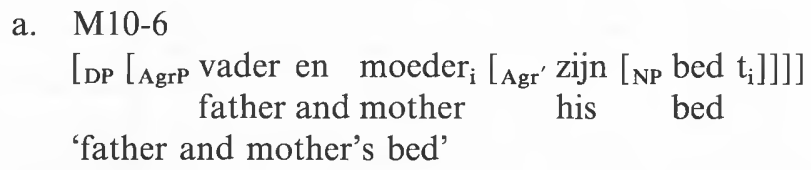

b. M17-3

$$
\begin{aligned}
& \text { [DP } \left.\left.\left[{ }_{\text {AgrP }} \text { mama }_{i}\left[{ }_{\text {Agr' }} \text { 'n [NP } \text { zusje }_{\mathbf{i}}\right]\right]\right]\right] \\
& \text { mommy his sister } \\
& \text { 'mommy's sister' }
\end{aligned}
$$

A reason for being reserved in drawing the conclusion that all children have acquired the grammar of pronominal possessives (i.e. the $Y_{p} X$ pattern) is the fact that this presupposes that they have acquired the knowledge that there is possessor movement of a pronominal DP from the complement position of $\mathrm{N}$ to Spec,AgrP. This would imply that the child knows that Agr can have a strong Spec-related feature. However, if this were so, the question would arise as to why children have such great difficulty in acquiring the target $Y_{n} X$ pattern. Recall from Table 24 that only six out of 16 children produce target possessive constructions instantiating the $\mathrm{Y}_{\mathrm{n}} \mathrm{X}$ pattern. 
In short, the conclusion that all children in our corpus have acquired the target knowledge for the production of strong possessive pronominals seems too optimistic. Given the fact that the children's data manifest both strong and weak possessive pronominal forms, it may be concluded that they are/become aware of the different grammatical properties of the two forms.

\subsection{The $X Y_{n / p}$ pattern: possessor-final constructions (analytic)}

The Moroccan learner of Dutch is familiar with analytic constructions. As we have seen in section 4, Moroccan Arabic has constructions like l-weld dyal t-tažer 'the-son of the-merchant'. What he has to find out is what element spells out morphologically the genitive case assigned to the final possessor. In view of its semantically vacuous status, one could imagine that this item is absent at first in constructions of the analytic type. That is, although the possessor is in the complement position to the noun, the learner does not know yet which element morphologically spells out the abstract genitive case assigned to the possessor; see (99).

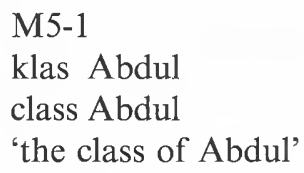

The structure that would be assigned to a string like (99) under this analytic interpretation is the following: ${ }^{66}$

$$
\text { [DP [NP klas [DP [NP Abdul]]]] }
$$

It should be noted, though, that (99) could also be assigned a constructstate analysis like (101):

$$
\left[{ }_{D P}\left[\mathrm{klas}+\mathrm{Agr}_{\mathrm{i}}\right]_{\mathrm{j}}\left[{ }_{\mathrm{AgrP}} \mathrm{Abdul}_{\mathrm{k}}\left[{ }_{\mathrm{Agr}} \mathrm{t}_{\mathrm{i}}\left[{ }_{\mathrm{NP}} \mathrm{t}_{\mathrm{j}} \mathrm{t}_{\mathrm{k}}\right]\right]\right]\right]
$$

Given the availability of the construct-state analysis, which is in complete correspondence to $\mathrm{L}_{1}$ construct states, we will analyze these possessive variants as conserved construct-state constructions.

The main task for the $L_{2}$ learner in acquiring the $X Y_{n / p}$ pattern is the identification of the adpositional marker that spells out genitive case, that is, van. As illustrated in Table $25,{ }^{67}$ possessive constructions featuring this element are attested in the learner's data early in the developmental process.

As shown in Tables 25 and 26, both the two adult informants and the children produce target constructions featuring van. Their widespread 
Table 25. Possessive variation of the type $X Y_{n / p}$ attested in the developmental stages of Moroccan learners

$\begin{array}{lll}\text { Stage } & \text { Example } & \begin{array}{l}\text { Subject } \\ \text { code }\end{array}\end{array}$

1. Construction stage

- Content-word state (CWS) $\mathrm{Y}_{\mathrm{n}}$

- jongen mij familie

MOH-1 boy my family 'a boy from my family'

- klas Abdul

M5-1

class Abdul

$\mathrm{Y}_{\mathrm{p}}$ : pronominal clitic

'the class of Abdul'

- zus-ik

sister-I

'my sister'

- Free-functional-morpheme state (FFS)

$\mathrm{Y}_{\mathrm{n}}$ (= target stage)

- twee dag van week two days of week 'two days of the week'

- broer van mijn moeder brother of my mother 'my mother's brother'

$Y_{\mathrm{p}}$ : demonstratives

- baas van die

boss of that

'the boss of him'

- vriend van hij

MOH-3

2. Restructuring stage

$\mathrm{Y}_{\mathrm{p}}$ : strong pronoun (subject form) friend of he 'his friend'

3. Target stage

- Bound-functional-morpheme state (BFS)
- opa van hem grandfather of him 'the grandfather of him' - een ander kerk van ons 'an other church of us'

MOH-10

M17-2

occurrence in cycle 1 for both adults indicates that this target possessive construction type is acquired without difficulty as far as nominals are involved. The analytic pattern for pronominals is used by only $50 \%$ of the adults and the children. The two adult learners clearly exhibit an intermediate stage in which they use an adpositional marker + demonstrative pronoun before passing to the use of adpositional marker + personal pronoun (FAT does not use the latter pattern at all). The pattern "adpositional marker + demonstrative" (e.g. baas van die, 
Table 26. Distribution of possessive variants of the type $X Y_{n / p}$ produced by Moroccan learners over developmental stages

\begin{tabular}{|c|c|c|c|c|c|c|}
\hline & & \multicolumn{3}{|c|}{ 1. Conservation stage } & \multirow{2}{*}{$\begin{array}{l}\text { 2. Restructuring } \\
\text { FFS : } Y_{p}\end{array}$} & \multirow{2}{*}{$\begin{array}{l}\text { 3. Target } \\
\text { stage } \\
\text { BFS : } Y_{p}\end{array}$} \\
\hline & & CWS : $Y_{n}$ & CWS: $Y_{p}$ & $\begin{array}{l}\text { FFS : } Y_{n} \\
=\text { target }\end{array}$ & & \\
\hline \multirow[t]{3}{*}{ FAT } & cycle 1 & 3 & 1 & 29 & 1 & - \\
\hline & cycle 2 & - & 1 & 47 & 2 & - \\
\hline & cycle 3 & - & - & 20 & 6 & - \\
\hline \multirow[t]{3}{*}{$\mathrm{MOH}$} & cycle 1 & 1 & - & 55 & 7 & 6 \\
\hline & cycle 2 & 1 & - & 49 & 3 & 28 \\
\hline & cycle 3 & - & - & 27 & - & 34 \\
\hline \multirow{2}{*}{\multicolumn{2}{|c|}{$\begin{array}{l}\text { Group } 1 \text { ( } 7 \text { children) } \\
\text { Group } 2 \text { ( } 9 \text { children) }\end{array}$}} & $6 / 3^{a}$ & $-1-$ & $78 / 7^{\mathrm{a}}$ & $-1-$ & $-1-$ \\
\hline & & $-1-$ & $-1-$ & $101 / 9^{a}$ & $4 / 2^{a}$ & $17 / 9^{a}$ \\
\hline
\end{tabular}

a. The first number is the number of occurrences, the second is the number of subjects producing these constructions.

boss of that/'his boss') looks like a conserved pattern: besides such analytic expressions in which dyal has a pronominal clitic attached to it (e.g. dyal-u 'of him'), Moroccan Arabic allows a demonstrative pronoun together with dyal (e.g. dyal hada, of that-masc/'of him'; dyal hadi, of that-fem/'of her').

In order to get a better view (see Table 26) of the development by the children, we divided them into two groups: those who are not able to construe pronominal analytic constructions (group 1) and those who are. The former (seven children) are clearly in an earlier (and more conservative) stage of acquisition, still displaying construct states (three of them). The latter (nine children) produce analytic patterns containing both nominal and pronominal possessors and a limited number of pronominal construct-state constructions. It is quite striking that no more than $58 \%$ of the children use the pronominal analytic pattern. A possible explanation might be that children master the possessor-initial pattern for full pronouns and reduced pronouns and are less in need of an analytic pattern.

\section{4. $Y_{p} X Y_{n}$ pattern: the double possessor construction}

In this section, we will discuss possessive variants attested in the $\mathrm{L}_{2}$ data that come very close to the doubling possessive construction found in Moroccan Arabic (see [102]). Recall that this construction was charac- 
terized by the presence of a clitic pronoun in Agr that was doubled by a possessor argument in the complement position to the possessed noun.

(102) xet-ha dyal Touria sister-her of Touria

'Touria's sister'

Two examples of the doubling possessor construction are given in (103).

$\begin{aligned} & \text { (103) a. } \text { FAT-11 } \\ & \text { haar vader van Touria } \\ & \text { her father of Touria } \\ & \text { 'Touria's father' } \\ & \text { b. } \text { M3-6 } \\ & \text { zijn bril van zijn vader } \\ & \text { his glasses of his father } \\ & \text { 'his father's glasses' }\end{aligned}$

These doubling constructions are attested in the production data of Fatima and one Moroccan child. The differ in only one respect from the $\mathrm{L}_{1}$ construction, viz. the lack of overt $\mathrm{N}$-raising to Agr (and subsequently to D). In (104), the structural representation of the learner's variant, (104b), is compared to the Moroccan Arabic construction in (104a).

$$
\begin{aligned}
& \text { a. [DP } \left.\left[\mathrm{xet}_{\mathrm{k}}+\mathrm{ha}\right]_{1}\left[_{\mathrm{AGR}} \mathrm{t}_{1}\left[\mathrm{NP} \mathrm{t}_{\mathrm{k}} \mathrm{dyal}_{<+\mathrm{gen}>}[\mathrm{DP} \text { Touria }]\right]\right]\right] \\
& \text { b. [DP [Agr' haar [NP vader van } \left.\text { ( }_{<+ \text {gen }}>[\mathrm{DP} \text { Touria] }]\right]
\end{aligned}
$$

In essence, the structure (104b) is a possessive construction that is partially conserved and partially restructured. It is partially conserved in the sense that the possessive clitic in Agr has a < weak > Spec-related feature; as a consequence of this, the doubled argument must remain in the complement position. It is partially restructured in the sense that the clitic in Agr has a $<$ weak $>$ head-related feature, just like the target grammar. These doubling patterns typically occur at a stage preceding that at which variants of the $Y_{n} X$ pattern (Saxon genitive and the doubling possessive pattern) appear. The appearance of these nominal possessor-initial patterns indicates that the conserved $<$ weak $>$ Specrelated feature of Agr has been replaced by the <strong $>$ feature specification of the target language.

\subsection{Overview and main conclusions}

Taking our findings of section 7 together, we can depict the acquisition of the possessive relationship by Moroccan learners in the way given in Figures $4-6^{68}$ for the representation of the three different acquisition stages, 


(i) Hidden construct pattern (possessor-initial)

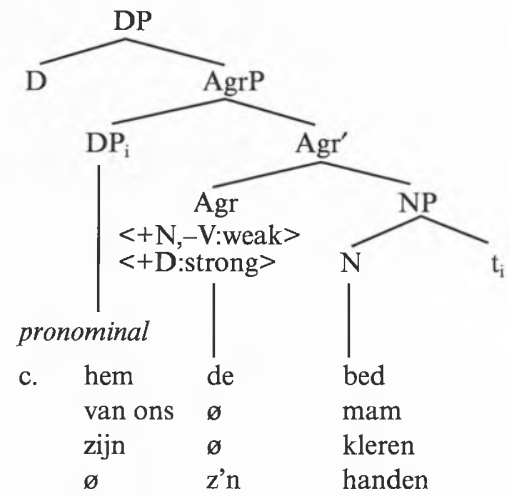

nominal

$\begin{array}{cll}\text { die jongen } & \text { hem } & \text { vriendin } \\ \text { van de wielen } & \text { de } & \text { dingen } \\ \text { mama } & \text { z'n } & \text { zusje }\end{array}$

(ii) Analytic pattern (possessor-final)

pronominal

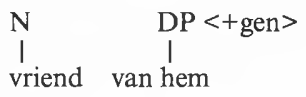

Figure 6. Restructuring stage II $(a=C W S ; b=F F S ; c=B F S)$

and in Table 27 for the grammatical knowledge corresponding to these stages. With regard to these figures and the table, it should also be remarked that the stages are not strictly delineated in time; overlap is at issue.

A major alteration in the acquisition process concerns the overtness of $\mathrm{N}$-raising. The learner identifies the absence of $\mathrm{N}$-raising in Dutch at a very early stage. The head-related feature of the functional heads is set as $<$ weak $>$. As for the Spec-related feature of (nonclitic) Agr, we can observe that the $\mathrm{L}_{1}$ setting (i.e. $<$ strong $>$ ) is conserved (restructuring column). We find the same for the clitic-Agr constructions: the headrelated feature is reset as being $<$ weak $>$, but the $<$ weak $>$ Spec-related feature is conserved. This explains the occurrence of such double possessor constructions as mij zusje van mij.

We should add here that the nonpronominal hidden construct-state pattern (vader vriend) is far less frequent than the pronominal one (mijn man). This might be caused by the availability of the analytic pattern (see die bloes van jurk in the first column). It seems that after the stage 
Table 27. Overview of the developing grammatical knowledge of Moroccan $L_{2}$ learners: changes in the conservation stage are in italics; $\emptyset=$ phonetically empty

\begin{tabular}{|c|c|c|}
\hline Conservation stage & $\begin{array}{l}\text { Restructuring stage } \\
\text { (essential) }\end{array}$ & $\begin{array}{l}\text { Prolonged } \\
\text { restructuring stage }\end{array}$ \\
\hline $\begin{array}{l}\text { Lexicon L1 } \\
\text { Construct-state construction: } \\
\text { Agr } \emptyset \text { : } \\
\text { strong head-feature } \\
\text { strong Spec-feature } \\
\text { Agr clitic: } \\
\text { strong head-feature } \\
\text { weak Spec-feature }\end{array}$ & $\begin{array}{l}\text { Lexicon L2 } \\
\text { Agr } \emptyset \text { : } \\
\text { weak head-feature } \\
\text { strong Spec-feature } \\
\text { Agr clitic: } \\
\text { weak head-feature } \\
\text { weak Spec-feature } \\
\text { (FAT: } \\
\text { strong Spec-feature) } \\
\text { weak head-feature }\end{array}$ & $\begin{array}{l}\text { Lexicon L2 } \\
\text { Agr } \emptyset \text { : } \\
\text { weak head-feature } \\
\text { strong Spec-feature } \\
\text { Agr non } \emptyset \text { : } \\
\text { weak head-feature } \\
\text { strong Spec-feature }\end{array}$ \\
\hline $\begin{array}{l}\mathrm{D} \emptyset \text { : } \\
\text { strong head-feature }\end{array}$ & $\begin{array}{l}\text { D } \emptyset: \\
\text { weak head-feature }\end{array}$ & $\begin{array}{l}\mathrm{D} \emptyset \mathrm{:} \\
\quad \text { weak head-feature }\end{array}$ \\
\hline $\begin{array}{l}\text { Analytic construction: } \\
\text { X: } \\
\quad[\text { - complement }]\end{array}$ & $\begin{array}{l}\text { Analytic construction: } \\
\mathrm{X}: \\
\quad[- \text { complement }]\end{array}$ & $\begin{array}{l}\text { Analytic construction: } \\
\mathrm{X} \text { : } \\
\quad[- \text { complement }]\end{array}$ \\
\hline $\begin{array}{l}\text { Morphology L1 } \\
\qquad P_{<+ \text {gen }>} \rightarrow \mathrm{P}+\mathrm{DP}\end{array}$ & $\begin{array}{l}\text { Morphology L2 } \\
\mathrm{DP}_{<+ \text {gen }>} \rightarrow \text { van }+ \text { DP }\end{array}$ & $\begin{array}{l}\text { Morphology L2 } \\
\text { DP }_{<+ \text {gen }>} \rightarrow \text { van }+ \text { DP }\end{array}$ \\
\hline \begin{tabular}{ll}
\multicolumn{3}{l}{ Vocabulary L2 } \\
auto, & N \\
$\emptyset$, & Agr \\
$\emptyset$, & D \\
mijn, & Agr \\
mij, & Agr \\
ik, & Agr \\
& \\
dyal, & P \\
$\{\ldots\}$ &
\end{tabular} & 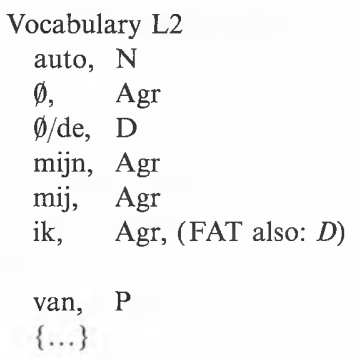 & $\begin{array}{ll}\text { Vocabulary } & \mathrm{L} 2 \\
\text { auto, } & \mathrm{N} \\
\emptyset, z^{\prime} n /-s, & \mathrm{Agr} \\
\text { de, } & \text { Agr } / \mathrm{D} \\
\text { mijn, } & \mathrm{Agr} / D \\
\text { mijn, } & D \\
\text { ik, } & D \\
\text { hem, } & \text { Agr } / D \\
\text { van, } & \mathrm{P} \\
\{\ldots\} & \end{array}$ \\
\hline
\end{tabular}

at which the Spec-related features of Agr and clitic-Agr are different (as is the case for Fatima), the learner arrives at a stage in which Agr is only specified as <weak $>$ (as is the case for Mohamed and many of the children). Less than half of the children enter the prolonged restructuring stage (third column of Table 27), in which the Spec-related feature of Agr has taken the $\mathrm{L}_{2}$ value $<$ strong $>$.

\section{Conclusions}

In this section we draw general conclusions on (i) the conservation of L1 grammatical knowledge and on (ii) restructuring of the L2 grammar and the availability of UG to the L2 learner. 


\subsection{Conservation of grammatical knowledge}

There is evidence, from possessive patterns produced by both Moroccan and Turkish learners of Dutch, that at the initial stages of acquisition the L2 learner is "guided" by his L1 grammatical knowledge in constructing the L2 grammar. At the level of parameter-based grammatical knowledge, conservation of L1 properties in L2 utterances is suggested among others by (i) the occurrence of construct-state patterns (and other nominal constructions featuring overt $\mathrm{N}$ movement) in early L2 output of Moroccan learners (e.g. school de trui, school the sweater/'the knitting class'), and (ii) the early occurrence of possessor-initial patterns produced by Turkish learners, especially those in which a demonstrative determiner intervenes between the possessor and the possessed noun: garage die naam (garage that name/'the name of the garage').

At the level of morphological realization, conserved morphological knowledge is evident from the Turkish learners' use of van as a genitival suffix element in such expressions as examen van tolk. L1 knowledge of the morphological rule of the genitive case suffix on a nominal stem induces the Turkish learner to maintain a similar rule for Dutch. At the level of language-specific lexical knowledge, we tentatively hint at the occurrence of demonstrative determiners with possessive pronouns in the L2 output of Turkish learners: die mijn dochter (that my daughter/'my daughter'), where die was analyzed as forming a constituent with mijn. This cooccurrence is a reflex of the conserved L1 knowledge that possessive pronouns are pronominals (i.e. of the category $\mathrm{N}$ ) rather than proDETERMINERS (i.e. of the category D).

One might expect that these properties of the L2 derivational output are not so much reflexes of conserved L1 knowledge, but rather reflexes of UG. Although we do believe that UG is potentially available from the very start onward (i.e. the L2 initial state), there are reasons for adopting the view that at the very early stages the L2 learner is guided by his L1 knowledge only. If the L2 learner was guided by UG only in the construction of his L2 grammar, it would be quite surprising (i) to find construct-state patterns in the Moroccan learners' L2 output, but not in the Turkish learners' output; (ii) to see that van appears as a genitival inflectional suffix of the noun in the Turkish learners' L2 output, but not in the Moroccan learners' L2 output. All in all, we would expect a greater structural similarity in the derivational output of the two learner groups in the nominal domain.

\subsection{Restructuring and the availability of $U G$}

As was discussed in the previous sections, restructuring applies at various levels of grammatical knowledge. Within the bounds of the grammatical 
construct we are dealing with in this paper (i.e. the possessive noun phrase), we distinguished

- Restructuring of UG-defined parameterized lexical knowledge: assignment of a value to a parametrized grammatical property (e.g. head directionality of $[+\mathrm{N},-\mathrm{V}]$; strong versus weak settings) that is different from the value assignment in L1.

- Restructuring of morphological knowledge: incorporation of a morphological rule format by the L2 learner at acquisition stage ${ }^{\mathrm{n}}$, which was not part of the learner's grammar at interlanguage $\operatorname{stage}^{\mathrm{n}-1}$ (e.g. incorporation of the UG-defined morphological rule spelling out genitive case by means of an adpositional marker; incorporation of language-specific suppletion rules).

- Restructuring of language-specific lexical knowledge: incorporation into the L2 lexicon of L2 lexical items and their properties (e.g. $-s / z^{\prime} n$ as instantiations of Agr).

As for restructuring of parameterized lexical knowledge, we concluded from the L2 data that apparently L2 learners are able to identify at a rather early stage of L2 acquisition differences between their L2 output and the primary L2 data of the linguistic environment and to change the parameter settings accordingly. Moroccan L2 learners, for example, discover at an early stage that Dutch lacks overt N-raising in the extended nominal projection; the parameterized strength property, defining the overtness or covertness of movement, is assigned a $<$ weak $>$ value instead of a $<$ strong $>$ value, which is the value assigned in the L1 grammar and conserved at the really initial stage of L2 acquisition. Early parametric restructuring is also found in the L2 data of our Turkish subjects in relation to the headedness parameter. As shown by the emergence of the possessor-final (i.e. analytic) pattern, the Turkish L2 learners are able to identify rather early a mismatch between the environmental linguistic input and their ( $\mathrm{L} 1$ and) early L2 grammar. This mismatch leads to an early restructuring of the L2 grammar: the <head-final > value associated with the lexical category $\mathrm{N}$ is replaced by a $<$ headinitial $>$ value, which results in generated nominal projections (DPs) that are head-initial, at least for the lexical domain NP, but possibly also for the functional domain (AgrP, DetP, and DP), depending on whether restructuring applies globally (i.e. evidence for head-initiality of $\mathrm{N}$ leads to a $<$ head-initial $>$ value for all head categories within the extended nominal domain) or locally (i.e. evidence for head-initiality of $\mathrm{N}$ leads to a $<$ head-initial $>$ value of $\mathrm{N}$ only).

We want to emphasize that restructuring goes most smoothly in the case of parameterized lexical knowledge, especially when word-order asymmetries are involved between L1 and L2. The speed at which the 
L2 learner is able to identify such mismatches and, subsequently, to generate strings in which the L2 output matches the primary L2 input is consistent with the hypothesis that UG is available to him. On the other hand, restructuring at the level of morphological and vocabulary knowledge (e.g. the categorial status of a pronoun) is much harder. Comparison of the adult informants and the children shows that only the latter group reaches the stage in which morphological and vocabulary restructuring applies.

Further evidence for the availability of UG knowledge in the construction of the L2 grammar is found in the occurrence of possessive patterns that are attested in certain natural languages and hence conform to the grammatical systems allowed by universal grammar, but for which there is no evidence in the primary L2 data, nor in the L1 grammar. The L2 patterns we have in mind here are the double possessor constructions formed by Turkish children (e.g. z'n naam van de land, his name of the country/'the country's name'). Such a pattern does occur in human language, for example in Moroccan Arabic. Of course, one might argue that this pattern is entirely accidental and that the child gets this structure by combining two different structures: z'n naam and naam van de land. However, combining presupposes knowledge about what is possible in natural language and what is not. For example, the L2 learner always obeys the rule of person/number agreement between the pronoun and the nominal complement; the fact that the L2 learner uses a string like $z^{\prime} n$ naam van de land with an obligatory coreferential interpretation of $z^{\prime} n$ and de land implies that the L2 learner has access to UG-defined theta-theoretic knowledge: the pronoun and the nominal in complement position are in a chain relation and share a thematic role. Furthermore, if the above string is the result of combination rules that do not fall under UG, the question arises as to why many combinatorial possessive patterns (but, according to UG, impossible ones) are not attested in our L2 data, as is illustrated by the examples in (105) and (106).
a. [examen van] tolk (attested)
exam of interpreter
'the interpreter at the exam'
b. tolk [examen van] (unattested)
a. [auto] z'n lamp (attested)
car its light
'the car's light'
b. z'n lamp [auto] (unattested)

(106)

In short, we believe that the occurrence of the double possessor construc- 
tion in the L2 data of Turkish children strongly suggests the availability of UG.

Received 20 October 1998

Tilburg University

Revised version received

19 January 2000

\section{Notes}

* Parts of this paper have been presented at various workshops and conferences: GALA '97, Eurosla '97, SLRF '97, ANELA '97. We wish to thank our audiences for helpful questions and comments. We are also grateful to our informants for judgments of and discussion on the Turkish/Moroccan Arabic data: Jaklin Kornfilt, Murat Kural, Rik Boeschoten, Hanneke van der Heijden, Mustafa Güleç, Kutlay Yagmur, Abderrahman El Aissati, Redouan Saidi.

Norbert Corver would like to thank the Netherlands Institute for Advanced Studies in the Humanities and Social Sciences (NIAS), Wassenaar, for having provided an excellent working environment during his NIAS stay from February through July 1997.

Correspondence address: Tilburg University, P.O. Box 90153, 5000 LE Tilburg, The Netherlands. E-mail: c.d.vdcraats@kub.nl.

1. Earlier research on the L2 acquisition of the noun phrase and possessive relationships on the same data as in this study has been done by Broeder $(1991,1992)$ and by Broeder and Extra (1991).

2. Although we are aware of the comparative fallacy (Bley-Vroman 1983), it is necessary to define the target state in order to know whether a given interlanguage is (not) identical to the target. It is obvious that in $\mathrm{L}_{2}$ acquisition the target state is not necessarily the learner's final state.

3. See Odlin (1989) for a clarifying discussion of the concept of transfer.

4. See Chomsky $(1993,1994)$ for extensive discussion.

5. In Chomsky (1994) it is argued that only the idiosyncratic formal features are part of the lexical item as a member of the vocabulary. Optional formal features are added to the lexical item when it is selected from the lexicon to form a numeration with other items. We will further abstract away from this distinction. Cf. Chomsky (1994: 235ff.).

6. Naturally, child $\mathrm{L}_{2}$ learners have a vocabulary knowledge characteristic of children at age $x$.

7. For illustrative reasons, the parameter settings of $\mathrm{L}_{1}$ and $\mathrm{L}_{2}$ have opposite values in Table 1. It is possible of course that parameters have the same value in both $L_{1}$ and $L_{2}$. That does not imply, however, that such a parameter will not be reset in the process of acquiring the $\mathrm{L}_{2}$, to a value that is not found in either of the two languages involved. We will come back to this phenomenon later in the article.

8. Or more precisely, lexical items having a feature constellation consisting of an $\mathrm{L}_{2}$ phonological matrix and, possibly, an $\mathrm{L}_{1}$ feature constellation, e.g. the Turkish pronouns in section 6.2.

9. Similar hierarchies play a role in language contact (Haugen 1950; Van Hout and Muysken 19944).

10. It is important to note here that vocabulary knowledge means more than bare knowledge of sound-meaning pairing. Initially, an $\mathrm{L}_{2}$ learner may have learned an $\mathrm{L}_{2}$ item (morpheme/word) in the sense that he has identified its phonological matrix. He may 
have assigned it the wrong grammatical status. For example, van is assigned affixal status, which is not the right status from the Dutch perspective.

11. An alternative interpretation of the conservative vocabulary state is one in which there is only one vocabulary that contains certain lexical entries with two phonological matrices, one of the $\mathrm{L}_{1}$ and one of the $\mathrm{L}_{2}$.

12. In this paper, we will use the term "possessive" as a cover term. The syntactic configuration(s) expressing the possessive relationship in the languages under discussion may also be used for expressing other kinds of semantic relations, such as theme, source, etc. The variety of semantic relations expressed by configurations also used for expressing possession is evident from the following examples from English: John's car (possession), Rome's destruction (theme), Hannibal's destruction of Rome (agent).

13. An obvious reason for assuming that superficially prenominal possessor Jan receives its thematic role in the (postnominal) complement position to the possessed noun is the fact that this is also the position where the possessor receives its thematic role in analytic constructions (see [8] in the main text). We should note that in this paper, we will only consider simplex genitive constructions, i.e. nominal constructions featuring a single genitive phrase. Nominal constructions containing more than one genitive phrase (e.g. Jans foto van Marie; Jan's picture of Marie) were not attested in our $\mathrm{L}_{2}$ data.

14. "No" in the third and fourth rows implies that the feature to be checked is weak. The feature is checked after feature raising has applied at LF. Overt raising of XP from Spec,DetP to Spec,DP applies to demonstrative determiners, at least.

15. In Turkish, presence of a cardinal expressing plurality in the nominal structure blocks the occurrence of the plural suffix on the noun (cf. Kornfilt 1990).

(i) *iki er-ler-in-de two hand-plur-2sg-LOC

'in your two hands'

16. A note is in order about the distribution of bir ' $a$ '; 'one'. As a numeral ('one') it must precede the attributive AP. In that case, Spec, QP is a plausible locus. Under the indefinite interpretation, it must follow the AP. We tentatively propose that indefinite bir is adjective-like and as such can be placed quite low in the nominal structure. Suppose further that the linear ordering of adjectival bir with respect to other attributive APs is determined by ordering constraints on sequences of attributive adjectives. See Lewis (1967: 54) for discussion.

(i) a. bir güzel kitap one beautiful book; ?a beautiful book

b. güzel bir kitap a beautiful book; *one beautiful book

17. For approaches in which genitive case is treated as a structural case, see e.g. Ritter (1991), Valois (1991), De Wit (1997).

18. A structural case feature like accusative case is -interpretable and therefore must be checked (i.e. erased and deleted) before LF (and before spell-out if strong).

19. In line with Chomsky (1995), we make a distinction between head features and Spec features of the Agr head. Head features of Agr are those grammatical features that are typically checked by (features of) the nominal head N; Spec features of Agr are those features that are typically checked by (features of) the possessor DP. In Chomsky (1993) Spec features and head features are referred to as $\mathrm{N}$ features and V features, respectively. A Spec-related feature of a functional head $\mathrm{F}$ is a feature that is checked 
off by some other feature in the checking domain of $F$. This checking feature may be part of an element in Spec,AgrP (typically in the case of overt XP movement) but can also be adjoined to the Agr head (when the checking relation is established at LF).

20. We assume the AgrP projection to be absent if it fulfils no licensing role within the nominal domain.

21. For recent analyses of the (Hebrew) CS, see e.g. Ritter (1988, 1991), Siloni (1991), Longobardi (1996).

22. N-to-D raising is incompatible with the realization of a definite article in the $\mathrm{D}$ position. As shown in (i), demonstrative elements, which we analyzed as occupying Spec,DP, cannot occur in construct states either. Note, furthermore, that they can occur in analytic constructions.

(i)

*had bab d-dar

that door the-house

'that door of the house'

(ii) had l-bab dyal ḍ-dar

that the door of the-house

'that the door of the house'

23. The clitic pronominal possessive form also appears in the analytic possessive construction. It is then attached to the adpositional element dyal (as in $d$-dar dyal-i, the house of me/"my house'). It seems plausible to analyze the form dyal-i as the result of a cliticization process that adjoins the clitic pronominal to the adposition.

24. See Ritter (1991) for a discussion of similar construction in Modern Hebrew.

25. Certain kinship nouns (e.g. tante 'aunt', oom 'uncle') fall within the class of proper names. They are permitted in the Saxon genitive construction, cf. tantes fiets 'aunt's bicycle'.

26. The analytic construction featuring a pronominal possessor is not used very frequently. Instead of het boek van haar 'the book of her' speakers tend to use haar boek 'her book'. In possessive constructions having an indefinite interpretation, however, it is only possible to use the analytic construction: een boek van haar 'a book of her'.

27. For reasons of space, our discussion of the CS-like properties of the Saxon genitive and the doubling possessive leaves many issues unaddressed. Besides the above-mentioned similarities, there are some obvious differences. For one, in Dutch, the lexical head N does not occur in first position. Second, there is no strict adjacency between the lexical head noun and the possessor. The possessor can be separated from the possessed noun by intervening modifiers. The question is how to reconcile these two apparently nonCS-like properties with the ones in (34)-(36). A possible answer to this question is that Dutch $\mathrm{N}$-to-D raising (or more precisely, raising of categorial feature $[+\mathrm{N},-\mathrm{V}]$, together with the rest of the formal feature complex of the possessed noun) applies in covert syntax rather than in overt syntax (see Longobardi 1996). Thus, Dutch differs from Moroccan Arabic with respect to the point at which N-to-D raising applies in the (Saxon genitive/doubling/construct-state) possessive construction. See Longobardi (1996) for further discussion.

28. At this point, we would like to point out the ill-formedness of such examples as (i):

(i) a. *die Jans broers those Jan's brothers

'those brothers of Jan's'

b. *een Jans broer

a Jan's brother

'a brother of Jan's' 
Evidently, it is not possible to move the determiner from Spec,DetP to Spec,DP when there is a possessor in Spec,AgrP. We tentatively assume that this relates to the fact that (in)definiteness of the entire DP is determined by the possessor in Spec,AgrP. More specifically, one might assume that the (in)definiteness feature gets associated with the Agr head under Spec-head agreement and subsequently projects to the highest functional projection (DP). The idea now would be that, since (in)definiteness gets associated with the entire DP through this mechanism, it is no longer necessary to express (in)definiteness by means of a determiner.

29. $-s$ should not be interpreted as an inflectional case suffix; see Corver (1990).

30. The written form jouw is pronounced in the same way as the object form of the personal pronoun.

31. In a speaker's mother tongue, possessive expressions at the word level can quite easily be distinguished from phrase-level expressions, for example by such cues as (i) adjectival modification or (ii) morphological markers. In $\mathrm{L}_{2}$ data such distinguishing properties are often absent. In these cases contextual clues and intonation were decisive.

32. See also the alternation hypothesis (Jansen et al. 1981) for this idea. The same idea in relation to the basic variety is formulated by Klein and Perdue (1997).

33. We only discuss simple possessive constructions. It should be noticed that recursive patterns do occur in the adults' data, e.g.

(i) $\mathrm{MAH}-17$

[mijn vrouw [oma [andere man [dochter]]]]

[my wife [grandmother [other husband [daughter]]]]

'the daughter of the second husband of my wife's grandmother'

34. Recall the meaning of the term "numeration." From now on the term numeration will be used as lexical input to the computational system. This way no confusion will arise with the notion of lexical input in the sense of primary linguistic data.

35. The structure indicated is the representation of the input to the morphological/phonological components and to LF. It is the overt syntax representation. All representations given from now on will be "overt syntax" representations, unless otherwise indicated.

36. Of course, one might argue that additional movement of de auto van to Spec,DP has taken place. At this stage of acquisition $d e$ is analyzed on a par with demonstratives like die; it occupies Spec,DetP.

37. The L2 variants (50) and (51) are not from the same L2 learner. The existence of die van $z$ ' $n$ ding (uttered by a child learner) shows that van and $z$ ' $n$ need not be in complementary distribution. Strictly speaking, one might still argue that in a sequence like die van auto (uttered by an adult learner), which lacks a possessive clitic, the element van occupies the Agr slot. However, as both the child and adult learners have the same $\mathrm{L}_{1}$ and show similar developing stages, it is plausible to consider van an inflectional suffix rather than a functional head Agr.

38. Four children use a prepossessor van in combination with a lexical element in Agr: T25, T29, T39, and T41. This learner variant emerges at the same time as or shortly after the first occurrences of the analytic constructions.

39. Except for one example by Ergün.

40. Strictly speaking, the label "lexical morpheme" is not so adequate for strings like mijn buurman given the fact that mijn is a function word rather than a content word, in the traditional sense. From that perspective, it would be better to place these forms under $b$. However, we would like to restrict $b$ to possessive patterns in which, besides the pronominal possessor and the possessed noun, free-functional morphemes show up, like demonstratives. 
41. Although errors in number and person occur in the first and second cycle (see Broeder 1992).

42. Equivalents of the $\mathrm{L}_{2}$ expression die mijn broer are not found in Turkish. Pronominals cannot be modified/specified in Turkish.

43. Structures with an intervening demonstrative emerge at the same time as the pronominal structures preceded by die.

44. Importantly, the first occurrence of such structures is attested at later stages of acquisition: [die jongen] naam - ERG-10, that boy name/"the name of that boy'; [die grote broer [die dochter]] — MAH-4, that big brother that daughter/'that big brother's daughter'.

45. One might interpret the presence of die as a way of encoding the property of emphasis. Lexical realization of the possessive pronominal implies emphasis in Turkish (see also Kornfilt 1997: 284).

46. The $\mathrm{X}+$ van pattern is more frequent with nominals than with pronominals. The pronominal variant is not attested in the adults' data.

47. Although we have chosen here for a head-final structure, we should not exclude the possibility of a head-initial structure in this case. The reason for this is that at the time child T25 produced this possessive variant, he also produced doubling constructions in which the possessive clitic $z^{\prime} n$ is in Agr.

48. The variants die van mij auto and die van mijn broer, for example, are attested in early recordings of our adult informants, viz. ERG-3 and MAH-9. As is clear from Table 16, analytic forms featuring van appear much later, viz. ERG-25, MAH-21.

49. Although we have opted for a head-final structure here, it is quite likely that the structure is head-initial given the fact that child T33 produces doubling possessive structures that under our analysis must receive a head-initial analysis.

50. Een is used here as indefinite article and not as numeral. The use of full forms instead of reduced forms is rather common in early learner varieties. See also Broeder (1992).

51. The first occurrence of the string die van + poss. pronoun is for ERG in session 3 and for MAH in session 9; die + poss. pronoun occurs as early as session 5 for MAH.

52. The categorial restructuring of pronouns from $\mathrm{N}$ to $\mathrm{D}$ precedes the absence of attachment of van to possessor pronouns; i.e. the $\mathrm{L}_{2}$ learner is aware that Dutch has prodeterminers rather than pronouns. In adults' data the string die $i k$ is not completely absent at the end of the data collection. In children's data this string is restricted to an exceptional occurrence: die hij kleren - T29-2, that he clothes/'his clothes'.

53. This table also contains the data from ERG's last recording in order to better show his progress from CWS to BFS and to indicate the predominance of possessive pronominals featuring van.

54. There is an earlier occurrence of the $Y_{p}$-full pronoun construction in the fifth recording: grotevader van me (grandfather of $\mathrm{me} / \mathrm{my}$ grandfather). This utterance, in which a clitic pronominal form occurs as a complement in the analytic construction, forms an exception to the general pattern; that is, normally, only full forms occur in the complement position. In view of this, grotevader van me is probably an imitation.

55. Except for informant T42: although he produces $\mathrm{Y}_{\mathrm{p}} \mathrm{X}$ before producing the doubling pattern, he produces the doubling pattern at session 2 and utters his first analytic constructions at session 5. Because of the relatively long time between the audiorecordings we might have missed earlier instantations of the analytic pattern.

56. Although strictly speaking the CS patterns do not represent instances of possessorinitial patterns, we have included them here because of their close relation to possessorinitial patterns (which we have analyzed as hidden construct states). An alternative 
interpretation would be an analytic construction lacking van. The systematic absence of determiners in this construction makes a construct-state analysis more plausible.

57. The variant hem vaders auto in Table 21 belongs to the target state as regards the instantiation of Agr; suppletion, however, is not yet acquired.

58. We tentatively assume here that $m^{\prime} n$ is in Agr.

59. Unless van is attached to the determiner.

60. In general, most Moroccan Arabic learners use the forms $z$ ' $n$ and zijn interchangeably in doubling constructions. This suggests that at that stage, they treat the two possessive elements on a par. That is, zijn is not interpreted yet as a (suppletive) strong pronominal form.

61. These two examples by $\mathrm{M} 2$ in sessions 1 and 6 prove that this child has not yet fully mastered the suppletion rules.

62. The examples found are all by adult $\mathrm{L} 2$ learners. That is, no examples of the pronominal construct state were found in the children's data.

63. Overt raising of $\mathrm{N}$ has already stopped in the earliest recordings.

64. Dutch clitic possessive pronouns do not occur at all in the adults' data, possibly because they are less easy to perceive in the environmental input.

65. This stage is not named target stage since there is not sufficient evidence for a targetlike syntax, although the full and reduced forms are found. In this (completion) stage, only noun phrases are counted that are evidently suppletive forms such as zijn and not haar.

66. Recall that Turkish learners have analytic constructions lacking an adpositional marker.

67. In Table 25 we abstract from $\mathrm{N}$-raising to a higher functional projection resulting in a noun-adjective order. Thus, the analytic pattern for nominals is considered to be a conserved pattern that is similar to the target language.

68. Only the most relevant functional projections are represented in Figures 4-6 (e.g. not the DetP projection).

\section{References}

Abney, Stephen (1987). The English noun phrase in its sentential aspect. Unpublished doctoral dissertation, MIT.

Benveniste, Emile (1966). 'Etre' et 'avoir' dans leurs fonctions linguistiques. Bulletin de la Société de linguistique de Paris 55(1), 113-134. (Reprinted [1966]. In Problèmes de linguistique générale. Paris: Gallimard.)

Bley-Vroman, Robert W. (1983). The comparative fallacy in interlanguage studies: the case of systematicity. Language Learning 24, 235-243.

-(1989). What is the logical problem of foreign language learning. In Linguistic Perspectives on Second Language Acquisition, Susan M. Gass and Jacquelyn Schachter (eds.), 41-68. Cambridge: Cambridge University Press.

Broeder, Peter (1991). Talking About People. A Multiple Case Study on Adult Language Acquisition. Amsterdam and Lisse: Swets and Zeitlinger.

- (1992). Possession in a new language. Applied Linguistics 13(2), 100-118.

-; and Extra, Guus (1991). Acquisition of kinship reference. A study on word formation processes of adult language learners. International Journal of Applied Linguistics 1, 209-227.

Chomsky, Noam (1981). Principles and parameters in syntactic theory. In Explanations in Linguistics, Norbert Hornstein and David Lightfoot (eds.), 123-146. London: Longman. 
-(1986). Knowledge of Language. Its Nature, Origin, and Use. New York: Praeger.

-(1993). A minimalist program for linguistic theory. In The View from Building 20: Essays in Linguistics in Honor of Sylvain Bromberger, Kenneth Hale and Samuel Jay Keyser (eds.), 1-52. MIT Occasional Papers in Linguistics 1. Cambridge, MA: MIT Press.

-(1994). Bare Phrase Structure. MIT Occasional Papers in Linguistics 5. Cambridge, MA: MIT Press.

-(1995). The Minimalist Program. Cambridge, MA: MIT Press.

Cinque, Guglielmo (1993). On the evidence for partial N-movement in the Romance DP. Unpublished manuscript, Università de Venezia.

Clahsen, Harald; and Muysken, Pieter (1986). The availability of universal grammar to adult and child learners: a study of the acquisition of German word order. Second Language Research 2, 93-119.

-; Eissenbeiss, Sonja; and Vainikka, Anne (1994). The seeds of structure: a syntactic analysis of the acquisition of case marking. In Language Acquisition Studies in Generative Grammar, Teun Hoekstra and Bonnie D. Schwartz (eds.), 85-118. Amsterdam: Benjamins.

Corver, Norbert (1990). The syntax of left branch extractions. Unpublished doctoral dissertation, Tilburg University.

Dede, Müşerref (1986). Definiteness and referentiality in Turkish verbal sentences. In Studies in Turkish Linguistics, Dan I. Slobin and Karl Zimmer (eds.), 147-163. Amsterdam: Benjamins.

de Wit, Petra (1997). Genitive case and genitive constructions. Unpublished doctoral dissertation, University of Utrecht.

Enç, Murvet (1991). The semantics of specificity. Linguistic Inquiry 22, 1-25.

Epstein, Samuel D.; Flynn, Suzanne; and Martohardjono, Gita (1996). Second language acquisition: theoretical and experimental issues in contemporary research. Behavioral and Brain Sciences 19(4), 677-714.

Flynn, Suzanne (1984). A universal in L2 acquisition based on PBD typology. In Universals of Second Language Acquisition, Fred Eckman, Lawrence Bell, and Diane Nelson (eds.), 75-87. Rowley, MA: Newbury House.

-(1987). A Parameter-Setting Model of L2 Acquisition. Dordrecht: Reidel.

-; and Espinal, I. (1985). Head-initial/head-final parameter in adult Chinese L2 acquistion. Second Language Research 1, 93-117.

Freeze, Ray (1992). Existentials and other locatives. Language 68, 553-595.

Grimshaw, Jane (1991). Extended projections. Unpublished manuscript, Brandeis University.

Harrell, Richard (1970). A Short Reference Grammar of Moroccan Arabic. Washington, D.C.: Georgetown University Press.

Haugen, Einar (1950). The analysis of linguistic borrowing. Language 16, 210-231.

Heine, Bernd (1997). Possession, Cognitive Sources, Forces, and Grammaticalization. Cambridge: Cambridge University Press.

Jansen, Bert; Lalleman, Josine; and Muysken, Pieter (1981). The alternation hypothesis: acquisition of Dutch word order by Turkish and Moroccan foreign workers. Language Learning 31, 315-336.

Kayne, Richard (1993). Towards a modular theory of auxiliary selection. Studia Linguistica 47, 3-31.

Klein, Wolfgang; and Perdue, Clive (1997). The basic variety. Or: couldn't natural languages be much simpler? Second Language Research 13, 301-347.

Kornfilt, Jaklin (1990). Remarks on headless partitives and case in Turkish. In Grammar in Progress, Joan Mascaró and Marina Nespor (eds.), 285-303. Dordrecht: Foris. 
- (1997). Turkish. London and New York: Routledge.

Lewis, Geoffrey L. (1967). Turkish Grammar. Oxford: Oxford University Press.

Longobardi, Giuseppe (1996). The syntax of N-raising: a minimalist theory. Unpublished manuscript, Utrecht University.

Odlin, Terence (1989). Language Transfer. Cross-Linguistic Influence in Language Learning. Cambridge: Cambridge University Press.

Penner, Zvi; and Weissenborn, Jürgen (1996). Strong continuity, parameter setting and the trigger hierarchy. In Generative Perspectives on Language Acquisition, Harald Clahsen (ed.), 161-200. Amsterdam: Benjamins.

Perdue, Clive (ed.) (1993). Adult Language Acquisition: Cross-Linguistic Perspectives, vol. I: Field Methods. Cambridge: Cambridge University Press.

Ritter, Elisabeth (1988). A head-movement approach to construct-state noun phrases. Linguistics 26, 909-929.

- (1991). Two functional categories in noun phrases: evidence from Modern Hebrew. In Perspectives on Phrase Structure, Susan Rothstein (ed.), 37-62. Syntax and Semantics 25. San Diego: Academic Press.

Schwartz, Bonnie D.; and Sprouse, Rex (1994). Word order and nominative case in nonnative language acquisition: a longitudinal study of (L1 Turkish) German interlanguage. In Language Acquisition Studies in Generative Grammar, Teun Hoekstra and Bonnie D. Schwartz (eds.), 317-368. Amsterdam: Benjamins.

-; and Sprouse, Rex (1996). L2 cognitive states and the full transfer/full access model. Second Language Research 12, 40-72.

Siloni, Tali (1991). Noun raising and the structure of noun phrases. MIT Working Papers in Linguistics 14, Jonathan Bobaljik and Tony Bures (eds.), 255-270.

Sportiche, Dominique (1995). Clitic constructions. In Phrase Structure and the Lexicon, Lauri Zaring and Johan Rooryck (eds.), 213-276. Dordrecht: Kluwer.

Szabolsci, Anna (1987). Functional categories in the noun phrase. In Approaches to Hungarian, vol. 2, Istvan Kenesei (ed.), 167-189. Szeged: Jate.

-(1992). The noun phrase. In The Syntactic Structure of Hungarian, Ferenc Kiefer and Katalin Kiss (eds.), 179-274. Syntax and Semantics 27. San Diego: Academic Press.

Valois, Daniel (1991). The internal syntax of DP. Unpublished doctoral dissertation, UCLA.

van Hout, Roeland; and Muysken, Pieter (1994). Modeling lexical borrowability. Language Variation and Change 6, 39-62.

Vermeer, Anne (1986). Tempo en structuur van tweede-taalverwerving bij Turkse en Marokkaanse kinderen. Unpublished doctoral dissertation, Tilburg University.

White, Lydia (1983). Markedness and parameter setting: some implications for a theory of adult language acquisition. McGill Journal of Linguistics 11, 1-21.

- (1985). The pro-drop parameter in adult second language acquisition. Language Learning $35,47-62$.

(1986). Implications of parametric variation for adult second language acquisition: an investigation of the "pro-drop" parameter. In Experimental Approaches to Second Language Acquisition, Vivian Cook (ed.), 55-72. Oxford: Pergamon. 